University of Louisville

ThinkIR: The University of Louisville's Institutional Repository

$5-2020$

\title{
Promoting healthy aging: an investigation of the relationships among sport satisfaction, sport identity, and sport commitment in the well-being of older adults.
}

Seonghun Lee

University of Louisville

Follow this and additional works at: https://ir.library.louisville.edu/etd

Part of the Sports Studies Commons

\section{Recommended Citation}

Lee, Seonghun, "Promoting healthy aging: an investigation of the relationships among sport satisfaction, sport identity, and sport commitment in the well-being of older adults." (2020). Electronic Theses and Dissertations. Paper 3375.

https://doi.org/10.18297/etd/3375

This Doctoral Dissertation is brought to you for free and open access by ThinkIR: The University of Louisville's Institutional Repository. It has been accepted for inclusion in Electronic Theses and Dissertations by an authorized administrator of ThinkIR: The University of Louisville's Institutional Repository. This title appears here courtesy of the author, who has retained all other copyrights. For more information, please contact thinkir@louisville.edu. 
PROMOTING HEALTHY AGING: AN INVESTIGATION OF THE RELATIONSHIPS AMONG SPORT SATISFACTION, SPORT IDENTITY, AND SPORT COMMITMENT IN THE WELL-BEING OF OLDER ADULTS

\author{
By \\ Seonghun Lee \\ B.S., University of Dayton, 2006 \\ M.S., University of Louisville, 2010 \\ M.S., Wright State University, 2014

\begin{abstract}
A Dissertation
Submitted to the Faculty of the

College of Education and Human Development of the University of Louisville in Partial Fulfillment of the Requirements

for the Degree of
\end{abstract} \\ Department of Educational Leadership, Evaluation and Organizational Development \\ University of Louisville \\ Louisville, Kentucky
}

May 2020 
Copyright 2020 by Seonghun Lee

All rights reserved 

PROMOTING HEALTHY AGING: AN INVESTIGATION OF THE RELATIONSHIPS AMONG SPORT SATISFACTION, SPORT IDENTITY, AND SPORT COMMITMENT IN THE WELL-BEING OF OLDER ADULTS

\author{
By \\ Seonghun Lee \\ B.S., University of Dayton, 2006 \\ M.S., University of Louisville, 2010 \\ M.S., Wright State University, 2014 \\ A Dissertation Approved on
}

April 17, 2020

by the following Dissertation Committee:

Mary A. Hums, Chair

Marion E. Hambrick

Namok Choi

T. Christopher Greenwell 


\section{DEDICATION}

This dissertation is dedicated to the Living God, my Savior; to my lovely wise wife, Mi Suk; to my precious children, Harim Lee and Zion Lee; to my dear parents, IlSung Lee, and Ae Ja Yoon and mother-in-law, Soon-Ok Kim; and to my beloved brother, Won Suk Lee. This PhD journey and dissertation work would not have been possible without their love, care, support, and encouragement.

I would also like to dedicate this dissertation to my father-in-law, Jong Sul Jung, and my third baby, "Ell." They could not be with us but they show me how my God loves me and my family during this promised journey.

"Delight yourself in the LORD, and He will give you the desires of your heart."

Psalm 37:4 


\section{ACKNOWLEDGEMENT}

I would like to thank my advisor and committee chair, Dr. Mary Hums, for her guidance and mentorship in conquering milestones (especially completing my dissertation) during my entire doctoral program. Dr. Hums constantly challenged and improved my academic knowledge and skills, both which are essential for not only teaching and research but also academic services (e.g., mentorship and administration) in higher education. This PhD journey would not have been possible without her advice, encouragement, and support. Thank you, Dr. Hums, for all you have done for me. I am also very grateful to Dr. Chris Greenwell for his guidance and assistance in helping me conduct academic research and improve my critical and analytical thinking skills along with scientific writing skills to become a better scholar. I learned a lot from his valuable comments and suggestions. I sincerely appreciate the time you spent reviewing my abstracts and manuscripts as well as the dissertation work.

I would also like to thank the other committee members, Dr. Namok Choi and Dr. Marion Hambrick, for their support, patience, and flexibility over the past few years. Without their assistance, I could not have completed my dissertation work and the doctoral studies. Thank you to Dr. Choi for taking the time to provide valuable guidance and advice for Chapter III and IV of the dissertation. I truly appreciate your prayers and encouragement throughout my doctoral studies. Thank you to Dr. Hambrick for your understanding and encouragement regarding the changes that I have made to the 
dissertation earlier. I sincerely appreciate the time you spent reviewing my dissertation work. I am indebted to Dr. Hambrick for your thoughtful comments and suggestions.

Also, many thanks to the faculty and staff members in the College of Education \& Human Development at University of Louisville (U of L): Professor Anita Moorman, Dr. Megan Shreffler, Dr. Evan Frederick, Professor Regina Presley, Professor Liza Ledford, Dr. Carla Vidoni, Dr. Kristi King, Dr. Meera Alagaraja, Dr. Jason Immekus, Dr. Kyle Ingle, Dr. Hongryun Woo, Michel Ball, Patsy Maguire, and Erica Camp. I especially want to thank two leaders, Dr. Meg Hancock and Dr. Dylan Naeger for their guidance and support during a period of difficulties.

My appreciation is also extended to the great group of doctoral students and alumni who were supportive throughout my entire doctoral program: Dr. Jae-Pil Ha, Dr. Jason Simmons, Dr. Alicia Cintron, Dr. Matt Huml, Dr. Chulwhan Choi, Dr. Jeff Levine, Dr. Sam Schmidt, Dr. James Weiner, Dr. Sarah Williams, Dr. Tyler Spencer, Dr. Adam Cocco, Youngjik Lee, Jessica Murfree, Chelsea Police, Addison Pond, Achyut Kulkarni, and Nina Siegfried. I would especially like to thank Dr. Brigitte Burpo for her kindness and support over the past few years. Without her encouragement and friendship, I would not be completing this $\mathrm{PhD}$ degree. "We got this! We will finish this strongly together!" I also would like to thank Dr. Hyunin Baek for helping me understand the advanced statistical methods and quantitative research techniques. I am extremely blessed to have been surrounded by great professors, staff, and colleagues.

I would like to thank the staff members of the Graduate School (especially Dr. Michelle Rodems, Dr. Barbara Clark, and Dr. Paul DeMarco), the Writing Center (especially Dr. Bronwyn Williams, Dr. Cassie Book, Amber Yocum, and both assistant 
directors, and consultants), and the International Student and Scholar Services (Thomas Beard, Barbara Jones, Connie Martinez, and Beverly Cooper) at U of L. For me, these services and staff members have provided priceless and supportive environments during my $\mathrm{PhD}$ journey. I appreciate all the help, support, advice and guidance through the years. Moreover, many thanks to all my students who took my sport administration courses and provided me with excellent feedback to improve my teaching skills.

I also would like to thank the employees who allowed me to collect paper surveys at their sites (I am sorry that I cannot specify your names here), and also those who took the survey voluntarily and provided valuable comments. Without their help, support, and participation, I could not complete my dissertation.

Importantly, I would like to express my gratitude to my wise wife, Mi Suk Jung, my lovely children, Harim Lee and Zion Lee, and the members of my family in South Korea for their understanding and patience while I could not be with them. I really appreciate all your endless support. Moreover, I would like to extend my sincere gratitude and deep appreciation to my friends, pastors, and church members for all your prayers, support, and encouragement for the $\mathrm{PhD}$ journey (I am sorry that I cannot specify your names here).

Lastly, thank you, God the Father, the Son Jesus Christ, and the Holy Spirit. Your grace for me is always enough! Thank you for this promised journey. "The Lord will keep you from every kind of harm. He will watch over your life. The Lord will watch over your life no matter where you go, both now and forever" Psalm 121:7-8. 


\begin{abstract}
PROMOTING HEALTHY AGING: AN INVESTIGATION OF THE RELATIONSHIPS AMONG SPORT SATISFACTION, SPORT IDENTITY, AND SPORT COMMITMENT IN THE WELL-BEING OF OLDER ADULTS
\end{abstract}

Seonghun Lee

April 17, 2020

People are living longer and the aging population in the U.S. is showing significant growth, but it does mean they are necessarily living healthier lives. Public health representatives recommended people who want to live a healthy lifestyle as they get older need to regularly participate in sport and physical activity earlier in their life because it improves health and psychological and social well-being. However, approximately 80 percent of U.S. adults/older adults are insufficiently active; they participate for fewer than 150 minutes in moderate-intensity physical activity per week. To promote sport engagement, older adult sport and fitness service providers need a better understanding of older adults' attitudes toward participation in organized sport and physical activity. Activity theory (Havighurst, 1961) proposed successful aging occurs when individuals continue to participate in leisure activities into old age. Snyder (1981) suggested the concept of sport commitment might be incorporated with activity theory to explore the physical participation behavior as people age.

Using the Sport Commitment Model (SCM) and activity theory, this study examined two overarching questions (RQ1: Do the antecedent factors [e.g., sport 
enjoyment], sport satisfaction, and sport identity predict the level of sport commitment toward organized sport activity?; and RQ2: Is there a significant relationship between the level of life satisfaction and sport satisfaction, sport identity, and sport commitment among older adults who participate in organized sport activity regularly?) to gain a better understanding of participation in organized sport activities among older adults over 55 years of age.

The results of multiple regression analyses revealed sport enjoyment, sport satisfaction, involvement opportunities and sport identity were significant predictors of sport commitment for the sample of older adults who participated in organized sport activity. Moreover, sport satisfaction was an important factor which contributed not only to sport commitment but also to life satisfaction among older adults. This study expanded and advanced knowledge on sport participation among older adults by addressing the theoretical relationships of activity theory, sport identity, sport satisfaction and the SCM. The findings provide a helpful resource for older adult sport programmers to promoting and increasing organizing sport participation. 


\section{TABLE OF CONTENTS}

PAGE

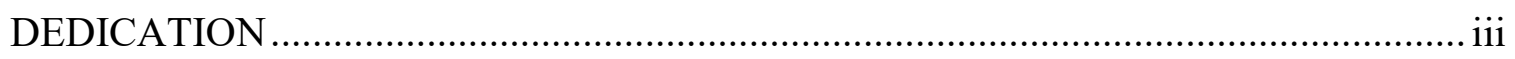

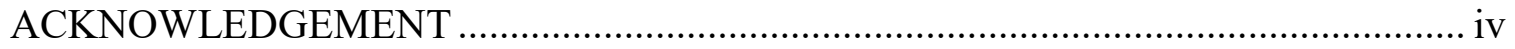

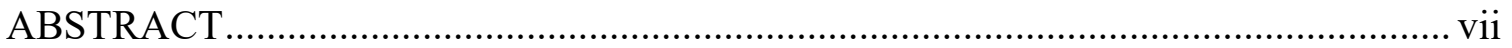

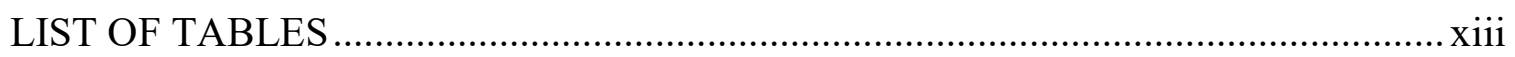

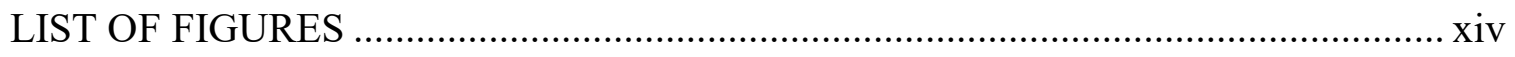

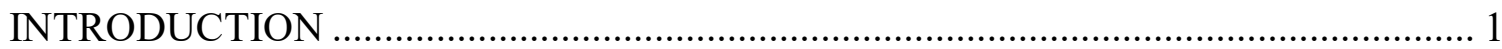

Older Adults and Sport and Physical Activity ......................................................... 2

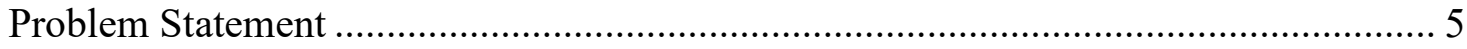

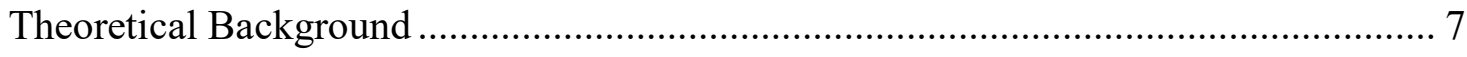

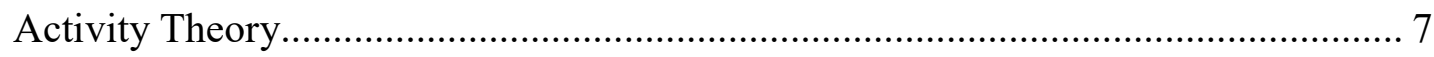

The Concept of Commitment ........................................................................... 8

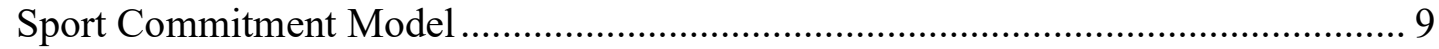

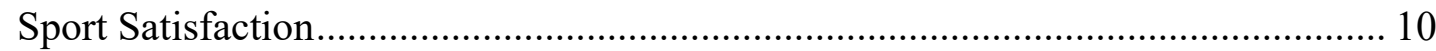

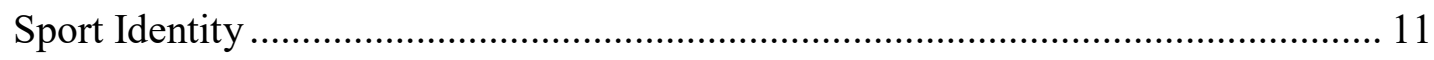

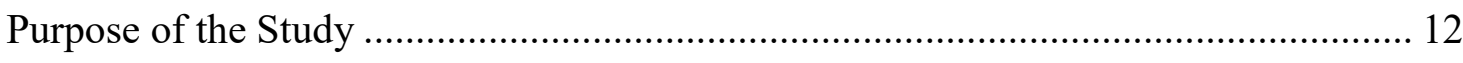

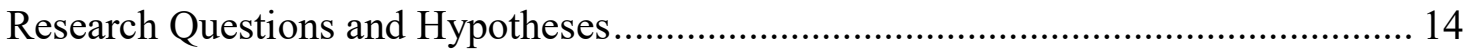

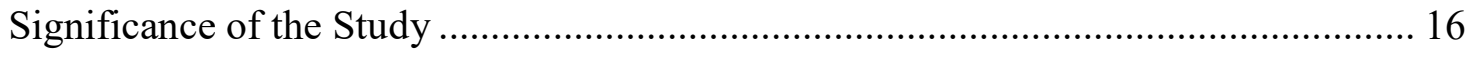

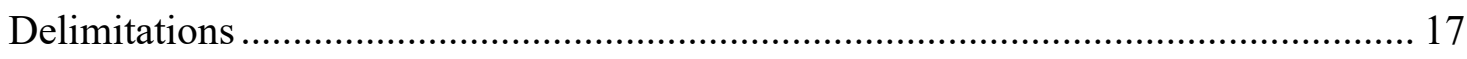

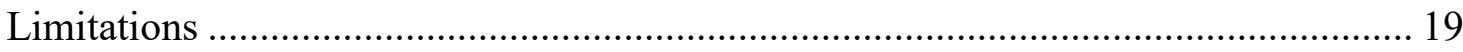

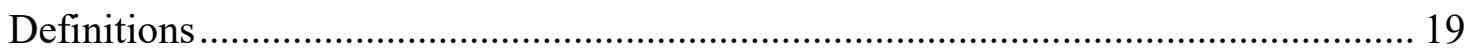

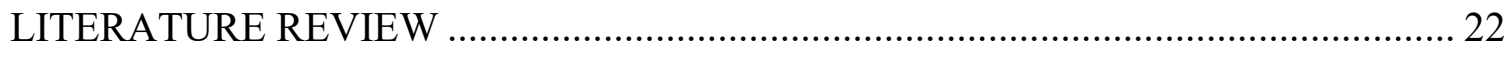

Older Adult Organized Sport Participation ....................................................... 22

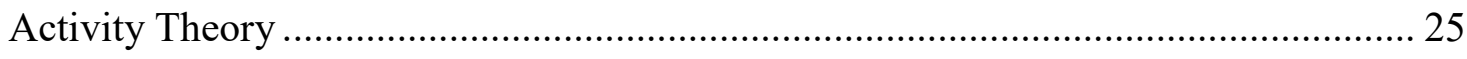

Benefits of Sport and Physical Activity Participation............................................. 26

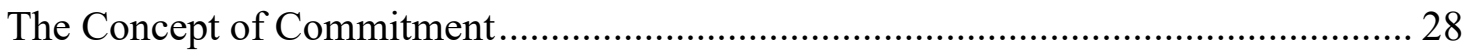

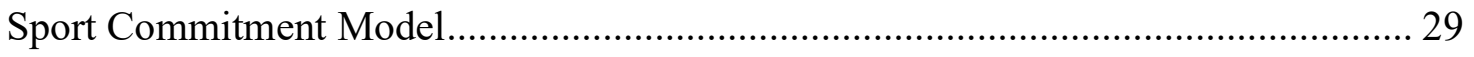


Development of the Sport Commitment Model ....................................................... 29

Sport Commitment Model with Social Support …………………………………..... 33

Sport Commitment Model and Exercise Behavior..................................................... 36

Sport Commitment Model and Demographics........................................................... 37

Sport Commitment Model and Behavior Outcomes …………………………….... 41

Association of Sport Commitment and Life Satisfaction ............................................ 43

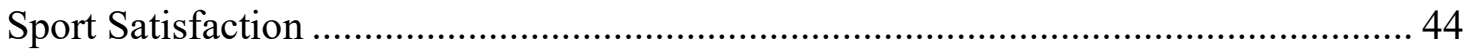

The Concept of Satisfaction ................................................................................ 44

Sport Satisfaction and Sport Commitment Model................................................... 44

Association of Sport Satisfaction and Life Satisfaction ............................................. 46

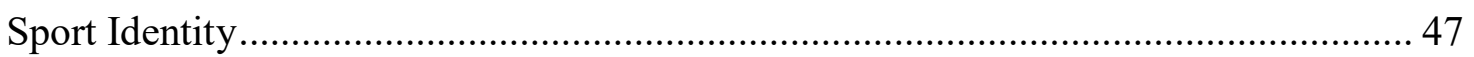

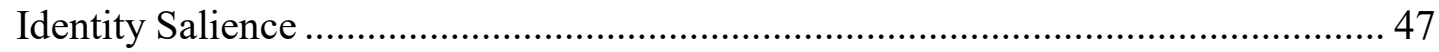

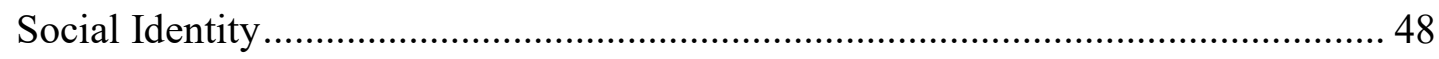

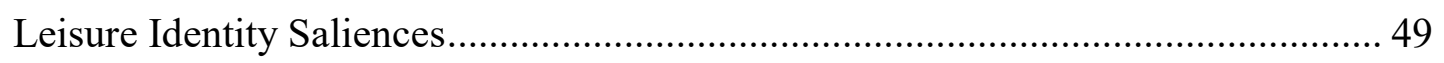

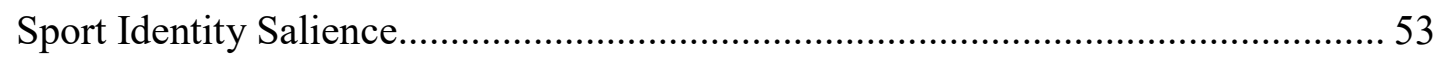

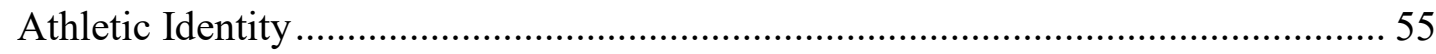

Sport Identity and Sport Commitment Model ........................................................... 60

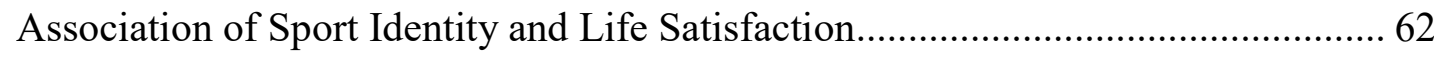

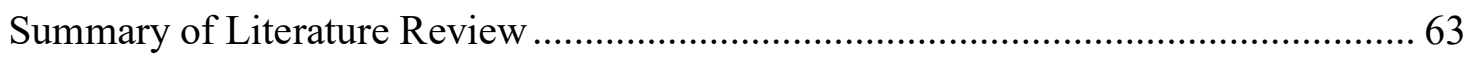

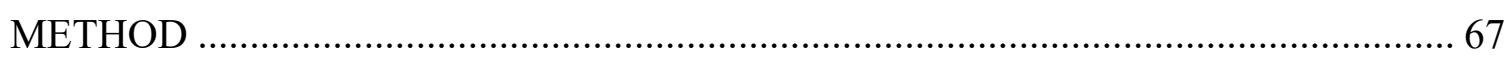

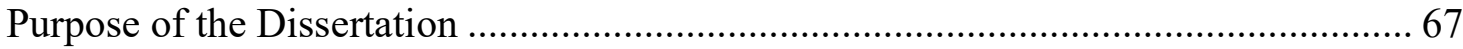

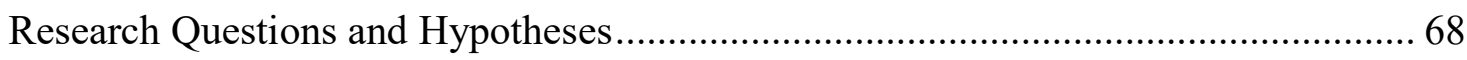

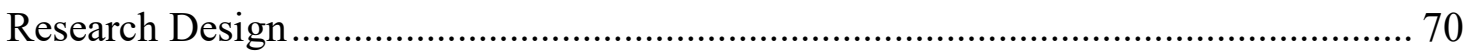

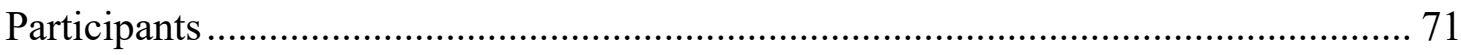

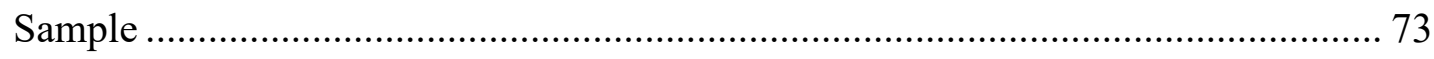

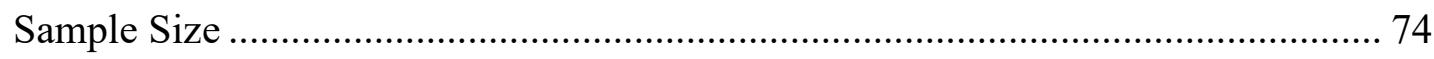

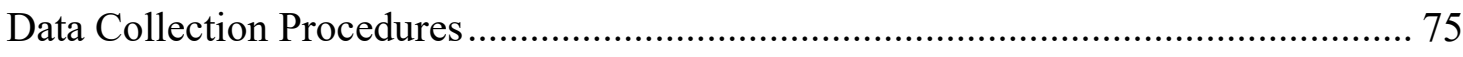

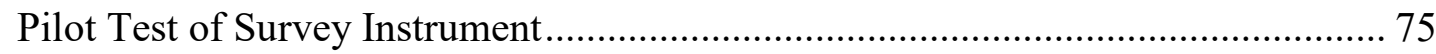

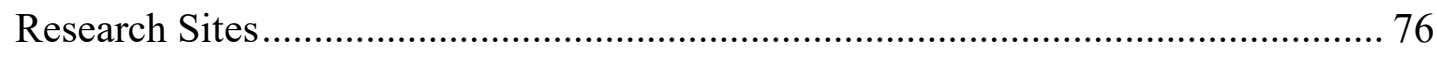

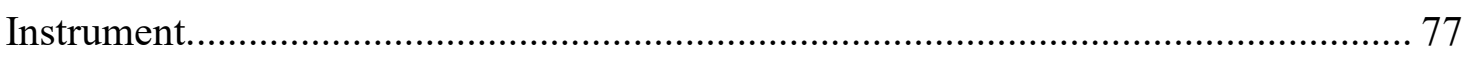

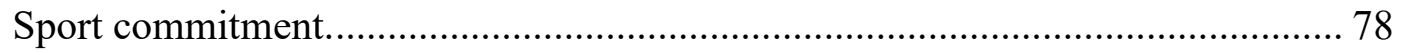

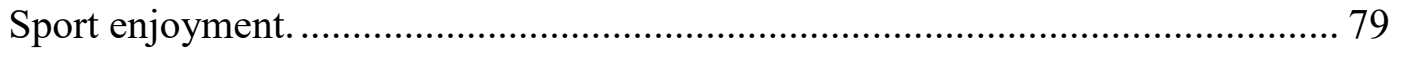


Involvement alternatives...................................................................... 79

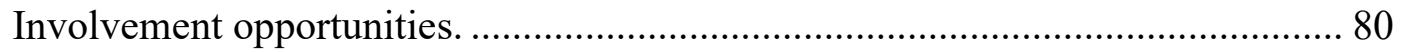

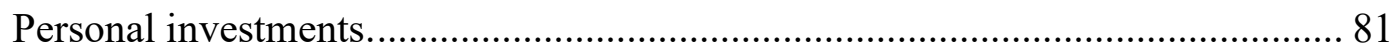

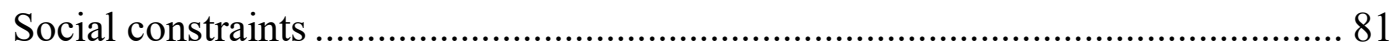

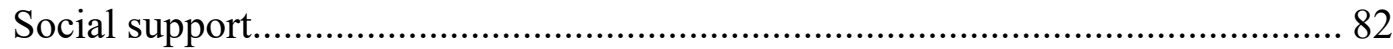

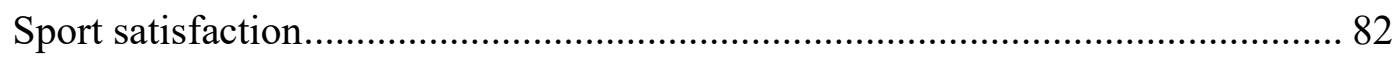

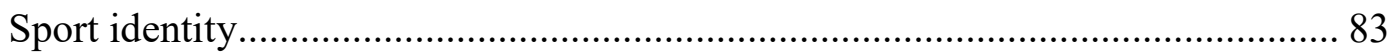

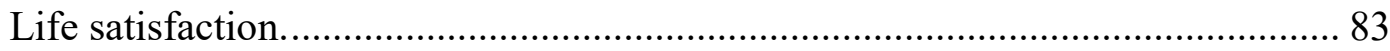

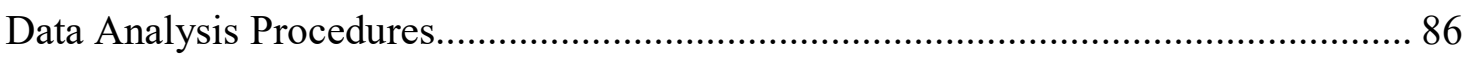

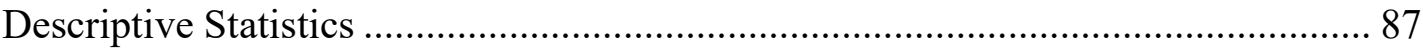

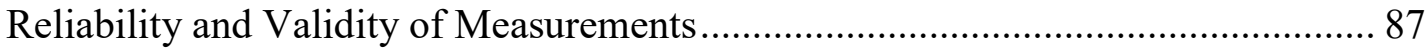

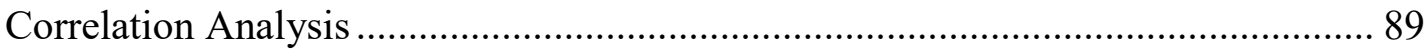

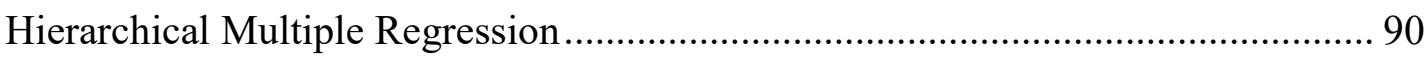

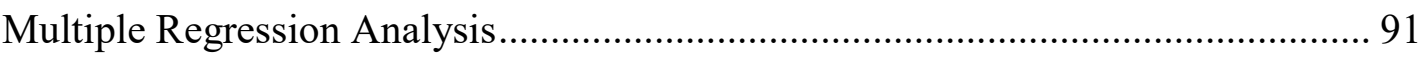

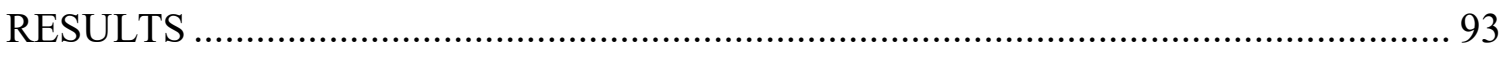

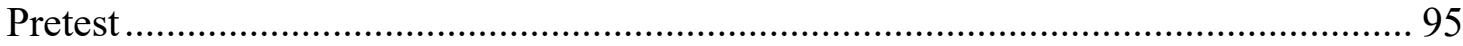

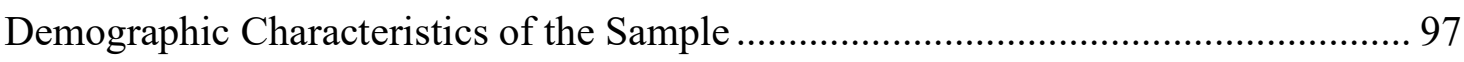

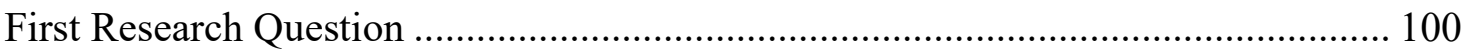

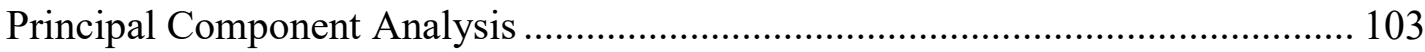

Descriptive Statistics and Correlation Analysis ............................................. 108

A Three Stage Hierarchical Multiple Regression............................................... 109

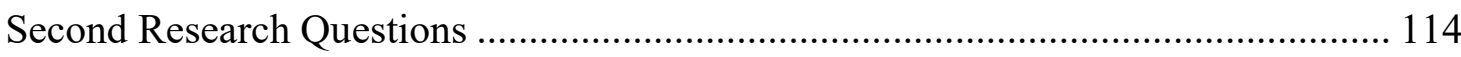

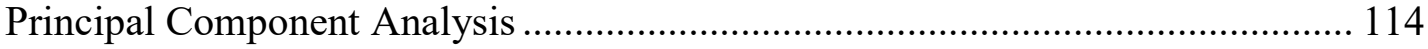

Descriptive Statistics and Correlation Matrix ................................................... 116

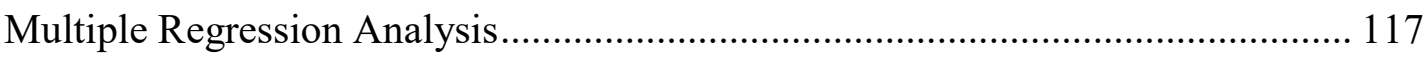

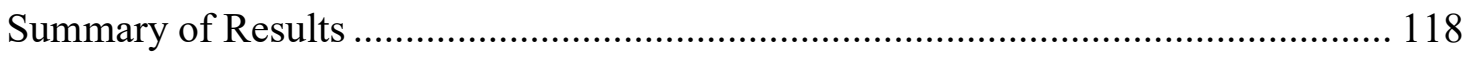

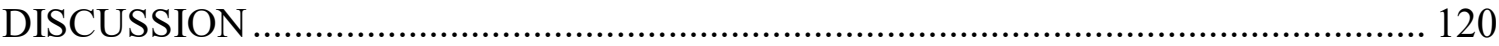

Theoretical Implications of First Research Question ........................................ 123

Original Sport Commitment Model............................................................... 125

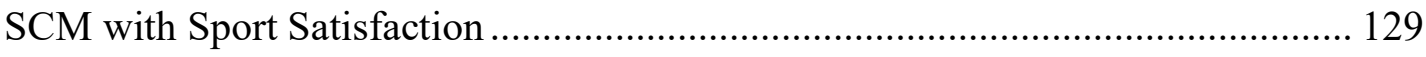

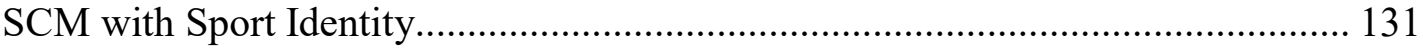

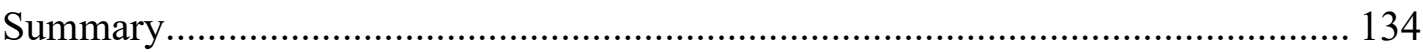


Theoretical Implications of Second Research Question .......................................... 135

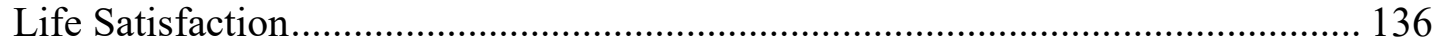

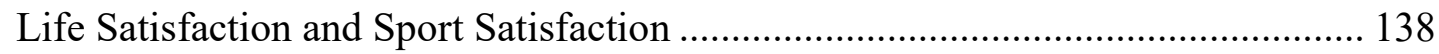

Life Satisfaction and Sport Identity .................................................................... 139

Life Satisfaction and Sport Commitment ............................................................ 140

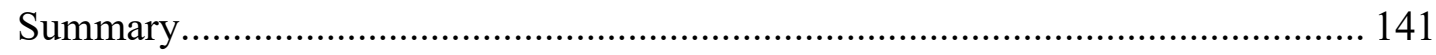

Recommendations for Future Research ................................................................. 142

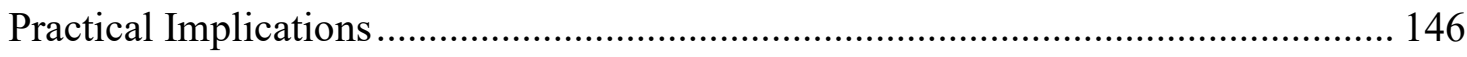

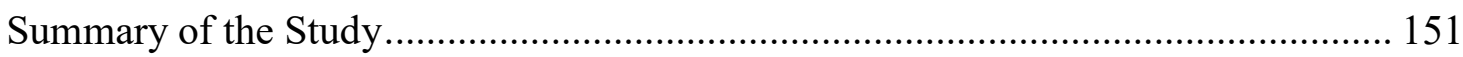

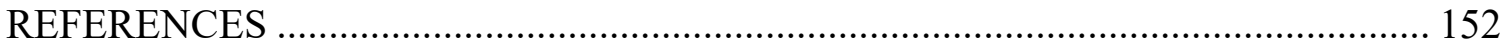

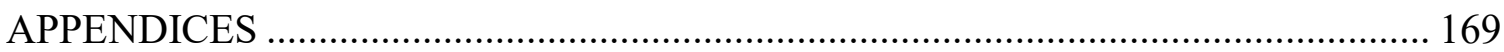

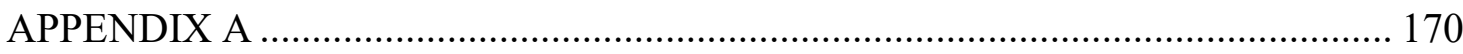

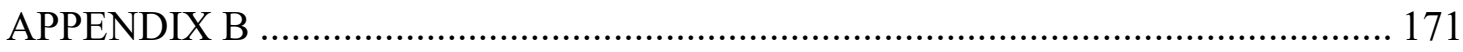

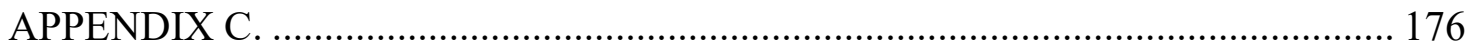

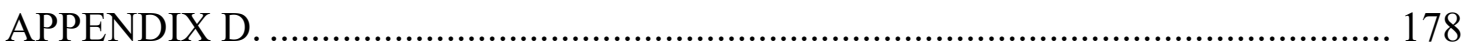

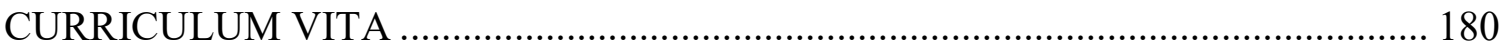




\section{LIST OF TABLES}

TABLE PAGE

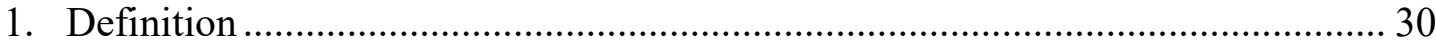

2. The Questionnaire of SCM, Sport Satisfaction, Sport Identity, and Life

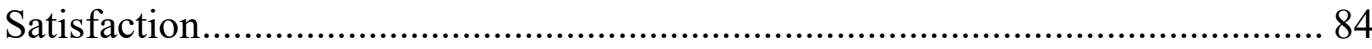

3. The Pilot Test's Demographics Characteristics ………………………………..... 95

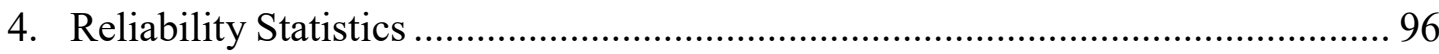

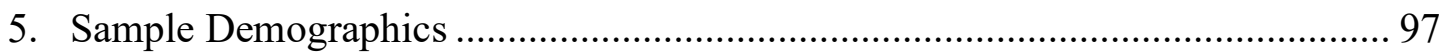

6. Organized Sport Activity Involvement .................................................................. 99

7. Descriptive statistics of each item: Mean, SD, and Skewness and Kurtosis ...... 101

8. Results of the Pattern Coefficients, Communities, and Cronbach's alpha ......... 106

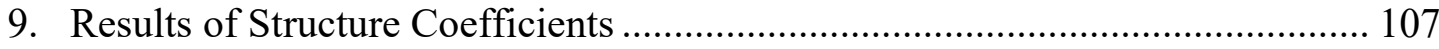

10. Descriptive Statistics and Correlation Matrix..................................................... 109

11. The Results of Hierarchical Linear Regression Analysis for Sport Commitment 113

12. Descriptive Statistics and Correlation Matrix...................................................... 117

13. Results of Multiple Regression for Life Satisfaction.......................................... 118

14. Summary of Significant Findings from RQ1 ................................................... 124

15. Summary of Significant Findings from RQ2 ………...................................... 136 


\section{LIST OF FIGURES}

$\begin{array}{lll}\text { FIGURE PAGE } & \text { PAR }\end{array}$

1. The Expanded Sport Commitment Model with Sport Satisfaction. .................... 13

2. The Expanded Sport Commitment Model with Sport Satisfaction and Sport

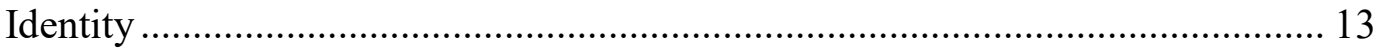

3. Conceptual Model to Presents the Psychological Outcomes (Sport Satisfaction, Sport Identity, and Sport Commitment) of Organized Sport Participation Relevant

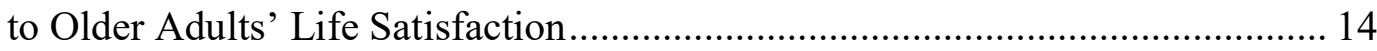

4. A Simple Model of Factors Affecting Participation ........................................ 27

5. Incorporation of Benefits into the Preferences-Participation Model ................... 27

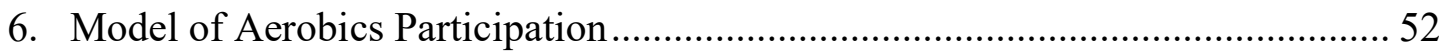

7. Lau et al.'s (2004) Proposed Model of Children's Sport Participation ................ 57 


\section{CHAPTER I}

\section{INTRODUCTION}

According to the World Health Organization (WHO, 2018a), people are living longer lives and the aging population is showing significant global growth. Specifically, U.S. Census Bureau projections indicate that by 2050 , the elderly will make up a full quarter of all people in the United States. This does not, however, mean that older adults are necessarily living healthier lives (Barratt, 2017, Brockman, 2019). As people get older, they begin to think more about their financial plans and investments (e.g., retirement plans) rather than investing their time to participate in physical activities. This is because their financial resources are limited by retirement and many people experience a decline in physical strength. For instance, healthcare costs can increase significantly for older adults. People 65 to 84 years old spend about $\$ 15,000$ per year while the average 85 -year-old person spends nearly $\$ 35,000$ per year on healthcare (Gladych, 2016).

Nevertheless, researchers have suggested that people need to plan for a healthy lifestyle through regular participation in physical activities earlier in their life, which will help save health costs later in life (McPhee, French, Jackson, Nazroo, Pendleton, \& Degens, 2016).

Unfortunately, U.S. Department of Health and Human Services (2018) reports indicated that approximately 80 percent of U.S. adults are insufficiently active, meaning they participate for less than 150 minutes in moderate-intensity physical activity (e.g., brisk walking, dancing, swimming, bicycling, tennis [doubles], or gardening) per week. 
This report also suggested that adults (18 to 64 years old) should avoid physical inactivity and do at least 150 minutes a week of moderate-intensity aerobic physical activity and at least 2 days a week of muscle-strengthening activity to maintain and improve their health (U.S. Department of Health and Human Services, 2018). More specifically, the WHO (2018b) suggested involvement in physical activities such as walking, cycling, sports, and recreation can be popular ways to be active. WHO defined physical activity "as any bodily movement produced by skeletal muscles that require energy that expenditure" and "can be done at any level of skill and for enjoyment" (2018b, para. 1). International and national governing bodies, scholars and practitioners have recognized both the importance of participating in sport and physical activities and the risks of physical inactivity among adults in their later life (Baker, Fraser-Thoma, Dionigi, \& Horton, 2010; Hirvensalo \& Lintunen, 2011; Jenkin, Eime, Westerbeek, O’Sullivan, \& Van Uffelen, 2017; Jenkin, Eime, Westerbeek, \& van Uffelen, 2018). These authors recommended that engaging in physical activity plays an important role at different stages of life. Being active positively impacts a healthy lifestyle and promotes healthier aging (e.g., psychological and social well-being) (Hirvensalo \& Lintunen, 2011; Jenkin et al, 2017, 2018; McPhee et al, 2016).

\section{Older Adults and Sport and Physical Activity}

The research indicates older adults in the US sit for longer times and spend less leisure time in participating in physical activity compared to younger adults (Ussery, Fulton, Galuska, Katzmarzyk, \& Carlson, 2018). Prolonged sitting and being physically inactive can cause serious or negative physical and mental health consequences among older adults. Specifically, they are less likely to maintain or improve physical mobility, 
strength, and endurance (Shah, Weinborn, Verdile, Sohrabi, \& Martins, 2017). A

previous study found, however, that individuals who exhibited long-term sedentary behavior and later increased their level of physical activity experienced positive wellbeing and satisfaction with physical function (Rejeski, Shelton, Miller, Dunn, King, \& Sallis, 2001). Physical Activity Guidelines for Adults from the United States Department of Health \& Human Services (HHS) (2018) suggested adults should be more active and sit less during the day.

A significant number of studies (i.e., Adams, Leibbrandt, \& Moon, 2011; Dionigi \& Son, 2017; Jenkin et al., 2017; Jenkin et al., 2018; McPhee et al., 2016) across various social sciences disciplines have demonstrated physical, psychological, and social benefits of regular participation in sport and physical activity in different populations. However, sport and physical activity participation declines considerably as people get older (Jenkin et al., 2018). Since aging often correlates with a decline in physical health and financial resources, researchers argue that societal influences, expectations, and attitudes can encourage sedentary lifestyles and behavior, consequently diminishing interest in sport and physical activity (Dergance, Calmbach, Dhanda, Miles, Hazuda, \& Mouton, 2003; Ussery et al, 2018). For instance, societal approaches to aging often tend to suggest older adults should lead more sedentary lifestyles. It resulted in exercise programs being more targeted toward younger people and older adults being unaware of the right amount of time to spend on participation in sport and physical activity. Older adults "may believe that they have to be careful and not overexert themselves" (Dergance et al., 2003, p. 865; Hirvensalo \& Lintunen, 2011). 
In terms of theoretical perspectives on aging, both disengagement theory and activity theory have been widely utilized to show how individuals might respond to growing older (Hillier \& Barrow, 2007). As an early social science theory on aging, disengagement theory is based on a structural functional perspective that it is natural and acceptable for individuals to withdraw from society as they get older due to preparation for death. This idea suggests the process of disengagement (e.g., retirement) among older adults is important in order to allow the social system to remain stable and ordered (e.g., involving young generations). Therefore, it can be predicted that older adults are more likely to naturally withdraw from activities, roles, and social engagement (Hillier \& Barrow, 2007). An opposite view of disengagement theory due to aging was suggested by Havighurst and Albrecht (1953). These researchers claimed if individuals stay active and maintain social interactions as they get older, they will be happier and more satisfied with elderly life. Therefore, the activity theory of aging implies individuals who are able to maintain their degree of social activity as they age are more likely to live healthier mental, physical, and social lives as well as achieve positive self-image, social integration, and life satisfaction (Hillier \& Barrow, 2007). Therefore, activity theory responds to the disengagement theory of aging by suggesting there should be more options to participate in different and diverse recreational or leisure activities as people age, rather than being removed neglected from society.

Moreover, the World Health Organization (WHO) suggested that governments should focus on developing policies and programs to better meet the health and social care needs of citizens throughout their lives (Barratt, 2017). More sport and physical activity programs should be available for older adults because current sport policies and 
programs often prioritize participation by younger age populations (Jenkin et al., 2018). The research suggested that it is never too late to begin to participate in sport and physical activity to gain various benefits for later adulthood (Saint-Maurice, Coughlan, Kelly, Keadle, Cook, Carlson, ... \& Matthews, 2019). It is important to note that older adults should not be limited to participating in traditional forms of leisure or exercise, but also need to be encouraged to participate in a wide range of team and adventure sports and physical activities (Dionigi \& Sun, 2017). Therefore, in order to promote more active and healthy lifestyles, various recreational and niche sports need to be introduced to older adults. For instance, pickleball, a relatively new sport that combines tennis, badminton and table tennis, has become a popular sport for older adults. Additionally, there have been significant studies on participation in pickleball among older adults. Ryu, Yang, Kim, Kim \& Heo (2018) demonstrated that high commitment to the game of pickleball decreased levels of depression in older adults. They suggested that pickleball participation can be used as a strategy to cope with life transition for retirees to spend their free time productively (Ryu, Yang, Kim, Kim, \& Heo, 2018).

\section{Problem Statement}

Since the proportion of older adults who participate in sport and physical activity declines as people age, sport organizations, managers and practitioners who work closely with older adults need a better understanding of older adults' attitudes toward participation in sport and physical activity. Individuals participate in sport and physical activity for different reasons and benefits (e.g., enjoyment, group affiliation, fitness, healthy living, and joy of competition) and they also choose not to participate due to different constraints (e.g., cost, time, and ability). Motivational factors for being active 
are connected to social, internal, and external influences on participatory behaviors. Scholars suggested that psychological factors predict exercise behavior (Miller, Ogletree, \& Welshimer, 2002). Therefore, in order to better address regular and consistent sport participation in later life, more research is needed on the psychological aspects (e.g., identity, commitment, satisfaction) of understanding participation in sport and physical activity among older adults (Byers, Slack, \& Parent, 2012).

As an important indicator of successful aging, life satisfaction is a desired subjective feeling which may reflect an individual's health condition (Maher \& Conroy, 2015). A study indicated most adults between age 40 and 70 years old feel satisfied with their lives even though they may experience more physical problems and illnesses in later life (Baird, Lucas, \& Donnellan, 2010). Previous studies demonstrated levels of life satisfaction vary from day to day based on changes in sedentary behavior and physical activity in populations across the adult life span (Maher \& Conroy, 2015). Furthermore, despite feelings of positive life satisfaction, important changes such as the death of a spouse or retirement may cause difficulties and feelings of uneasiness, stress, and sadness (National Institute on Aging, 2017). Public health representatives and researchers suggested that regular participation in sport and physical activities may increase positive emotional experiences and improve self-esteem, quality of life, as well as psychological and social well-being (Hidalgo, 2019; Malm, Jakobsson, \& Isaksson, 2019; Mura \& Carta, 2013; Ruuskanen \& Ruoppila, 1995). Participation in sport and physical activity can play an important role in healthier aging, especially improving psychological well-being. More empirical evidence is needed to support the psychological benefits of sport participation for older adults. Specifically, researchers need to examine the different 
levels of sport participation involvement, motivation, and commitment in order to determine how to improve older adults' life satisfaction (Kim, Park, Kim, \& FontesComber, 2019).

\section{Theoretical Background}

Next it is important to highlight the literature related to activity theory and Sport Commitment Model (SCM). A brief overview of these areas follows.

\section{Activity Theory}

Life satisfaction represented "a cognitive evaluation of the quality of an individual's life as a whole" (Eklund \& Tenenbaum, 2013, p.609). As a psychosocial benefit, life satisfaction is one of the elements that determine successful aging (Ryu et al., 2018; Siegenthaler \& O’Dell, 2003). Scholars have recognized that regular participation in sport and leisure activities play an important role in increasing physical and psychological health. This included life satisfaction (Molanorouzi, Khoo, \& Morris, 2015). The influence of involvement in sport and physical activity on well-being among older adults can be understood using activity theory (Havighurst, 1961). This theory proposed that successful aging occurs when individuals continue to participate in social and leisure activities throughout their lives and then adapt when certain life roles are relinquished (e.g., retirement) (Adams et al., 2011; Snyder, 1981). Studies have empirically demonstrated a significant relationship between participation in sport and physical activities and life satisfaction among older adults (Jenkin et al., 2017; Jenkin et al., 2018; McPhee et al., 2016). However, Snyder (1981) argued that activity theory is limited in explaining why older adults are active or inactive, and why they continue or 
discontinue participating in physical activity. He suggested that it is important to know how older adults become committed to being more active.

\section{The Concept of Commitment}

To further understand aging and sport involvement, Snyder (1981) suggested that the concept of commitment might be incorporated with activity theory to explore sport participation behavior in middle and old age. Specifically, predictors of commitment such as enjoyment, satisfaction, and identity could explain continued engagement or disengagement from sport and physical activities in adulthood. Furthermore, Snyder (1981) stated that "the configuration and depth of commitment will be more critical in determining quality of life and well-being in old age" (p.115). Participation in sport and physical activity could therefore play a significant role in the later life, and it would be important to know how individuals achieved life satisfaction from commitment. Of specific interest would be how individuals achieve life satisfaction through sport commitment and its components such as sport identity and sport satisfaction. Understanding sport commitment could help explain how older adults can stay active and enjoy better health outcomes. However, no empirical evidence was found in the literature at the time to explain how older adults achieve improved life satisfaction from sport commitment and its components (e.g., sport identity, and sport satisfaction) simultaneously. Therefore, the current study tested the theoretical relationships among sport satisfaction, sport identity, sport commitment and life satisfaction for older adults who participate in organized sport. 


\section{Sport Commitment Model}

The concept of sport commitment has been widely examined as a construct explaining individuals' desire to continue to participate in specific sport and physical activities. Scholars in leisure and sport management demonstrated that highly committed sport participants are more likely to frequently engage in and spend considerable time, effort, and money on sport (Chang \& Gibson, 2015; Mullin, Hardy, \& Sutton, 2014; Tokuyama \& Greenwell, 2011; Snyder, 1981). Sport commitment plays an important role in the extent of sport and physical activity participants' behaviors. Previous studies indicated that older adults were more committed to their sport and physical activity (e.g., tennis and windsurfing) due to the length of time of participation. However, sport commitment can vary depending on the type of sport and physical activity (Casper \& Stellino, 2008). Relatively few studies, however, have examined the predictors or elements of sport commitment among older adults (Casper \& Stellino, 2008). For instance, only one investigation fully applied the SCM to older adults' sport and physical activity behavior (Wang \& Chu, 2016).

The SCM identified specific participation antecedents - sport enjoyment, involvement alternatives, involvement opportunities, personal investments, social constraints, and social support. These antecedents influence individuals to continue their participation in specific sports or physical activities and impact sport consumption behaviors such as participation frequency, purchase intentions, and media consumption (Carpenter \& Coleman, 1998; Scanlan, Carpenter, Schmidt, Simons, \& Keeler, 1993; Scanlan, Simons, Carpenter, Schmidt, \& Keeler, 1993). The SCM has been used to produce empirical evidence in a variety of sport contexts such as fitness (Alexandris, 
Zahariadis, Tsorbatzoudis, \& Grouios, 2002), tennis (Casper et al., 2007; Casper \& Stellino, 2008), windsurfing (Jeon \& Ridinger, 2009), and multiple youth sports (Scanlan, Carpenter, Schmidt, Simons et al., 1993; Scanlan, Simons, Carpenter, Schmidt et al., 1993; Weiss \& Weiss, 2007).

Demographic differences may also impact consumers' sport and recreational behaviors (Alexandris \& Carroll; 1997; Won, Hwang, \& Kleiber, 2009). For example, using the SCM, Casper (2007) examined how demographic market segments of tennis participants were different based on three variables: commitment, participation frequency, and purchase intention and also found age was a significant factor related to sport commitment (Casper, 2007). Jeon and Casper (2016) compared Taekwondo participants and found involvement opportunities only predicted commitment with adults while social support only predicted commitment with youth. In order to understand further why some older adults continue to participate in sport and physical activities, SCM can be applied to determine the relationships among specific antecedents and sport commitment. In addition, life satisfaction and identity constructs, two elements of sport commitment suggested by Snyder (1981), may add to SCM model to examine the population of older adults.

\section{Sport Satisfaction}

Sport satisfaction is defined as the positive perceptions or feelings that an individual gains as a result of engaging in sport activities and choices. It determines to what degree an individual is currently satisfied with their experiences with sport activities (Beard \& Ragheb, 1980). Previously, sport satisfaction was examined interchangeably with various constructs such as enjoyment, pleasure, fun, and intrinsic and extrinsic 
rewards (Casper et al., 2007; Eklund \& Tenenbaum, 2013, Granero-Gallegos, BaenaExtremera, Gómez-López, \& Abraldes, 2014; Snyder 1981).

Wilson and his colleagues (2004) replaced Scanlan's (1993) enjoyment construct with the satisfaction construct to develop the Exercise Commitment model (ECM). In the ECM, satisfaction "represented the degree to which current exercise participation was perceived as rewarding" (Wilson et al., 2004, p. 409) and was one of the strongest predictors of exercise commitment. This study employed sport satisfaction as a distinct construct which separated it from other original constructs of the SCM. Therefore, the current study added sport satisfaction as distinct construct to predict older adults' level of commitment to organized sports.

\section{Sport Identity}

Sport identity represents how sport and physical activity are "incorporated into one's sense of self" and "involves internalizing the meanings associated with" the specific sport or exercise (e.g., golf, swimming) (Eklund \& Tenenbaum, 2013, p.366). In the literature, the concept of identity has been applied in a wide range of sport participation contexts. Different theoretical constructs have been utilized (e.g., athletic identity, sport identity, exercise identity and leisure identity) to understand active sport participants' identity toward specific sport and physical activity behaviors. These studies demonstrated that the level of sport related identity was associated with psychological, emotional and behavioral outcomes (e.g., sport involvement, sport commitment, and life satisfaction).

Specifically, athletic identity was examined in the SCM as an additional predictor for professional football players (Hall, 1993) and adult recreational soccer league players 
(Frayeh \& Lewis, 2017). Results from both studies indicated that athletic identity had a direct significant positive effect on sport commitment. Previous studies indicated older adults with a strong physical activity identity participated in more physical activity and had greater life satisfaction compared to older adults with less strong physical activity identity (Strachan, Brawley, Spink, \& Glazebrook, 2010). Since loss of identity is a common worry of retirement, sport identity is a construct which could contribute to overcoming identity loss. More empirical research is needed to support the relationships among sport identity, sport commitment and life satisfaction among older adults.

Therefore, using the SCM to examine sport identity and satisfaction may find ways to keep older adults participating in organized sport activities. Increased organized sport participation among older adults would then lead to successful aging for older adults as an entire population.

\section{Purpose of the Study}

The primary purpose of this dissertation was to gain a better understanding of participation in organized sport activities among adults over 55 years of age, referred to as "older adults." Specifically, this purpose was twofold: (1) use the Sport Commitment Model (SCM) to identify antecedent factors that influence levels of commitment toward organized sport activity among older adults (Figure $1 \& 2$ ), and (2) investigate the relationships among sport satisfaction, sport identity, and sport commitment in the wellbeing of older adults who participate in organized sport activities (Figure 3). 


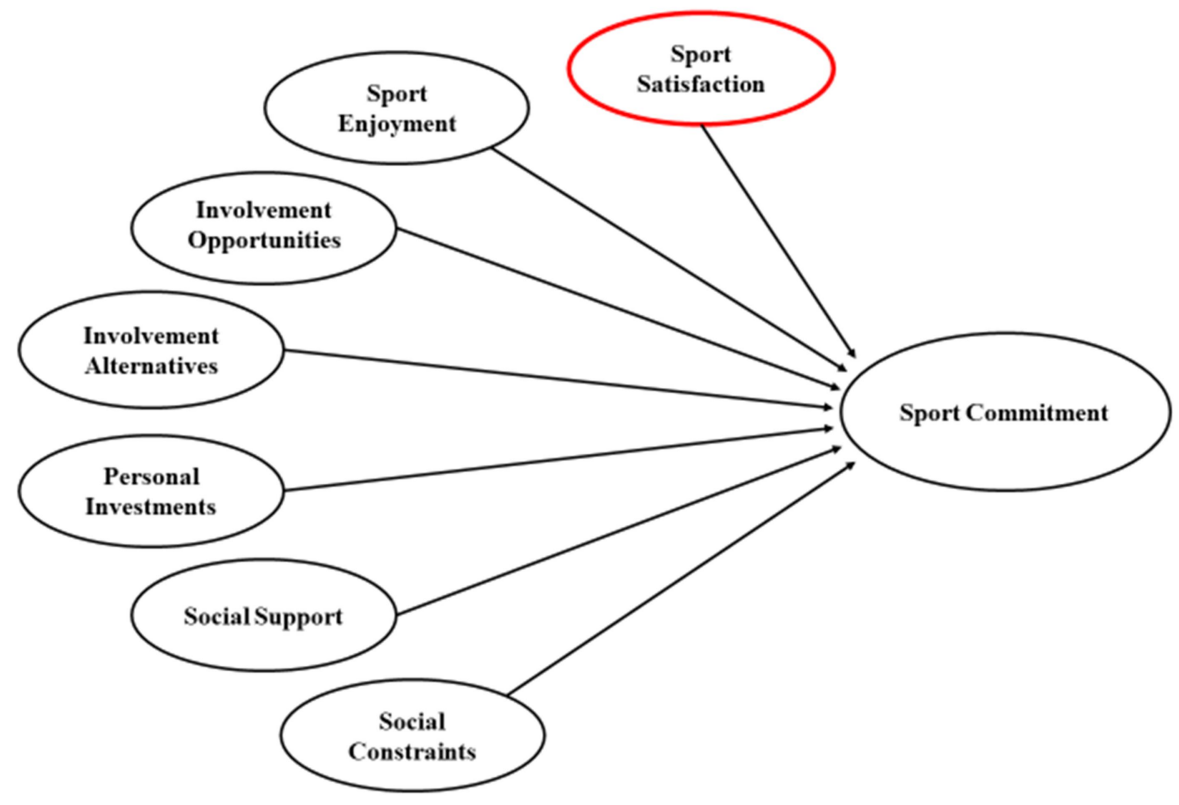

Figure 1. The Expanded Sport Commitment Model with Sport Satisfaction.

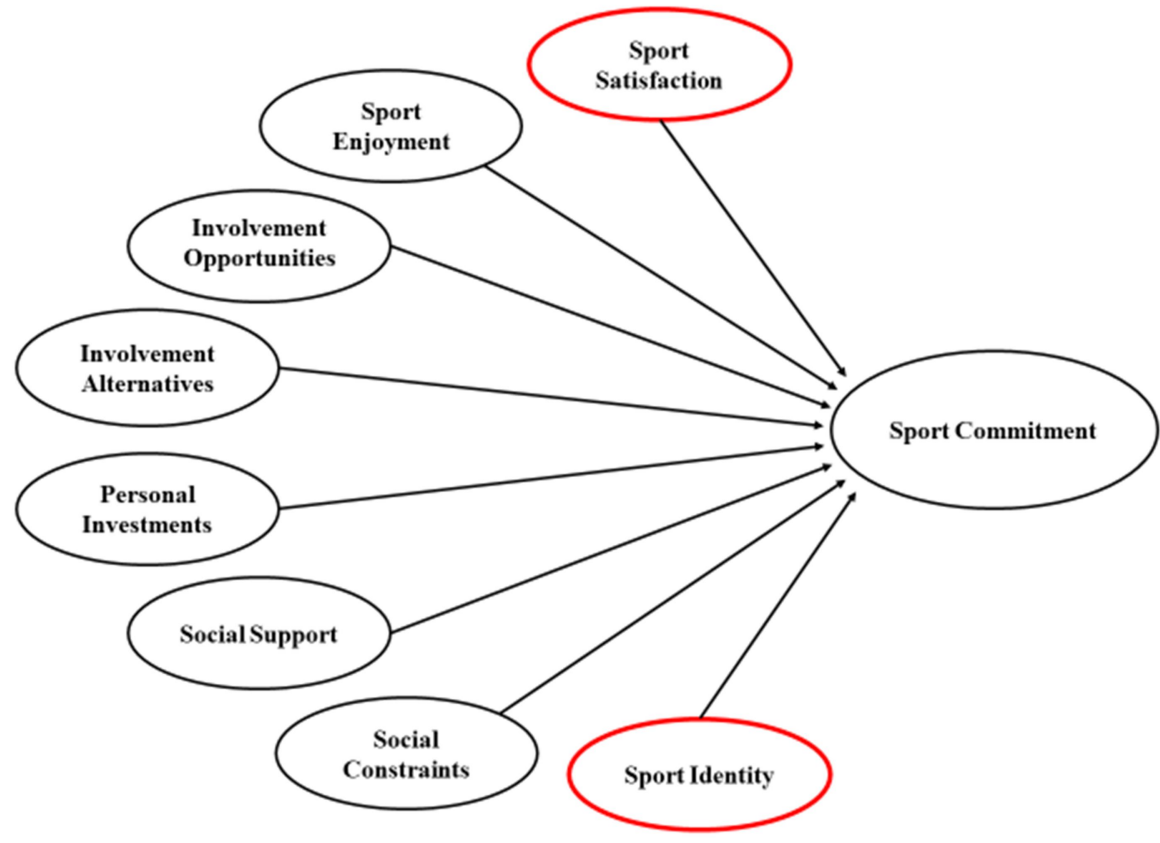

Figure 2. The Expanded Sport Commitment Model with Sport Satisfaction and Sport Identity 


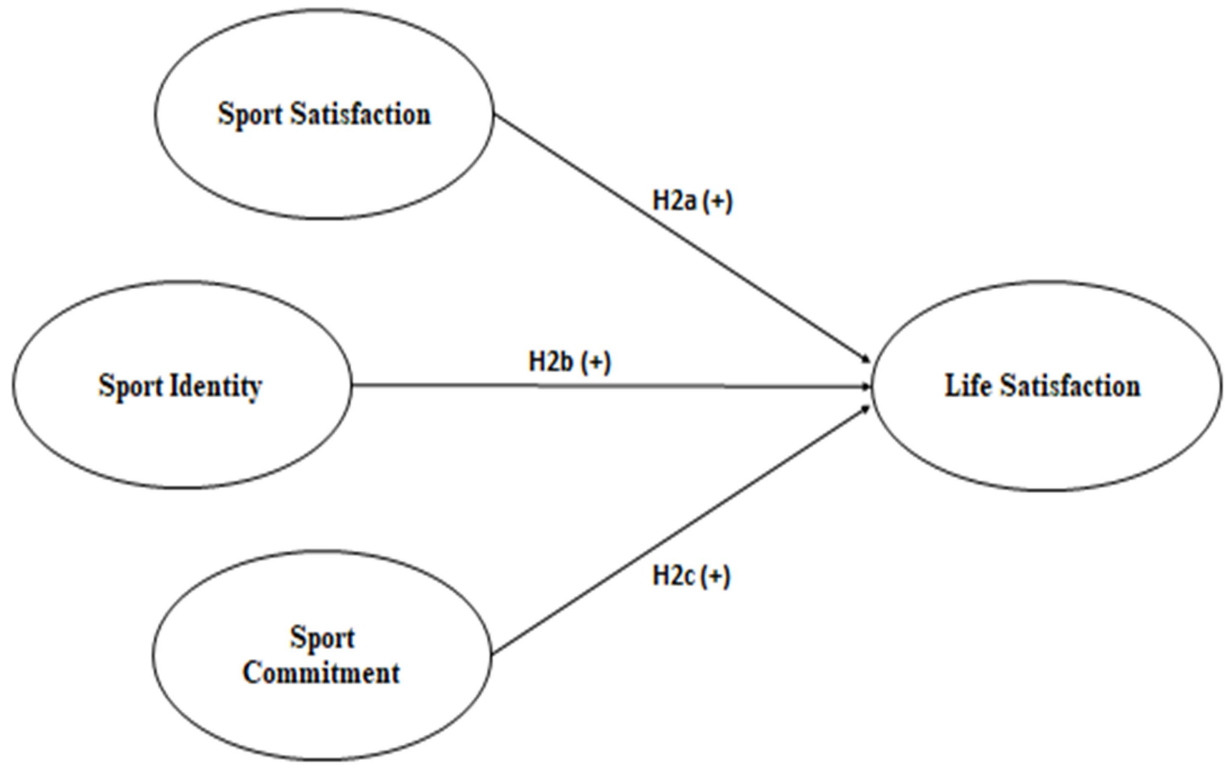

Figure 3. Conceptual Model to Presents the Psychological Outcomes (Sport Satisfaction, Sport Identity, and Sport Commitment) of Organized Sport Participation Relevant to Older Adults' Life Satisfaction

\section{Research Questions and Hypotheses}

To effectively address the two purposes of this dissertation, two overarching questions were examined and for each overarching question, there were a set of more specific questions.

Using the constructs of the SCM, the first research question was examined as follows:

RQ1. Do the antecedent factors (i.e., sport enjoyment, involvement opportunities, personal investments, involvement alternatives, social constraints and social support), sport satisfaction, and sport identity predict the level of sport commitment toward organized sport activity for older adults? Specifically:

1a. Which of the antecedent factors are the strongest predictors of older adults' sport commitment toward organized sport activity? 
1b. Does sport satisfaction explain a significant incremental variance in sport commitment over and above the six antecedent factors among older adults?

1c. Does sport identity explain a significant incremental variance in sport commitment over and above the seven antecedent factors including sport satisfaction among older adults?

In the first purpose, the following hypothesizes were proposed,

Hypothesis 1a: Sport enjoyment, involvement opportunities, personal investment, social constraints, and social support positively predict sport commitment, and involvement alternative negatively predicts sport commitment.

Hypothesis 1b: Sport satisfaction positively predicts sport commitment. Hypothesis 1c: Sport identity positively predicts sport commitment. A three stage hierarchical multiple regression was conducted to determine which antecedent factors of sport commitment (Step 1; RQ1a), sport satisfaction (Step 2; RQ1b), and sport identity (Step 3; RQ1c) significantly predict the level of sport commitment toward organized sport activity among older adults. Six antecedents (sport enjoyment, involvement opportunities, personal investments, involvement alternatives, social constraints and social support) from the original SCM and two new antecedents (sport satisfaction and sport identity) represented the independent variables and sport commitment represented the dependent variable.

In order to address the second purpose of the dissertation, the following research question was addressed: 
RQ2. Is there a significant relationship the level of life satisfaction and sport satisfaction, sport identity, and sport commitment among older adults who participate in organized sport activity regularly? Specifically:

2a. Is sport satisfaction significantly related to older adults' level of life satisfaction?

2b. Is sport identity significantly related to older adults' level of life satisfaction?

2c. Is sport commitment significantly related to older adults' level of life satisfaction?

Based on these specific questions, three hypotheses were examined as follows:

Hypothesis 2a: Sport satisfaction positively and uniquely relates to older adults' level of life satisfaction.

Hypothesis $2 b$ : Sport identity positively and uniquely relates to older adults' level of life satisfaction.

Hypothesis 2c: Sport commitment positively and uniquely relates to older adults' level of life satisfaction.

Therefore, simultaneous regression (as a multiple regression method) analysis was conducted to determine the extent of the influence of sport satisfaction, sport identity, and sport commitment on the level of life satisfaction among older adults who regularly participate in organized sport activity. Sport satisfaction, sport identity, and sport commitment were independent variables and life satisfaction was the dependent variable.

\section{Significance of the Study}

From a theoretical perspective, this dissertation expanded application of the SCM to the older adult population. Using activity theory, identity theory, the concept of overall 
satisfaction, and the concept of commitment, the findings advanced knowledge on sport participation among older adults by addressing the theoretical relationships between sport participation and life satisfaction.

From a practical perspective, sport organizations and practitioners working closely with older adults will benefit from the findings of this dissertation and gain a better understanding of (a) the importance of psychological aspects which influence older adults to continue to participate in organized sport activity, (b) the importance of the role of sport identity, sport satisfaction and level of sport commitment toward organized sport participation, and (c) the significant positive relationship between levels of sport satisfaction and sport commitment on the level of one's life satisfaction. Therefore, the findings provide a helpful resource for older adult sport programmers, especially in terms of enhancing identity and commitment in order to increase sport participation among retiree communities.

\section{Delimitations}

The following delimitations help establish the boundaries of this study.

First, the target population for this study was confined to older adults in the United States who participated in a sport activity one or more times per week. Casper and Stellino (2008) suggested that 55 and older fall under senior adult cycle based marketing research report and United States (U.S. Census) classifications of lifecycles. Moreover, it is important to note that the last members of the Baby Boomer generation turned 55 in 2019. Therefore, inclusion criteria of participants consisted of individuals who (a) were 55 years of age or older, (b) participated in sport activity (e.g., tennis, bowling, softball, water fitness, and others), and (c) were involved in sport activity as part of an organized 
group, membership, or league at sport facilities, clubs, or parks (e.g., local golf league, running group, or YMCA fitness group). Individuals who only participated in sport activity individually or in physical activity at home were excluded from this study. The U.S. Bureau of Labor Statistics indicated that individuals aged 55 and over were less likely to engage in team or group sport and exercise activities compared to other age groups (those aged 15 to 24 years and aged 25 to 54) (Woods, 2017). Therefore, this study focused primarily on investigating older adults' participation in organized sport because compared to youth sport participation, significantly less research has focused on older adults' participation in organized sport (Baker et al., 2010).

Secondly, the SCM was originally developed to examine a sample of youth sport athletes. Later, the SCM model was modified and expanded based on sport context and study samples as well as statistical analyses. This study adapted the Modified SCM models, including antecedents and questionnaires that examined recreational sports and fitness exercise contexts with adults or older adult samples.

Lastly, it is important to note that the non-probability sampling method does not allow generalizability across the target population as whole but does allow for generalization to theories or conceptual models. This means that this study sample does not represent the entire older adult population who participates in organized sport activity, but it can determine the applicability of SCM to an older adults' sample. Moreover, it can explore the relationships between psychological constructs (sport identity, sport satisfaction and sport commitment) of sport participation and life satisfaction. 


\section{Limitations}

Every research has limitations. Limitations of this study were acknowledged as follows. First, it is important to be aware of the nature of a cross-sectional study which generally provides no evidence of a temporal relationship between the independent variables (the cause) and the dependent variable (the effect).

Secondly, many theoretical constructs have been utilized (e.g., athletic identity, sport identity, exercise identity and leisure identity) to measure active sport participants' identity toward a specific sport and physical activity. Thus, caution should be taken with the findings of this study because the results may be different or vary depending on which theoretical constructs and measures were selected.

Lastly, this study utilized a convenience sampling method to collect the data from specific target subjects - adults over 55 years of age who participated in organized sport activities). This sampling technique was employed because the target subjects were readily available, but the sample of this study may not be representative of the entire older adult population who participates in organized sport activity. Furthermore, the researcher collected the data from limited geographical locations because of proximity. Thus, it may be uncertain whether the findings of this study are generalizable to other older adults who participate in organized sport activity elsewhere in the United States. Therefore, future studies should consider these limitations.

\section{Definitions}

Exercise - "a subset of physical activity that is planned, structured, and repetitive and has as a final or an intermediate objective the improvement or maintenance of physical fitness" (Caspersen et al., 1985, p.126). 
Involvement alternatives - The attractiveness of the most preferred alternative(s) to continued participation in the current endeavor (Scanlan et al., 1993).

Involvement opportunities - Valued opportunities that are present only through continued involvement (Scanlan et al., 1993). In this study, the valued opportunities were specifically related to health benefits.

Life satisfaction - "a cognitive evaluation of the quality of an individual's life as a whole" (Eklund \& Tenenbaum, 2013, p.609)

Older adults - Adults who are over 55 years of age (Petry, 2002; Walker, Volkan, Sechrist \& Pender, 1988).

Organized sport activity - Based on Stone et al.'s (2018) definition of sport, this study defined organized sport activity as any sport and physical activity that has structure to schedule practice or matches and leagues with supervision and rules (e.g., golf league). If physical activity and exercise are in organizational setting, both can fall under the category of sport activity. Therefore, this study included older adults who practice and exercise together regularly (e.g., running groups) and members of exercise classes (e.g., held at a YMCA).

Personal investments - Resources that are put into the activity which cannot be recovered if participation is discontinued (Scanlan et al., 1993).

Physical activity - It is defined as "any bodily movement produced by skeletal muscles that results in energy expenditure. The energy expenditure can be measured in kilocalories. Physical activity in daily life can be categorized into occupational, sports, conditioning, household, or other activities" (Caspersen, Powell, \& Christenson, 1985, p. 126). 
Sport - "a distinct form of physical activity that combines planned participation within a structure of rules and goals similar to formal exercise but also involve aspects of competition, social networking, and fun commonly associated with leisure activities" (Stone et al., 2018, p.674).

Sport commitment - "A psychological construct representing the desire and resolve to continue sport participation" (Scanlan et al., 1993).

Social constraints - Social expectations or norms which create feelings of obligation to remain in the activity (Scanlan et al., 1993).

Sport enjoyment - A positive affective response to the sport experience that reflects generalized feelings such as pleasure, liking, and fun (Scanlan et al., 1993).

Sport identity - Represents how sport and physical activity are "incorporated into one's sense of self" and "involves internalizing the meanings associated with" the specific sport or exercise (e.g., golf, swimming) (Eklund \& Tenenbaum, 2013, p.366) Sport satisfaction - Based on the definition of leisure satisfaction (Beard \& Ragheb, 1980), sport satisfaction is defined as the positive perceptions or feelings that an individual elicits and gains as a result of engaging in sport activities and choices. It determines to what degree an individual is currently satisfied with their experiences and sport activities (Beard \& Ragheb, 1980).

Social support - "perceptions of support and encouragement from significant others for sport participation is related to continued involvement" (Carpenter \& Coleman, 1998, p. 198) 


\section{CHAPTER II}

\section{LITERATURE REVIEW}

The primary purpose of this dissertation was to gain a better understanding of participation in organized sport activities among adults over 55 years of age, referred to as "older adults." Specifically, this purpose was twofold: (1) use the Sport Commitment Model (SCM) to identify antecedent factors that influence levels of commitment toward organized sport activity among older adults; and (2) investigate the relationships among sport satisfaction, sport identity, and sport commitment in the well-being of older adults who participate in organized sport activity.

The literature review mainly focused on the older adult population and their attitudes toward sport and physical activity (including exercise). Specifically, this chapter discussed the relevant research and existing literature associated with the benefits and importance of sport participation among older adults, the SCM, and relevant concepts of sport satisfaction and sport identity.

\section{Older Adult Organized Sport Participation}

The adult population can be categorized into three age groups: young adults aged 18-34, middle adults aged 35-54, and older adults aged 55 and older, based on the previous studies (Casper \& Stellino, 2008; Walker, Volkan, Sechrist \& Pender, 1988). Specifically, Casper and Stellino (2008) suggested that 55 and older fall under the senior adult cycle based on the marketing research report and United States (U.S. Census) classifications of lifecycles. The last members of the Baby Boomer generation turned 55 
in 2019. Thus, this study defined older adults as those aged 55 and older, based on previous health promotion studies and competitive sport participation reports (Dionigi, 2002; Lyons \& Dionigi, 2007; Walker et al., 1988; Woods, 2017).

Sport and physical activity participation has been recognized as an important contributor to improving psychological well-being (e.g. life satisfaction) among older adults (Lim \& Taylor, 2005; Ryu et al., 2018). Despite this fact, older adults are less likely involved in sport and physical activity. Older adults have inadequate sport and physical activity to achieve a psychological benefit and other health benefits (Lim \& Taylor, 2005). It is important to note that, in general, the proportion of the population which participates in sport, exercise, and physical activity declines as people age (Jenkin et al., 2018; Lim \& Taylor, 2005; U.S. Department of Health \& Human Services, 2017). Instead of organized sports, people were more interested in hobbies and home-based physical activities after 50 years of age (Lim, Warner, Dixon, Berg, Kim, \&NewhouseBailey, 2011). Interestingly, the Physical Activity Council (2020) determined that inactive, or no physical activity, older adults (aged 55 to 64 and 65+) were interested trying activities such as bicycling, swimming for fitness, working out with machines and weights and outdoor leisure activities (e.g., fishing, shooting, and birdwatching/wildlife viewing) that can be performed individually (Physical Activity Council, 2020).

Motives for older adults' sport and physical activity have been well documented in the literature (Allender, Cowburn, \& Foster 2006; Lim \& Taylor, 2005; Lim et al., 2011; Molanorouzi et al., 2015). Motives were as follows: (a) demographic and health related characteristics (e.g., and sex, age, smoking status, education level, income, weight, and self-efficacy); (b) organizational or program related variables (e.g, resources, 
financial and psychological costs, accessibility, and sport and physical types); (c) support from significant others and social networks (family members, friends or peers, and exercise program staff and members); (d) environmental variables (safe footpaths, safe neighborhoods, and the weather); (Allender et al., 2006; Lim \& Taylor, 2005). Using the Physical Activity and Leisure Motivation Scale (PALMS), Molanorouzi, Khoo, and Morris (2015) suggested that mastery, psychological condition, others' expectations, affiliation, and enjoyment were important motives for maintaining adequate level of sport and physical activity. Likewise, Lim, Warner, Dixon, Berg, Kim, and Newhouse-Bailey (2011) determined that challenge, the desire to stay active, opportunities to socialize, and physical health were important motives for older adults. Importantly, the authors suggested that "the more and varied sport and sport programs available, the more likely it is for an interested participants (all ages) to find one that meets their need and motivations in sport" (Lim et al., 2011, p.199). Therefore, sport programs and social opportunities were key factors to increasing the adult (including older adult) sport and physical activity (Lim et al., 2011).

Thus, organized or team sport activities may have greater social interaction aspects (social well-being), compare to individual exercise and physical activities (e.g., running/jogging) among older adults. Sport management scholars have noted the importance of organized sport events and programing (e.g., distance running events, family swim nights) in increasing the rate of participation in physical activity by establishing links between organized sport participation and public health benefits (e.g., life satisfaction) (Sato, Jordan, \& Funk, 2016). However, the U.S. Bureau of Labor Statistics indicated that individuals aged 55 and over were less likely to engage in team or 
group sport and exercise activities compared to other age groups (those aged 15 to 24 years and aged 25 to 54) (Woods, 2017). Compared to youth sport participation, significantly less research has focused on these older adults' participation in organized sport (Baker et al., 2010). To promote and encourage older adults' organized sport participation, sport practitioners need a better understanding of older adults' attitudes toward reasons for participation in sport, exercise, and physical activity.

\section{Activity Theory}

In terms of theoretical perspectives on aging, both disengagement theory and activity theory have been widely utilized to show how individuals might respond to growing older (Hillier \& Barrow, 2007). As an early social science theory on aging, disengagement theory is based on a structural functional perspective that it is natural and acceptable for individuals to withdraw from society as they get older due to preparation for death. This idea suggests the process of disengagement (e.g., retirement) among older adults is important in order to allow the social system to remain stable and ordered (e.g., involving young generations). Therefore, it can be predicted that older adults are more likely to naturally withdraw from activities, roles, and social engagement (Hillier \& Barrow, 2007). An opposite view of disengagement theory due to aging was suggested by Havighurst and Albrecht (1953). Havighurst and Albrecht (1953) claimed if individuals stay active and maintain social interactions as they get older, they will be happier and more satisfied with elderly life. Therefore, the activity theory of aging implies that individuals who can maintain their degree of social activity as they age will be more likely to live healthier mental, physical, and social lives as well as achieve positive selfimage, social integration, and life satisfaction (Hillier \& Barrow, 2007). Therefore, 
theoretically, the importance of involvement in sport and physical activity on well-being among older adults can be understood by activity theory (Havighurst, 1961).

Life satisfaction represents "a cognitive evaluation of the quality of an individual's life as a whole" (Eklund \& Tenenbaum, 2013, p.609). As a psychosocial benefit, life satisfaction is one of the elements that determine successful aging (Ryu et al., 2018; Siegenthaler \& O’Dell, 2003). Scholars have recognized that regular participation in sport and leisure activities play an important role in increasing physical and psychological health. This includes life satisfaction (Molanorouzi, Khoo, \& Morris, 2015). Studies have empirically demonstrated a significant relationship between participation in sport and physical activities and life satisfaction among older adults (Jenkin et al., 2017; Jenkin et al., 2018; McPhee et al., 2016).

\section{Benefits of Sport and Physical Activity Participation}

In the context of leisure and recreational activity, scholars suggested that researchers should focus more on "the benefits people expect to realize (anticipated benefits), hope to realize (desired benefits), and do in fact achieve (realized benefits)" in order to have a more sophisticated and inclusive understanding of leisure behaviors (Crompton, Jackson, \& Witt, 2005, p. 248). Driver and Bruns (1999) developed a conceptual framework of benefits and leisure behavior based on a simple leisure and recreational activity participation model (Crompton et al., 2005). The simple model presented in Figure 4 explains that age, interest and preferences, and motivation are factors that can be singly or in combination associated with individuals' leisure and recreational activity participation. 


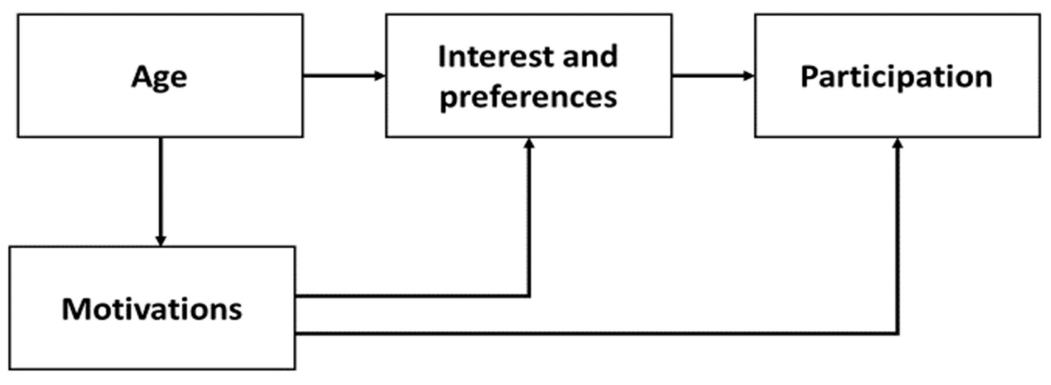

Figure 4. A Simple Model of Factors Affecting Participation

In the benefit and leisure behavior model, it is important to note that an individual's realized benefits are not the only outcome variable of the participation process. The realized benefits can impact further interest and preferences and future participation as shown in Figure 5.

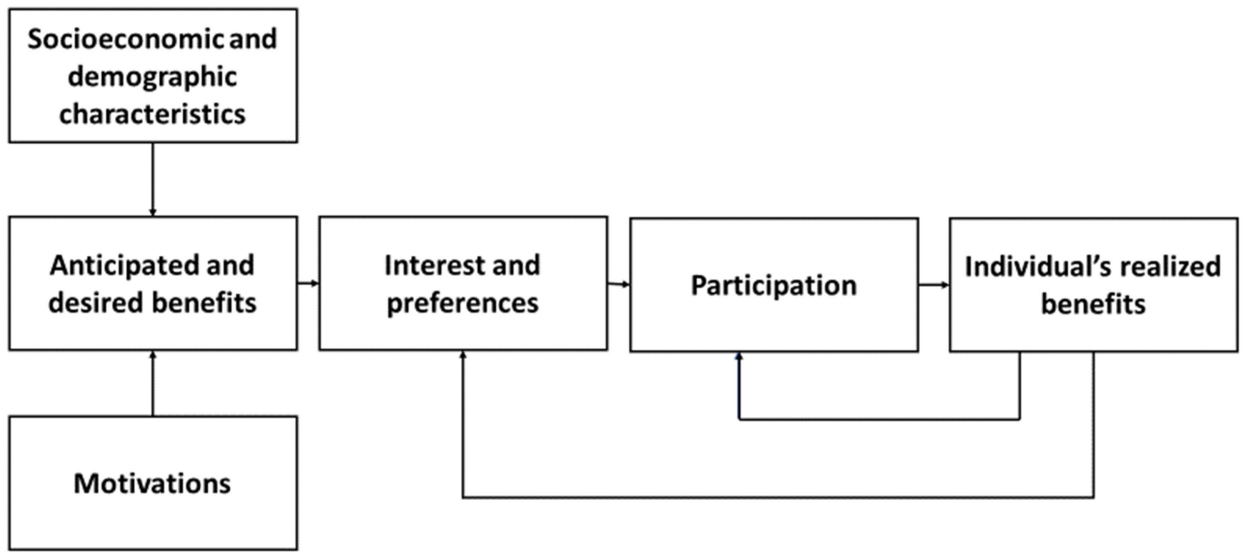

Figure 5. Incorporation of Benefits into the Preferences-Participation Model 
This sequence may lead to individuals realizing greater benefits which leads to strong interests and preferences and increased participation in sport and physical activity. Therefore, it becomes increasingly important to understand how interests and preferences and sport and physical activity behavior develop and subsequently enhance physical, social, and psychological health benefits (e.g., life satisfaction) in the older adults.

Funk, Alexandris, and McDonald (2016) incorporated the sport consumer decision-making sequence to understand sport participation behaviors from a sport marketing perspective. The three phases of the sport consumer decision-making sequence are input (external forces - marketing activities and sociocultural factors), internal processing - psychological forces (motivation, attitudes, personality, and perception of constraints), and outputs such as attitude formation and change and behavior and intention (Funk et al., 2016). This three-step sequence demonstrated the impact of psychological aspects on sport participation behaviors.

\section{The Concept of Commitment}

It is important to understand how older adults engage or disengage in sport and physical activity. Understanding commitment as a psychological aspect can help explain how older adult can stay active. Snyder (1981) argued that activity theory is limited in explaining why older adults are active or inactive, continue or discontinue participating, and maintaining certain roles. To have a further understanding of aging and sport involvement, Snyder suggested that the concept of commitment might be incorporated with activity theory to explore the sport participation behavior in middle and old age. Specifically, predictors (elements) of commitment (such as enjoyment, satisfaction, and identity) could explain continued engagement or disengagement from sport and physical 
activities in adulthood. Snyder (1981) stated that "the configuration and depth of commitment will be more critical in determining quality of life and well-being in old age" (p.115). Participation in sport and physical activity could therefore play a significant role in the later life, and it would be important to know how individuals' achieved satisfaction with life from commitment and components of commitment (e.g., identity, and satisfaction). However, there is much more empirical evidence to support his claim and the relationships among these constructs.

\section{Sport Commitment Model}

\section{Development of the Sport Commitment Model}

To explain the consistent psychological motivation and involvement of organized youth sport participants, Scanlan, Carpenter, Schmidt, Simons, and Keeler (1993) developed a theoretical model of sport commitment. These researchers defined sport commitment as "a psychological construct representing the desire and resolve to continue sport participation" (p. 6). Based on previous studies on social and peroneal commitment (e.g., social exchange theory and personal investment theory), Scanlan and her colleagues proposed specific sport commitment to explore persistence in sport participation (Crocker \& Augaitis, 2010; Jeon \& Ridinger, 2009). They also suggested that the level of sport commitment can be determined by five antecedents independently as follows: sport enjoyment, involvement alternatives, personal investments, social constraints, and involvement opportunities (Scanlan, Carpenter, Schmidt, Simons, \& Keeler, 1993). Sport enjoyment, personal investments, social constraints, and involvement opportunities were posited to positively associate with sport commitment, and involvement alternatives was 
posited to negatively associate with sport commitment (Scanlan et al 1993). They

defined each construct as follows in Table 1:

Table 1

Definition

\begin{tabular}{l|l}
\hline Constructs & Definition \\
\hline Sport enjoyment & $\begin{array}{l}\text { A positive affective response to the sport experience that reflects } \\
\text { generalized feelings such as pleasure, liking, and fun }\end{array}$ \\
\hline Involvement alternatives & $\begin{array}{l}\text { The attractiveness of the most preferred alternative(s) to continued } \\
\text { participation in the current endeavor }\end{array}$ \\
\hline Personal investments & $\begin{array}{l}\text { Resources that are put into the activity which cannot be recovered if } \\
\text { participation is discontinued }\end{array}$ \\
\hline Social constraints & $\begin{array}{l}\text { Social expectations or norms which create feelings of obligation to } \\
\text { remain in the activity }\end{array}$ \\
\hline Involvement opportunities & $\begin{array}{l}\text { Valued opportunities that are present only through continued } \\
\text { involvement }\end{array}$ \\
\hline
\end{tabular}

Three studies were conducted to develop the measurement of the Sport Commitment Model (SCM) and its validity in organized youth sport programs (Scanlan et al., 1993). In their first study, zero-order correlations and stepwise regression were conducted to determine a significant relationship between five antecedents and level of sport commitment among little league athletes (Scanlan et al., 1993). The results supported the hypothesized relationship between levels of sport commitment and five antecedents, with sport enjoyment and personal investments as the leading predictors among others for the youth athletes. The findings of this study determined that the more these youth athletes enjoyed their program during the season and the more they enjoyed investing time and effort in the program, the higher their sport commitment (Scanlan et al., 1993). 
In the second study, Scanlan, Simons, Carpenter, Schmidt, and Keeler (1993) develop the measurement of the SCM to assess the constructs of the SCM across samples of diverse youth sport athletes (swimmers and badminton players, $N=140$; Little League baseball and softball players, $N=178$; and football, soccer, and volleyball players, $N=$ $1,342)$ in terms of age, gender, and ethnicity. In addition, the researchers established modified items and scales of each construct to make the survey shorter. With a large sample $(N=1,342)$ of youth athletes, the structural-equation modelling confirmed that the SCM established the reliability and discriminant validity of measures for the antecedents (sport enjoyment, involvement alternatives, personal investments, social constraints, and involvement opportunities) and sport commitment (Scanlan, Simons, Carpenter, Schmidt, \& Keeler, 1993). However, the involvement alternatives construct was difficult to measure in samples of youth athletes because this construct may not reflect the sample of youth sport participants (Scanlan, Simons et al., 1993). Youth athletes may have enough time to do other activities without sacrificing their current involvement in the elite-sport programs (Scanlan, Simons et al., 1993). Nonetheless, the findings of the study supported the generalizability of the SCM in a wide variety of youth sport participants (Scanlan, Simons et al., 1993).

In the third study, Scanlan and her colleagues (Carpenter, Scanlan, Simons, \& Lobel, 1993) retested the SCM among youth athletes in terms of age, gender, and team sports using the structural equation modeling analysis. In this study, they reported that the involvement alternatives construct was excluded for the structural equation modeling because of measurement issues (Carpenter et al., 1993). The results of the study supported the notion that sport commitment is determined by sport enjoyment, 
involvement alternatives, personal investments, social constraints, and involvement opportunities. The findings of the study supported the concept that greater sport enjoyment, involvement opportunities, and personal investment led to greater sport commitment for youth sport athletes. However, unlike the initial hypothesis, the results of the association between social constraints and sport commitment were varied, from no relationship, very little, and negative (Carpenter et al., 1993). Caution should be taken in interpreting the results. The social constraints construct, where social expectations or norms create feelings of obligation to remain in the activity, was adopted based on the adult close relationship theory (e.g., romance and friendship) (Carpenter et al., 1993). Since continuing youth sport participants take part based on voluntary free-choice and enjoyment, they do not experience feelings of obligation to remain in the sport activity or program (Carpenter et al., 1993). In future studies, the conflicting results in the three studies should be acknowledged (Carpenter et al., 1993).

Sousa, Torregrosa, Viladrich, Villamarín, and Cruz, (2007) later used the SCM to better understand underlying reason why young Spanish soccer players $(N=437$; age ranged from 14 to 16 years) continued to play soccer. This study indicated social constraints did not predict sport commitment, and both personal investments and involvement opportunities failed to meet the criterion of the alpha coefficient score exceeding a level of .70 (Nunnally \& Bernstein, 1994; Sousa, Torregrosa, Viladrich, Villamarín, \& Cruz, 2007). Nevertheless, the researchers concluded that the sport constraints variable was moderately correlated with sport commitment $(r=.139)$, and sport enjoyment was the strongest sport commitment predictor, followed by involvement alternatives. Therefore, Sousa et al. (2007) suggested that the social constraints construct 
should have more investigation to support the relationship between sport commitment and social constraints.

In sum, Scanlan and her colleagues introduced a theoretical model of sport commitment using different samples of youth sports athletes. Despite the issues which appeared in the development of the SCM and the applicability of other samples, the five determinants in the SCM independently predicted sport commitment and "provided a fresh and potentially fruitful approach" to sophisticated understanding of reason and motivation to continue to involvement in organized sport activities (Scanlan, Russell, Scanlan, Klunchoo, Chow, 2013, p. 526). Overall, the SCM still needs more empirical support as a theoretical framework that could provide robust findings about the magnitude of the influences of sport commitment determinants (Sousa et al., 2007).

\section{Sport Commitment Model with Social Support}

The SCM has been modified and expanded based on sport contexts and samples as well as statistical analyses. Specifically, Carpenter and Coleman (1998) included social support as a new construct of the SCM along with negative sport affect and perceived ability. The social support construct reflected that "perceptions of support and encouragement from significant others for sport participation is related to continued involvement" (Carpenter \& Coleman, 1998, p. 198). Its assumption was that "the more support and encouragement perceived from significant others for involvement, the greater individuals' commitment" (Carpenter \& Coleman, 1998, p 198). Therefore, greater social support from significant others (e.g., family, friends, peers, or coaches) increases individuals' level of sport commitment. Using additional constructs, Carpenter and Coleman (1998) examined the sport commitment of English elite youth cricket athletes 
(ages 9-17 years) based on longitudinal assessment. A simultaneous multiple regression analysis was utilized to assess whether changes in the predictor variables were related to changes in commitment over time. The results indicated that significant predictors of commitment were sport enjoyment, recognition opportunities, and social opportunities (Carpenter \& Coleman, 1998). The results of the study indicated that an increase in sport enjoyment, recognition opportunities, social opportunities, and social support and a decrease in negative effect led to an increased level of sport commitment. Alternatively, a decrease in social support led to a decreased level of sport commitment (Carpenter \& Coleman, 1998). The findings of the study also provided evidence of the validity and reliability of the SCM for non-American elite youth athletes.

Using the social support construct in the SCM, Weiss and Weiss (2007) investigated the relationship between determinants and level of commitment in terms of female gymnasts' age and competitive level differences. Weiss and Weiss (2007) suggested that "the six determinants of sport commitment represent psychosocial factors that may likely be tied to developmental differences [age-related and competitive level] in predicting level of sport commitment" (p. 91). Weiss and Weiss (2007) added two more constructs, perceived competence and perceived costs, to the six determinants of SCM and posited that the perceived competence would be positively related to sport commitment while the perceived cost would be negatively related to sport commitment. Moreover, social constraints (including parent, coach, teammate, and best friend) were assessed, and social support also was assessed with five types of social support (companionship, instrumental aid, intimacy affection, admiration and reliable alliance) in terms of parents, coach, teammates, and best friends (Weiss \& Weiss, 2007). A total of 
304 female gymnasts, which comprised three age groups (8-11, 11-14.5, and 14.5-18 years old) and two competitive levels (Levels 5-6 and 8-10), from 16 private gymnastic clubs, participated in the study. Multiple regression analyses without the enjoyment construct indicated that perceived costs and social constraints from parents and best friends were the strongest predictors of commitment for the youngest gymnasts (ages 811). For 11-14.5-year-old gymnasts, perceived costs, personal investments and parent social constraints were significant predictors of sport commitment. For the oldest gymnasts (ages 14.5-18), perceived competence and costs were significant predictors of commitment. When competitive level differences emerged, the sport enjoyment construct was removed from the model due to the multicollinearity. For level 5-6 gymnasts, the authors determined that greater personal investments, perceived costs, coach social support, and social constraints by coach, best friend, and teammates were related to higher sport commitment. For level 8-9 gymnasts, the authors indicated that greater personal investment and teammate social constraints and lower perceived costs were related to higher commitment (Weiss \& Weiss, 2007). Weiss and Weiss (2007) suggested that developmental difference factors (age and competitive level) and additional determinants (perceived costs and competencies) are important to consider in future studies of the SCM.

SCM have been applied to various sports settings (including elite to non-elite) in youth sport context to explore the underlying psychological characteristics and behaviors of participants, as well as to determine the reasons to continue their participation within the sports. Later, the extension model of SCM provides an exhaustive conceptual framework for studying sport commitment of sport participants in a variety of sport 
contexts (e.g., college athletes, coaches, adult dancers; Chu \&Wang, 2012; Reams, 2016). A substantial number of empirical studies also indicated that social support was a positive predictor of sport commitment (e.g., female youth gymnasts, adult and junior tennis players and adult dancer; Casper, 2007; Casper et al., 2007; Weiss, Kimmel, \& Smith, 2001; Weiss \& Weiss, 2007; Wang \& Cho; 2016). Eastern scholars adapted the modified SCM to test Asian adult sport participation (Chu \& Wang, 2012; Wang \& Cho; 2016).

Wang and Cho (2016) demonstrated how the antecedents were associated with sport commitment for Taiwanese older adult ballroom dancers. The results revealed that sport enjoyment, personal investment, and involvement opportunities were significantly associated with sport commitment among the older adult ballroom dancers. Without, age comparison, this study was the only one that fully applied SCM to older adults' sport and physical activity behavior. There is still a lack of empirical contribution on adult or older adults sport participation, especially for the U.S. population.

\section{Sport Commitment Model and Exercise Behavior}

Using the SCM model without involvement alternative constructs (Carpenter et al., 1993), Alexandris, Zahariadis, Tsorbatzoudis, and Grouios (2002) examined the generalizability of the SCM in the context of Greek exercise and fitness participants $(N=$ 210), especially adult sport participation, using structural equation modeling. The structural model indicated the SCM was a good fit for the data $(\mathrm{CFI}=.957)$, and a simultaneous regression analysis revealed that the four constructs were significantly related to commitment and explained $44 \%$ of the variance of commitment (Alexandris et al., 2002). The results indicated that the involvement opportunities construct was the most powerful predictor among other constructs while the constraints were the least 
powerful predictors (Alexandris et al., 2002). The findings of the study provided evidence of the empirical validity and reliability of the SCM for Greek exercise and fitness participants, especially regarding adult sport participation. More research is needed on adult sport participants for applicability of the SCM.

Interestingly, Wilson, Rodgers, Carpenter, Hall, Hardy, and Fraser (2004)

replaced Scanlan's (1993) sport enjoyment construct with the satisfaction construct to develop the Exercise Commitment Model (ECM). In the ECM, satisfaction "represented the degree to which current exercise participation was perceived as rewarding" (Wilson, Rodgers, Carpenter, Hall, Hardy, \& Fraser, 2004, p. 409) and was one of the strongest predictors of exercise commitment. Their study suggested that employed sport satisfaction as a distinct construct which separated it from other original constructs of the SCM.

\section{Sport Commitment Model and Demographics}

Demographic predictors also have been examined in the SCM model. Casper and Stellino (2008) investigated demographic (age, income, sex, and skill level) differences of sport commitment and determinants of sport commitment for tennis participants based on the SCM. A total of 537 adult male $(n=247)$ and female $(n=290)$ recreational tennis players, ages ranged from 19 to 84 years old, participated in the study. For demographic segments, age was categorized into four groups (19-34, 35-44, 45-54, and 55 and above). Income was categorized into three levels ( $\$ 60,000$ or less, $\$ 60,001$ to $\$ 100,000$, and $\$ 100,001$ and above). Skill level was divided into four levels (3.0 or less, 3.5, 4.0, and 4.5 and above) based on the United States Tennis Association National Tennis Rating Program (NTRP). A multivariate analysis was conducted along with post-hoc tests to 
identify demographic differences based on the individual variables in the SCM. The results revealed that significant differences were indicated for participants' age (commitment, involvement alternatives, and social constraints) and sex (sport enjoyment, personal investments, and social support). For the age difference, the two youngest groups (ages 34 and under and 35-44) reported lower levels in commitment and higher levels in involvement alternatives and social constraints compared to the two oldest groups. For the gender difference, females reported higher sport enjoyment and personal investments while males reported higher social support for tennis participation. A regression analysis determined that the tennis enjoyment construct was a strong predictor of commitment across all demographic segments followed by involvement opportunities. The finding of the studies contributed to the leisure and recreational sport research by providing evidence that "personal, social, and monetary based variables directly contribute to commitment and suggest committed sport participants differ based on segmentation” (Casper \& Stellino, 2008, p. 94).

Jeon and Casper (2016) indicated the sport of Taekwondo, a popular sport for both adults and youth, has faced decreasing adult participation and poor retention of youth. Thus, to have a better understanding of Taekwondo participation and antecedents of sport commitment, the researchers examined similarities and differences of Taekwondo participants' sport commitment between two different age groups, adult and youth, utilizing the SCM. The multiple-group path analysis was utilized to identify similarities and differences among two age groups - youths age 18 or younger and adults ages 19 and older. For the similarities between adult and youth participants, the results indicated sport enjoyment, involvement opportunities, and personal investments as 
significant predictors of commitment. For differences, the results indicated that involvement alternatives predicted commitment only for adult participants while social support predicted commitment only for youth participants (Jeon \& Casper, 2016).

To combine previous antecedents and demographic predictors of sport commitment, previous research added consumer behavior (participation frequency and purchase intention) as a predictor variable of the sport commitment. Casper (2007) examined how demographic segments (age, gender, income and skill level) differ in terms of sport commitment, participation frequency, and purchase intention among the adult tennis population. For demographic segments, age was categorized into three groups (19-39, 40-54, and 55-64). Household income was categorized into three levels ( $\$ 60,000$ or less, $\$ 60,001$ to $\$ 100,000$, and $\$ 100,001$ and above; Casper, 2007). Skill level was divided into four levels (3.0, 3.5, 4.0, and 4.5) based on the United States Tennis Association National Tennis Rating Program (NTRP; Casper, 2007). Significant differences were observed in sport commitment based on tennis participants' age. Moreover, the younger participants (19-39) reported significantly lower commitment levels compared to other participants (Casper, 2007). Significant differences were found in participants' skill level and higher skill level participants played more often throughout the year (Casper, 2007). For purchase intention, significant differences were found based on income and skill level. People with higher income and higher skill level had higher purchase intentions than those with lower income and skill level (Casper, 2007).

In relation to Casper (2007), Jeon and Ridinger (2009) examined the relationship between predictor constructs and windsurfing commitment and also the relationship between windsurfing commitment and two predicated variables, participation frequency 
and purchase behaviors. In addition, Jeon and Ridinger (2009) examined the different relationships between demographic variables (e.g., gender, age, income, and skill level) with windsurfing commitment, participation frequency, and purchase behavior in windsurfers. Among the six constructs (sport enjoyment, involvement alternatives, personal investments, social constraints, social support, and involvement opportunities) of sport commitment, involvement opportunities were excluded due to the reliability of the model (Jeon \& Ridinger, 2009). The authors noted there were 29 female respondents (21\%) from a total of 139 respondents and that half of the respondents $(59 \%)$ represented income levels between $\$ 40,000$ and $\$ 80,000$. The factor analysis with principle extraction and Varimax rotation revealed a two-factor structure of motivation - intrinsic (sport enjoyment, involvement opportunities and personal investments) and extrinsic (social constraints and social support). To demonstrate evidence of reliability, the coefficient alpha was estimated for all factor scales, intrinsic motivation $(\alpha=.86)$, extrinsic motivation $(\alpha=.71)$, and windsurfing commitment ( $\alpha=.81$; Jeon $\&$ Ridinger, 2009). The regression analysis indicated that intrinsic motivation (which accounted for $68 \%$ of the variance of windsurfing commitment) was a stronger predictor of windsurfing commitment than extrinsic motivation (which accounted only $4.3 \%$ of variance). Moreover, the results of the study indicated participation frequency and purchase behavior were associated with sport commitment. Windsurfing commitment accounted for $15 \%$ of the variance of participation frequency and accounted for only $6.4 \%$ of the variance in purchase behavior (Jeon \& Ridinger, 2009). In terms of demographic differences, the results indicated that advanced or expert skill level and higher income participants were more committed to the sport and spent more money related to the sport 
than beginner or intermediate skill level and low-income participant groups. The results of the study also supported Casper's (2007) finding that level of skill was a strong predictor of sport commitment.

\section{Sport Commitment Model and Behavior Outcomes}

Previous research indicated that an increased level of commitment positively influenced sport consumption. Casper, Gray, and Stellino, (2007) examined the theoretical antecedents that influenced adult tennis players to continue to participate in the sport and also investigated the relationship between sport commitment and sport consumption behaviors (participation frequency and purchase intention) among adult tennis population (Casper et al., 2007). In addition, the authors examined a direct/indirect model where the sport enjoyment construct was the mediator of the relationship between determinants and level of commitment (Casper et al., 2007). Structural equation modelling indicated that by using previous original SCM, sport enjoyment and personal investments were the strongest predictors of commitment, with involvement opportunities being the significant predicator (Casper et al., 2007). Moreover, tennis commitment was associated with participation frequency and purchase intention in which the model explained $98 \%$ of the variance in commitment, $16 \%$ of participation frequency, and $18 \%$

of purchase intention (Casper et al., 2007). Structural equation modelling determined that the direct/indirect model indicated acceptable model fit, but the original model fit better for the data of the adult tennis participants (Casper et al., 2007). The results of the study indicated that sport enjoyment was hypothesized to increase commitment and sport commitment was hypothesized to increase participation frequency and purchase intention (Casper et al., 2007). 
Likewise, Fernandes, Correia, Abreu, and Biscaia (2013) examined the relationship between sport commitment and three types of sport consumer behaviors: participation frequency, sporting goods and media consumption among sport participants (both individual and team sports, $n=300$; fitness activities, $n=300$; outdoor activities, $n$ $=300$ ). Using structural equation modeling, the authors found $18 \%$ of the variance of sporting good consumption, $14 \%$ of the variance of participation frequency, and $7 \%$ of the variance of media consumption were explained by sport commitment (Fernandes et al., 2013). The results of the study indicated that increasing the commitment level of adult sport participants should help increase their participation frequency, consumption of sporting goods, and media consumption (Fernandes et al., 2013). Therefore, the findings suggest that greater sport commitment may lead to greater consumption behaviors (e.g., participation frequency, sporting goods, and media consumption). Moreover, the findings could help marketers and practitioners understand their consumers based on the levels of commitment, create retention marketing strategies, and establish effective relationships with sport participants (Fernandes et al., 2013).

Through previous research, the SCM provided empirical evidence in a variety of sport contexts such as adult fitness participation (Alexandris et al., 2002), adult and youth tennis players (Casper et al., 2007; Casper \& Stellino, 2008; Weis et al., 2001), windsurfer participations (Jeon \& Ridinger, 2009), and multiple youth sport participants (Scanlan, Carpenter, Schmidt, Simons et al., 1993; Scanlan, Simons, Carpenter, Schmidt et al., 1993; Weiss \& Weiss, 2007). Therefore, the SCM can be utilized in this study to explore the underlying psychological characteristics and behaviors of older adult sport 
participants, as well as to determine the reasons to continue their participation within the sport and physical activities.

\section{Association of Sport Commitment and Life Satisfaction}

In the leisure literature, evidence supports the notion that individuals pursuing sport and physical activity (e.g., Taekwondo) as a serious leisure activity lead to greater life satisfaction. Stebbins (1992) defined serious leisure as "the systematic pursuit of an amateur, hobbyist, or volunteer activity sufficiently substantial and interesting for participants to find a career there in the acquisition and expression of a combination of its special skills, knowledge, and experience" (p. 3). Stebbins used the term of serious leisure to refer to the orientation of individuals who are seriously committed and engaged in a particular recreation activity that is personally meaningful to them (Kim, Dattilo \& Heo, 2011; Heo, Stebbins, Kim, \& Lee, 2013). Previous studies demonstrated that individuals who have a strong commitment to a specific serious leisure activity (e.g., bass fishing, mountain climbing, and ice skating) exceed their personal and social benefits through their engagement (Kim Dattilo \& Heo, 2011). Kim Dattilo and Heo (2011) suggested that serious leisure activity may help to enhance personal satisfaction and promote health. In response to the research of Kim et al. (2011), Heo, Stebbins, Kim, and Lee (2013) explored the relationships among serious leisure, life satisfaction, and health among a sample of 454 older adults from the 2008 Indiana Senior Olympic Games and 2008 Colorado Senior Olympic Games. The results demonstrated significant positive relationships among level of involvement in serious leisure, life satisfaction, and health among older adults. However, no study to date has examined the direct and positive relationship between sport commitment and life satisfaction. 


\section{Sport Satisfaction}

\section{The Concept of Satisfaction}

In sport and exercise psychology, satisfaction was defined as "a positive cognitive affective state resulting from a cognitive judgment process that what is received or experienced meets or exceeds a personal standard" (Eklund \& Tenenbaum, 2013, p. 609). In the sport services and quality literature, satisfaction represents a consumer attitude toward products and services, and it is also recognized as an important determinant of future behavior (e.g., revisit or reuse), impacting other consumers (e.g., word of mouth) (Funk et al. 2016). Essentially, consumer loyalty is reflected by individual's level of satisfaction which means that satisfied consumers are more likely to be loyal (or possess greater psychological commitment) compared to dissatisfied consumers (Bodet, 2012). Using a sample of 252 French health and fitness club members, Bodet (2012) determined that overall consumer sport satisfaction positively influenced consumers' psychological commitment and also subsequently affected consumers' loyalty. The findings were consistent with previous studies which demonstrated a significant association between sport satisfaction and psychological commitment and supported the notion that consumer satisfaction is an antecedent of sport commitment (Alexandris, Zahariadis, Tsorbatzoudis, \& Grouios, 2004; Kelley \& Davis 1994; Kelley, Hoffman, \& Davis, 1993). Therefore, previous research documented that satisfaction is an important predictor of commitment in the sport and exercise context (Eklund \& Tenenbaum, 2013).

\section{Sport Satisfaction and Sport Commitment Model}

Sport satisfaction has been examined interchangeably with various constructs such as enjoyment, pleasure, fun, and intrinsic and extrinsic rewards in the sport and 
exercise literature (Eklund \& Tenenbaum, 2013; Snyder,1981). In the original SCM, which was applied to youth elite programs, sport satisfaction was excluded as an antecedent of sport commitment, but satisfaction was used in previous studies with adult athletes (e.g., tennis), measuring constructs such as sport enjoyment and fun. For instance, Casper et al. (2007) added the item "are you satisfied with tennis as your choice of an activity?" (Factor loading $=.77$ ) to the sport enjoyment construct. Similarly, Spanish scholars adapted the Sport Satisfaction Instrument (SSI) to measure the satisfaction/fun construct to sport commitment for female Spanish athletes ages 12 to 38 years old (Granero-Gallegos, Baena-Extremera, Gómez-López, \& Abraldes, 2014). The modified SSI measured participants' satisfaction and intrinsic interest with sport practices. The findings supported the modified SSI scale in the SCM and the construct of satisfaction/fun was a strong predictor of sport commitment for these Spanish female athletes (Granero-Gallegos et al., 2014). Although sharing the positive affective experiential aspects of these constructs, scholars suggested that satisfaction should be examined as a distinct construct (Eklund \& Tenenbaum, 2013).

Wilson et al., (2004) replaced Scanlan's (1993) sport enjoyment construct with the satisfaction construct to develop the Exercise Commitment Model (ECM). In the ECM, satisfaction "represented the degree to which current exercise participation was perceived as rewarding" (Wilson et al., 2004, p. 409) and was one of the strongest predictors of exercise commitment. Their study employed sport satisfaction as a distinct construct which separated it from other original constructs of the SCM.

For older adults, Snyder (1981) suggested that the level of sport commitment could be influenced by extrinsic rewards or satisfaction such as trophies, social approval, 
recognition, pride, sympathy, and health. Unlike young adults, older adults can develop and maintain higher levels of skills from these external rewards which also link to higher performance and victory (Snyder, 1981). Therefore, the current study will add sport satisfaction as distinct construct to predict older adults' level of commitment to organized sports.

\section{Association of Sport Satisfaction and Life Satisfaction}

Since a major goal of sport, recreation, and leisure services is to contribute to individuals' satisfaction and pursuit of happiness, development of procedures and instruments for objectively measuring leisure satisfaction is needed (Beard \& Ragheb, 1980). Therefore, Beard and Ragheb (1980) developed the Leisure Satisfaction Scales (LSS) to "provide a measure of the extent to which individuals perceive that certain personal needs are met or satisfied through leisure activities" (p. 22). In the leisure

literature, Beard and Ragheb's (1980) leisure satisfaction scale has been widely used and demonstrated a positive linear relationship between leisure satisfaction and life satisfaction in the context of sports recreation and physical activities (Lapa, 2013). Despite the benefits of participating in sport and physical activities among older adults, some studies determined that physical activity "has very little association with life satisfaction" (Eklund \& Tenenbaum, 2013, p. 609). Therefore, this current study examined how the satisfaction with the organized sport activities associated with life satisfaction among older adults. Based on the definition of leisure satisfaction (Beard \& Ragheb, 1980), sport satisfaction therefore is defined as the positive perceptions or feelings that an individual elicits and gains as a result of engaging in sport activities and 
choices. It determines to what degree an individual is currently satisfied with their experiences and sport activities (Beard \& Ragheb, 1980).

\section{Sport Identity}

According to Shamir (1988), personal commitment is demonstrated when an individual defines himself or herself in terms of an activity, role, or relationship to which he or she is committed. Based on the person's self-identity (Stryker, 1980), Shamir (1988) stated that "a person is internally committed to a leisure activity, role, or relationship when he or she sees it as expressing a valued aspect of his or her identity" (p. 244). In general, personal identity is defined as "what makes every person unique, defining them through their specific biographies (e.g., name, birthplace), unique characteristics (e.g., intelligent, athletic), role identities (e.g., daughter, employee), and the particular combination of private and public experiences" (Andriot \& Ownes, 2012, p. 1).

\section{Identity Salience}

The construct of identity has been established as a primary motivator of an individual's choice and behavior (Jun \& Kyle, 2011). Identity theorists argue that a person can have multiple identities based on various positions and roles that he or she holds in society (James, 1890; Jun \& Kyle, 2011). In addition, they suggest that these multiple or different identities are arranged hierarchically, known as identity saliences (Stryker, 1968; Stryker \& Burke, 2000). Based on the Stryker's (1968) identity theory, individual identities are hierarchically organized in self-concept in terms of importance of salience (Jacobson, 2003; Shamir; 1992). Therefore, identity salience can be defined as "the importance of an identity for defining one's self relative to other identities the 
individual holds" (p. 302). Jacobson (2003) argued that an individual's choice in different roles is seen as "a consequence of identity salience, which is a speciation of the general category of self" (p. 3).

\section{Social Identity}

Deaux (1993) argues that social identity is another important psychological component of identity. Identities can be both personal and social and, for instance, individuals' identity can be shaped by individuals' membership in particular groups, such as by gender, race and ethnicity. Specifically, social identity is the part of an individual's self-concept formed through the knowledge of an individual's membership in meaningful social groups and organizations (e.g., sport or city clubs) and categories (e.g., gender or race) that an individual claims as representative (Andriot \& Ownes, 2012; Deaux, 1993). In other words, individuals are able to simplify the world around them by using categorizations to infer their similarities and differences compared to other individuals (Andriot \& Ownes, 2012). To emphasize group processes and intergroup relationships, social identity theory has been widely used, and it posits that the groups to which individuals belong can provide a definition of who they are (Hogg, Terry, \& White, 1995; Tajfel \& Turner, 1979; Turner, 2010). Importantly three key components of identity are (a) coherence - multiplicity of personal and social identities might suggest separate selves, as in multiple personalities, but can be integrated into a coherent self; (b) salience - what is most important and of most significance to an individual; and (c) authenticity finding one's inner self, behaving naturally, establishing a level of comfort with the immediate environment (Deaux, 1992, 1993). 


\section{Leisure Identity Saliences}

Sport and leisure lifestyles have increasingly influenced individuals to establish their sense of identity (Wheaton, 2000). Unlike traditional social identity, in which a range of identifiers were relatively fixed and stable such as work, gender, ethnicity, religion, and age, Kellner (1992) argued that "identity becomes more mobile, multiple, personal, self-reflexive, and subject to exchange and innovation" (p. 141; Wheaton, 2004).

Applying identity theory to leisure choice and behavior, Shamir (1992) suggested that leisure identity can be salient and valued for individuals because, firstly, it expresses and affirms the individual's talents or capabilities. Secondly, it endows the person with social recognition. Finally, it affirms the individual's central values. Shamir (1992) defined leisure identity salience as the importance of leisure identity for self-definition relative to other identities.

To measure leisure identity salience (LIS), Shamir (1992) developed the LIS scale based on Hoelter's (1983) role identity salience scales and Neulinger's (1974) selfdefinition through work or leisure scale. Three studies were conducted to explore the relationship between LIS and five factors - (a) social commitment, (b) effort and skill, (c) state of mind (including intrinsic motivation, enjoyment, perceived choice, control, and freedom of exit), (d) commitment to activity (including years participating in activity, time investment, financial investment, and continuance commitment), and (e) nonfinancial commitment to work (Shamir, 1992). The results of the study indicated that social commitment, effort and skill, intrinsic motivation, enjoyment, freedom of exit, time investment, financial investment, continuance commitment, and non-financial 
commitment to work were significantly correlated to LIS within different leisure activities and diverse populations. However, the results of the relationship between LIS and related factors are likely to be circular; therefore, the direction of causality cannot be drawn or explained. The findings of the study suggest that LIS is an important psychological dimension to understand individuals' choice, behavior, and attitudes toward leisure activity.

Using a qualitative approach, Laverie (1998) investigated personal and social factors that influence individuals who frequently participate in a particular fitness activity, namely aerobics. Based on three dimensions (identity salience, social connections, and comparisons) of social identity theory, Laverie conducted in-depth interviews with 15 participants (14 women and one man) whose frequent involvement in aerobics ranged between five months and 13 years. Previous research indicates that various factors such as enjoyment, good feeling, social interaction, competition, health, fitness, sense of achievement, satisfaction, and a desire to be thin influenced participation in leisure including sport and fitness activities, (Crandall, 1980; Frederick, Morrison, \& Manning, 1996; Maguire \& Mansfield, 1998; Mathes \& Battista, 1985; Summers, Machin, \& Sargent, 1983).

Similar to previous findings and using the grounded theory method, Laverie (1998) determined that positive feelings, social connections, the atmosphere, physical and psychological benefits, and addiction influenced participants' continued participation in aerobics and also formed and maintained their identity with aerobic activity. Based on the differences and similarities in motivations of aerobic participants, the author divided interviewees into four groups - totally immersed, socially influenced, outcome focused, 
and detached performers. The results of the study indicated that the level of identify salience was the primary differentiation across groups. Laverie (1998) found totally immersed and detached performers have a highly salient aerobics identity, while the other two groups have a low or moderate salient aerobics identity, even though the outcome focused group often participated in aerobics. The findings of the study support that identity with particular sports and fitness activities can be an important construct to explain an individual's leisure choice and behavior, specifically frequency of participation. In addition, it also supports that high identity salience will be more likely to increase frequency of participation (Klenin, Kleine, \& Kernan, 1993). Laverie (1998) developed the conceptual model of continued participation in fitness activities based on the findings presented in Figure 6. In order to generalize the findings of the study, a larger number of sport or fitness participants need to be examined using a quantitative approach. 


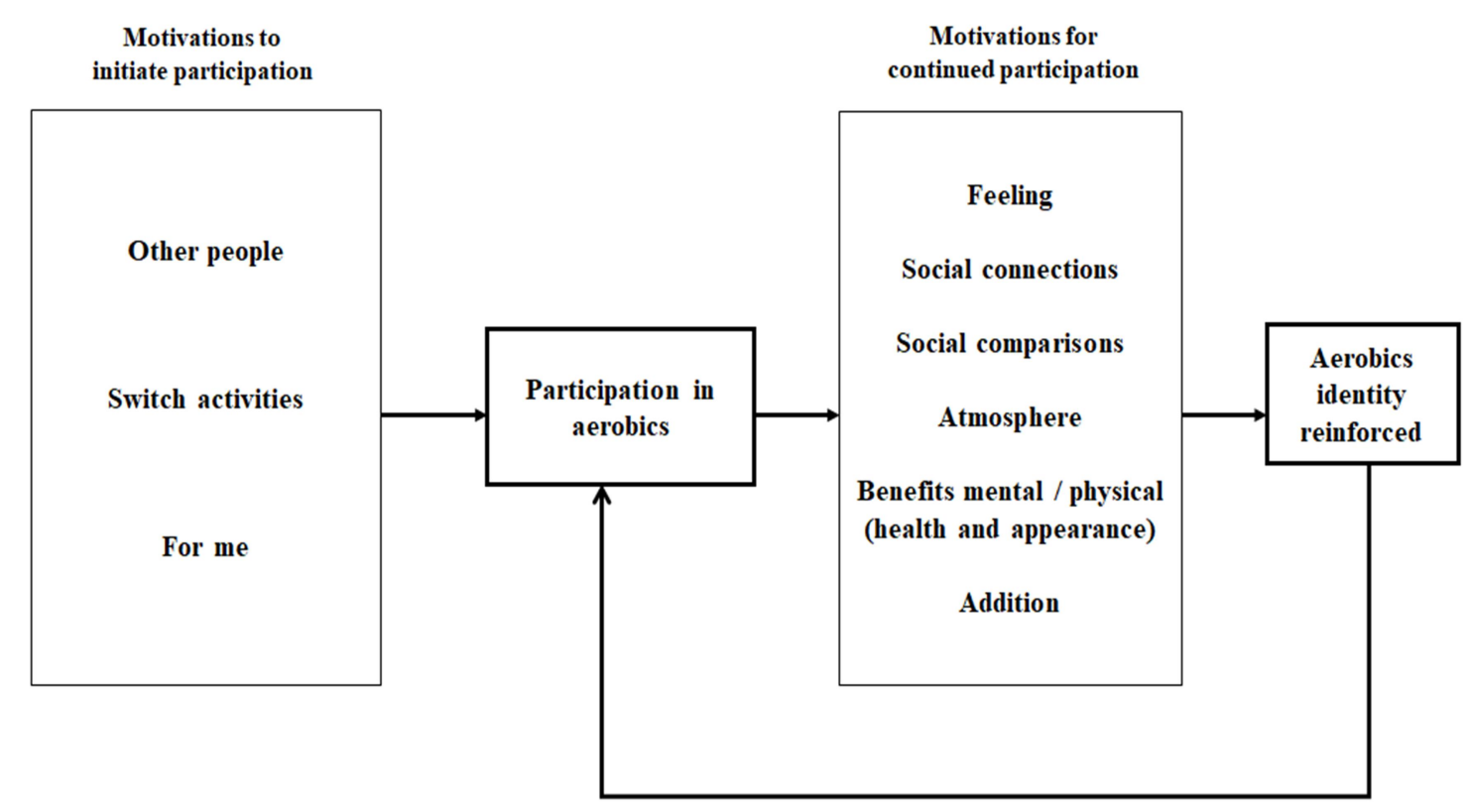

Figure 6. Model of Aerobics Participation

Won and Hwang (2008) investigated how two socio-demographic characteristics (age and income) and level of leisure identity salience in recreational golf activity influenced perceived constraints such as social isolation, accessibility, personal reasons, cost, time, and facilities. Won and Hwang hypothesized that more highly identified participants are more likely to perceive stronger constraints or barriers than lower identified participants because highly identified golfers are willing to play more golf rounds (Kay \& Jackson, 1991; Won \& Hwang, 2008). A multiple analysis of covariance (MANCOVA) revealed that there was a statistically significant difference between highly identified golfers and less identified golfers on their perceived constraints after controlling for the combined effects of golfers' age and income level as covariates. The findings of the study support that highly identified golfers perceived stronger constraints in access, personal reasons, and facilities than less identified golfers. 
Jun and Kyle (2012) utilized identity theory to demonstrate the leisure behavior model that hypothesizes that gender identity (masculine and feminine) and leisure identity are important predictors of leisure participation. Specifically, Jun and Kyle hypothesized that recreational golfers' gender identity and their leisure identity as golfers would influence the intensity of participation in recreational golf (Jun \& Kyle, 2012).

\section{Sport Identity Salience}

Based on Stryker and Serpe's (1982) identity salience, Curry and Weaner (1987) developed the Sport Identity Index (SII) to measure the sport role identification of male college students and student-athletes within their sport participation (e.g., varsity athletics, competitive non-varsity sports, and fitness activities). Based on the previous studies by Jackson (1981), Callero (1985), and Santee and Jackson (1979) measuring the identity salience construct, Curry and Weaner attempted to measure the relationship between role identity and eight categories of behavior - emotion; decision-making; objective choice; social comparison; long-range plans; self-presentation; anxiety about the role's performance; and use of time, care, and effort in performing the role - to investigate the hypothesis that "there will be a strong association between the salience of a sports role-identity and the involvement of the self in the role" (p. 281). To measure sport identity, a purposive sample of college students and student athletes ranked (to represent the identity ranking variable) and rated (to represent the importance rating variable) six different role identities including kin, peer, academic, romantic, sport, and religious. The zero-order correlations indicated that the importance rating of sport identity correlated consistently higher with other independent variables (including involvement of self in the role and the categories of commitment) and two dependent 
variables (including time spent in the sport role and enjoyment of the sport role) compare to the identity ranking variable. Interestingly, sport identity was ranked 5 th in the importance rating variable. The results of the study revealed that sport identity salience (combination of identity ranking and importance rating) were associated with level of commitment, sport enjoyment, time spent in role, and involvement of self in the role (Curry \& Weaner, 1987).

Later, Curry and Parr (1988) modified the sport identity salience scales to compare levels of sport and religious identities among student groups (female and male) at a small Christian college. The results of the study indicated that sport identity had more salience for males than for females based on the three measurements of saliences: ranking, rating, and involvement of self in the role (Curry \& Parr, 1988). The correlation analysis indicated that the five categories of commitment were strongly associated with three salience measures and two dependent variables (sport satisfaction and time spent in role) for both female and male students (Curry \& Parr, 1988). The findings of the study supported the validity of the SII (combined three measurements of ranking, rating and involvement of the self in role) within the college student and athletes' population.

To establish cross-cultural validity of SII, Curry and Weiss (1989) investigated how the cultural differences exist between American college athletes and Austrian student sport club members in terms of level of sport identity toward the sport they participate in and their motivation (competition, fitness and social motivation) for participating. In this study, the involvement of the self in role was used to measure the sport identity salience (labeled as the self-role scale) and examine the relationship among self in role (sport identity salience), gender, and three motivation variables by two 
different societies. The results of the study indicated that the three types of motivation for sport participation were positively associated with the involvement of the self in the sport role. Moreover, significant gender and cultural differences in sport identity existed between American college athletes and Austrian student sport club members.

In sum, the findings of Curry and his colleagues $(1997,1989)$ supported the concept of identity saliences that sport participation and related behaviors are influenced by salience of identity in sport for the population of college students and athletes. However, there are limitations for a lack of generalizability of the findings to other groups or populations.

\section{Athletic Identity}

Based on the multidimensional self-concept framework, Brewer, van Raatlte, and Linder (1993) established the Athletic Identity construct to measure the degree of individual identity with the role of athlete. Brewer et al. (1993) found that existing instruments of athletic identity, like Curry and his colleagues $(1997,1989)$, self-role scales (or SII), only measured the strength of identification with the athlete role but not the exclusivity of identification with the athlete role. Therefore, Brewer et al. (1993) developed the Athletic Identity Measurement Scale (AIMS) to reflect both strength and exclusivity of identification with the athlete role of sport participants. Athletic identity represents two components: self-schema, or cognitive structure; and social role, or occupational self-image. Also, athletic identity includes social, cognitive, and affective aspects. Therefore, the conceptualization of athletic identity posits that individuals with higher athletic identity are more likely to participate in sport or physical activity than individuals with lower athletic identity. To evaluate the psychometric properties of the 
AIMS, three studies were conducted using samples of college students and studentathletes. The results of these studies demonstrated that the AIMS was a reliable and valid instrument to measure the strength and exclusivity of identification with the athlete role of sample participants. However, Brewer et al. (1993) suggested that empirical examinations and further validation of the AIMS within noncollege student samples are needed.

The term, 'athletic identity' and 'sport identity' are occasionally used interchangeably because "athlete" refers to a participant in track and field in Europe, while the term is used to refer to an individual involved in one or multiple sports in North America (Lau, Fox, \& Cheung, 2004). Lau et al. (2004) utilized the AIMS to measure the sport identity salience of boys and girls aged 12 and 13 from a secondary school in England. Lau et al. (2004) proposed a model explaining sport identity as a mediator between psychosocial (including achievement goal orientations, intrinsic motivation, and perceived sport competence) and socio-environmental (including school sport orientation, family sport orientation and peer sport influence, accessibility to sport) variables and outcome variable of sport behavior (Figure 7). Lau et al. suggested that sport identity is an important theoretical construct for understanding sport participation, specifically, psychological commitment and consistent sport participation in children and adolescents. 


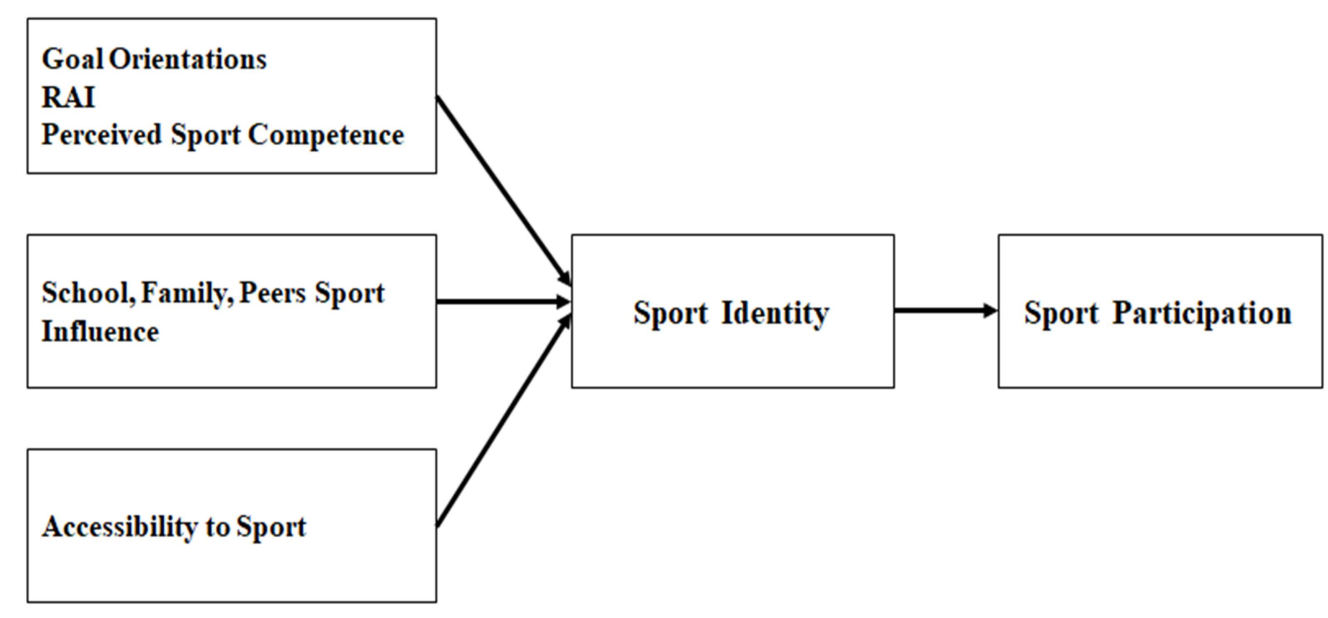

Figure 7. Lau et al.'s (2004) Proposed Model of Children's Sport Participation

For their regression analysis, sport identity was the strongest predictor of sport participation compared to other variables. Furthermore, the results of the factor analyses indicated that the data provided a good fit for the proposed model and the sport identity was statistically directly linked to sport participation. The findings of the study supported the idea that sport identity salience of children shapes and strengthens their sport behavior and validates the AIMS within secondary school-age children population in Western culture (Lau et al., 2004).

Furthermore, to establish the cross-cultural applicability of the sport identity construct, Lau, Cheung, and Ransdell (2007) investigated cultural differences in sport identity and sport participation between two culturally diverse societies, China and the United States. Lau et al. (2007) indicated that the construct of sport identity has been established as an important factor that positively influences an individual's sport behavior in Western societies valuing individualism. The concept, however, but not been examined in the eastern societies valuing individualism. Lau et al.'s (2004) conceptual model of 
sport identity and sport participation were adapted to compare Eastern and Western societies in terms of the relationship between sport identity and sport participation among high school students. In addition, the gender differences in two societies were investigated. The data were collected from high school students (grade 10 to 12) in Shanghai, China $(n=188)$ and Michigan, U.S. $(n=177)$. The results of path analysis determined that the data provided a good fit for the proposed path model for Chinese students as well as the model for American students (Lau et al., 2007). The results of chisquare difference test indicated that there were not significant gender differences in both Chinese and the American participants cultures in terms of sport identity and sport participation. Compared to female participants, male participants from both cultures indicated greater sport participation (Lau et al., 2007). Moreover, male high school students had higher sport identity than female students among the Chinese participants (Lau et al., 2007). However, gender differences in sport identity among American students did not exist. These findings of the study may support that the sport identity and sport participation model may explain be applicable in both individualistic and collective societies, but that predictive power is greater in western society (Lau et al., 2007).

Pot, Schenk, and Hilvoorde (2014) defined "sport identity" as the degree to which sport plays a part in one's life and is considered an important factor in making sportrelated choices. Since sport identity can be influenced by life experiences (Wright \& Laverty, 2010), Pot et al. (2014) argued that school sport participation, as a socialization process, can influence the sport identity of students. Using a longitudinal survey study, Pot et al. (2014) investigated how participation in the one-year school sport competition program organized by the Dutch Football Association can influence changes in sport and 
student identities as well as with physical activity participations in the Netherlands. Students' ages 10-12 years old participated in the study. They responded to the survey items (those included the Psychological Sense of School Membership, the Athletic Identity Measurement scale, and the Moderate to Vigorous Physical Activity Measure) at the three different (beginning, middle, and end) competitions during the school year. The results of the fixed effects regression indicate that participation in the competition program was not associated with changes in the sport and student identities of participants (Pot, Schenk, \& Hilvoorde, 2014).

Pot et al. (2014) assumed that the students who participated in the study may already have a strong sport identity with the school sport program prior to the participation in competition program. For the students who did not participate in any sport prior to the competition program, their sport identity can be constructed from other elements such as sport spectatorship, involvement of a family member in sport, the cultural expectation of individuals, and other sport involvement prior to participation in the competition program (Pot et al., 2014). The finding is important for future investigations to measure the level of sport identity of older adult participants within a organized sport activity.

Abbott, Weinmann, Bailey, and Laguna (1999) investigated the extent to which the salience-level (high, low, and medium) of the sport identity influenced sport choice and behavior in college student-athletes. Data were collected from eight Division I college baseball teams $(n=159)$. Three levels (high, low, and medium) of sport salience groups were categorized based on the numeric importance rating from 1 (low) to 6 (high). The results of the one-factor ANOVA analyses revealed that there was significant 
different between three levels of sport salience and choice behavior. Specifically, significant differences in choice behavior were found between the high and medium sport salience groups, and between the high and low salience groups, but not between medium and low salience groups. The findings of the study demonstrated that the salience-level of sport identity influenced choice and sport behaviors among Division I collegiate athletes. However, caution should be applied in the interpretation of the data. Abbott et al. (1999) did not report the reliability and validity of the choice behavior scale which the authors developed for the study. This measurement may also limit the generalizability of the findings.

\section{Sport Identity and Sport Commitment Model}

In the context of elite athletes, Researchers have suggested that identification with one's sport and as athletes appear to be significant determinants of elite and professional athletes' commitment to the sport and a major determinant of continued participation in that sport (Hall, 1993; Lerch, 1984; Murrell \& Dietz, 1992; Ogilvie \& Howe, 1986; Rosenberg, 1984; Wolff \& Lester, 1989; Yair 1990).

In addition, the following studies have specifically examined the identity construct as an additional predictor of sport commitment in the context of SCM. Hall (1993) applied the SCM to identify the important determinants of sport commitment among professional football players. Specifically, Hall added the identification construct as an antecedent of one's commitment and tested the extension with an elite professional athlete population. The results of the study supported that identification is a significant predictor of professional athletes' commitment to the sport, and the author suggested that the identification construct should be included in the original SCM. 
Zahariadis, Tsorbatzoudis, and Alexandris (2006) examined 343 youth athletes from different team sports (e.g., soccer and water polo) to study associations between sport motivation variables (intrinsic, extrinsic, identification, amotivation, and introjection) and sport commitment utilizing the sport motivation scale (from utility of self-determination theory) and the sport commitment questionnaire (from SCM). The results revealed that intrinsic motivation, identification, and amotivation were associated with sport commitment. Specifically, path analysis revealed that identification had a small path to commitment. Overall, the findings suggested that greater self-determination in youth athletes leads to greater sport commitment. It is important to note that there was no clear number of items for conceptualizing identification. One example of an identification item was "Because, in my opinion, it is one of the best ways to meet people" (Zahariadis et al., 2006, p. 410). Clear investigations of the relationship between sport identity and sport commitment are still needed.

Frayeh and Lewis (2017) suggested using the extended SCM including two additional predictors (athletic identity and social cohesion) of sport commitment to explore the relationships among antecedents (enjoyment, valuable opportunities, attractive alternatives, investments, and social support), sport commitment, and participation in co-ed adult recreational soccer leagues (as a moderate to vigorous physical activity [MVPA]). Athletic identity was defined as the importance of physical activity to adults' self-identity. It was significantly related to sport commitment, and also mediated the relationship between sport commitment and weekly minutes of MVPA participation. The results supported the finding that the importance of physical activity relative to adults' self-identity was significantly associated with sport commitment. The 
findings also supported the mediation effect of athletic identity between sport commitment and MVPA in these soccer leagues. However, more research is needed to investigate relationships between sport identity and sport commitment to support the notion that sport identity is positively related to sport commitment.

\section{Association of Sport Identity and Life Satisfaction}

With the growing body of evidence supporting the influence of sport and physical activity identity on sport and physical activity behavior, the association between sport and physical identity and psychological health (or benefits), becomes increasingly important (Miller \& Hoffman, 2009; Rejeski \& Mihalko, 2001). Rejeski and Mihalko (2001) suggested that physical activity and exercise interventions in older adults help to define self and influence self-cognitions (e.g., self-efficacy belief and self-esteem). These interventions may also affect psychological outcomes (e.g., life satisfaction) in later life.

Miller and Hoffman (2009) used a sample of 791 undergraduate college students to demonstrate the relationships among individual and team sport participation, sportrelated identities (athlete identity and jock identity), gender, depression, and suicidal behavior. The results revealed that team sport participation and athletic identity were associated with lower depression rates and reduced suicide behavior (Miller \& Hoffman, 2009). Moreover, the findings suggested that athletic identity would mediate the relationship between team sport participation and level of depression rate and number of suicide attempts among college students (Miller \& Hoffman, 2009). The study supported the idea that greater athletic identity leads to improved social and mental well-being.

Hardcastle and Tayler (2005) conducted a study using a qualitative approach to investigate how a10-week community exercise program affected physical self-cognitions 
(i.e., exercise identity) over time for 15 older women (aged from 44 to 77 years old). The results of the interviews revealed that exercise identity was developed through feelings of achievement, control, a sense of belonging, and social interaction. Moreover, exercise identity impacts feelings of empowerment and well-being (Hardcastle \& Tayler, 2005). Using a larger sample size $(N=84)$ and a quantitative approach, Strachan, Brawley, Spink and Glazebrook (2010) demonstrated the relationships between older adults' physical activity identity, physical activity involvement, their level of social cognitions (i.e., self-regulatory efficacy, intentions for physical activity) and life satisfaction. The results revealed that older adults with strong physical activity identity reported more involvement in physical activity, stronger self-regulatory efficacy, proximal intentions, and greater satisfaction with life compared to older adults with the least strong identity (Strachan et al., 2010). These previous studies supported that a strong physical activity identity leads to greater well-being in the older adults. More empirical research is needed to support the direct and positive relationship between identification with sport and physical activity and life satisfaction among older adults (Strachan et al., 2010).

\section{Summary of Literature Review}

The current study proposed two theoretical regression models: (a) the extended Sport Commitment Model (SCM) and (b) life satisfaction model based on the literature review. The first regression model was developed based on the original SCM model with six predictors (e.g., sport enjoyment) and two elements of commitment, sport satisfaction and sport identity, which were suggested by Snyder (1981). The original SCM model has been widely examined as a construct explaining individuals' desire to continue to participate in specific sport and physical activities. Sport commitment plays an important 
role in the extent of sport and physical activity participants' behaviors. Relatively few studies, however, have examined the predictors or elements of sport commitment among older adults (e.g., tennis and ballroom participants) (Casper et al., 2017; Wang \& Chu, 2016). As an element of commitment, sport satisfaction was added to this study as a distinct construct, which separated it from other original constructs (e.g., sport enjoyment) of the SCM, to predict older adults' level of commitment to organized sports. Previously, sport satisfaction was examined interchangeably with various constructs such as enjoyment, pleasure, fun, and intrinsic and extrinsic rewards in the sport and exercise literature (Casper et al., 2007; Eklund \& Tenenbaum, 2013). Additionally, sport identity was added in the extended SCM. Previous studies suggested that sport identity had a direct, significant effect on sport commitment and it is was an important predictor for older adults' sport behavior and choice.

Therefore, the extended SCM model suggested six antecedents (sport enjoyment, involvement opportunities, personal investments, involvement alternatives, social constraints and social support) from the original SCM and two new antecedents (sport satisfaction and sport identity) were important predictors of the sport commitment for older adults. The following hypotheses were proposed: (H1a) sport enjoyment, involvement opportunities, personal investment, social constraints, and social support positively predict sport commitment, and involvement alternative negatively predicts sport commitment; (H1b) sport satisfaction positively predicts sport commitment; (H1c) sport identity positively predicts sport commitment.

For the life satisfaction model, Snyder suggested that it would be important to know how individuals achieved satisfaction with life from commitment and components 
of commitment (e.g., enjoyment, satisfaction, and identity). Previous studies indicated that sport satisfaction is an important contributor to increasing life satisfaction among sport participants regardless of ages (Baudin et al, 2013; Ragheb \& Griffith,1982). For the sport identity, Strachan et al. (2010) indicated older adults with a strong physical activity identity participated in more physical activity and had greater life satisfaction compared to older adults with less strong physical activity identity. Kim et al. (2011) indicated that individuals who have a strong commitment to a specific serious leisure activity (e.g., bass fishing, mountain climbing, and ice skating) exceed their personal and social benefits through their engagement. However, there was no empirical evidence to explain how older adults achieve improved life satisfaction from sport commitment and its components (e.g., sport identity, and sport satisfaction) simultaneously. Furthermore, it is important to note that predictors (e.g., sport enjoyment) in the SCM were excluded from this study due to the lack of literature.

Therefore, sport satisfaction, sport identity, and sport commitment were added as important predictors of life satisfaction among older adults who participate in organized sport activity regularly. Three hypotheses were proposed as follows: (H2a) sport satisfaction positively and uniquely relates to older adults' level of life satisfaction; (H2b) sport identity positively and uniquely relates to older adults' level of life satisfaction; (H2c) sport commitment positively and uniquely relates to older adults' level of life satisfaction.

In sum, two theoretical regression models were developed to provide valuable insight towards understanding the factors that explain older adults' decision to continue to participate in organized sport and increase their level of life satisfaction. In Chapter III 
will highlight insights into what quantitative methods were chosen to examine the two regression models. Specifically, Chapter III will discuss the components as follows: research design, target population and sample, sampling procedures, instrumentation, data collection procedures, and statistical data analysis. 


\section{CHAPTER III}

\section{METHOD}

This chapter discusses the methodology of the dissertation to give context to the research questions and hypotheses. The Method chapter contains the following sections: purpose, research questions and hypothesizes, research design, target population and sample, sampling procedures, instrumentation, data collection procedures, and statistical data analysis.

\section{Purpose of the Dissertation}

The primary purpose of this dissertation was to gain a better understanding of participation in sport activities among adults over 55 years of age, referred to as "older adults." Specifically, this purpose is twofold:

(1) Use the Sport Commitment Model (SCM) to identify antecedent factors that influence levels of commitment toward organized sport and physical activity among older adults; and

(2) Investigate the relationships among sport satisfaction, sport identity, and sport commitment in the well-being of older adults who participate in organized sport and physical activity.

Theoretically, this dissertation expanded the applicability of the SCM to the older adult population. Using activity theory and the concept of sport commitment advanced knowledge of sport participation among older adults by addressing the theoretical relationships among sport participation and life satisfaction. Practically, sport 
organizations and practitioners working closely with older adults will be gained a better understanding of influential factors of sport commitment for organized sport and physical activity participation and the importance of sport identity, sport satisfaction, and sport commitment among older adults in terms of organized sport and physical activity participation and life satisfaction. Moreover, the findings will be provided a helpful resource for older adult sport programmers, especially in terms of enhancing identity and commitment in order to increase sport participation among the older adult population.

\section{Research Questions and Hypotheses}

To effectively address the two purposes of this dissertation, two overarching questions were examined and for each overarching question, there were a set of more specific questions.

Using the constructs of the SCM, first research question was examined as follows: RQ1. Do the antecedent factors (i.e., sport enjoyment, involvement opportunities, personal investments, involvement alternatives, social constraints and social support), sport satisfaction, and sport identity predict the level of sport commitment toward organized sport activity for older adults? Specifically:

1a. Which of the antecedent factors are the strongest predictors of older adults' sport commitment toward organized sport activity?

1b. Does sport satisfaction explain a significant incremental variance in sport commitment over and above the six antecedent factors among older adults?

1c. Does sport identity explain a significant incremental variance in sport commitment over and above the seven antecedent factors including sport satisfaction among older adults? 
In the first purpose, the following hypothesizes are proposed,

Hypothesis 1a: Sport enjoyment, involvement opportunities, personal

investments, social constraints, and social support positively predict sport commitment, and involvement alternative negatively predicts sport commitment.

Hypothesis 1b: Sport satisfaction positively predicts sport commitment. Hypothesis 1c: Sport identity positively predicts sport commitment. For the first research question, six antecedents (sport enjoyment, involvement opportunities, personal investments, involvement alternatives, social constraints and social support) from the original SCM and additional two new antecedents (sport satisfaction and sport identity) of this study were represented the independent variables and sport commitment was represented the dependent variable.

In order to address the second purpose of the dissertation, the following research question was addressed:

RQ2. Is there a significant relationship between the level of life satisfaction and sport satisfaction, sport identity, and sport commitment among older adults who participate in organized sport activity regularly? Specifically:

2a. Is sport satisfaction significantly related to older adults' level of life satisfaction?

2b. Is sport identity significantly related to older adults' level of life satisfaction?

2c. Is sport commitment significantly related to older adults' level of life satisfaction?

Based on these specific questions, three hypotheses were examined as follows: 
Hypothesis 2a: Sport satisfaction positively and uniquely relates to older adults' level of life satisfaction.

Hypothesis 2b: Sport identity positively and uniquely relates to older adults' level of life satisfaction.

Hypothesis 2c: Sport commitment positively and uniquely relates to older adults' level of life satisfaction.

For the second research question, sport satisfaction, sport identity, and sport commitment were represented the independent variables and life satisfaction was represented the dependent variable.

\section{Research Design}

This current study employed a quantitative and non-experimental research design to measure and analyzes older adults' attitudes and behaviors toward organized sport and physical activity participation. To address the research questions and test the hypotheses, a cross-sectional survey research design was used to collect the data at a particular point in time utilizing a survey instrument. Cross-sectional survey design is one of the most popular designs used in the social sciences and is commonly utilized for sport-related research (Gotten \& Jones, 2004). In general, this survey design provided a description of trends, attitudes, or opinions of a population by studying a sample of a target population at a particular point in time. Moreover, the design helped to draw inferences about specific characteristics and behaviors of the target population (Creswell, 2012, 2013; Gotten \& Jones, 2004). Therefore, cross-sectional survey design was appropriate for investigating the applicability of the SCM among the older adult population. 


\section{Participants}

The target population for this dissertation was older adults in the United States who participated in an organized sport activity one or more times per week. The adult population can be categorized into three age groups: young adults aged 18-34, middle adults aged 35-54, and older adults aged 55 and older, based on the previous studies (Casper \& Stellino, 2008; Walker, Volkan, Sechrist \& Pender, 1988). Specifically, Casper and Stellino (2008) suggested that 55 and older fall under the senior adult cycle based on the marketing research report and United States (U.S. Census) classifications of lifecycles. Moreover, the U.S. Bureau of Labor Statistics indicated that individuals aged 55 and over were less likely to engage in team or group sport and exercise activities compared to other age groups (those aged 15 to 24 years and aged 25 to 54) (Woods, 2017). The last members of the Baby Boomer generation turned 55 in 2019. Thus, this study defined older adults as those aged 55 and older, based on previous health promotion studies and competitive sport participation reports (Dionigi, 2002; Lyons \& Dionigi, 2007; Walker et al., 1988; Woods, 2017).

The inclusion criteria for participants consisted of individuals who (a) were 55 years of age or older, (b) participated in sport and physical activity (e.g., golf, tennis, cycling, swimming, running, fitness and others) and (c) were involved in sport activity as part of an organized group, membership, or league at sport facilities, clubs, or parks. This study focused on older adults who participated in community-based or socially organized sport activity (e.g., local golf league, running group, or YMCA fitness group) which is distinct from individual physical activities (e.g., housekeeping, gardening). People who only participated in sport activity individually or in physical activity at home were 
excluded from this study. It is important to note that three antecedent factors such as involvement opportunities, social constraints and social support are measuring social related to factors influencing participation in the sport and physical activity. For instance, the item in the involvement opportunities scale was "I would miss the people that I have met if I quit this sport activity" and the item in the social constraints was "I feel that I have to participate in this sport activity to be with my friends." To determine the significant and meaningful factors that related to attitude toward sport and physical activity participation, this study focused on the sample of the older adults who participating in organized sport activities.

The Physical Activity Council (2020) determined that the boomers (born were between 1945-1964) were more likely to participate in fitness sports (55\%; e.g., aquatic exercise, running/jogging), followed by individual sports (23\%; e.g., bowling, golf), racquet sports (5.5\%; e.g., pickleball, tennis), and team sport (4.3\%; e.g., basketball, softball). This report also determined that inactive, or no physical activity, older adults (aged 55 to 64 and $65+$ ) were interested in trying activities such as bicycling, swimming for fitness, working out with machines and weights and outdoor leisure activities (e.g., fishing, shooting, and birdwatching/wildlife viewing) that can be performed individually (Physical Activity Council, 2020). Based on these reports, older adults may generally not wanted to participate in racquet sports and team sports that required partners or a group to participate. Organized or team sport activities may have greater social interaction aspects (social well-being), compare to the individual exercise and physical activities (e.g., running/jogging) among older adults. Moreover, compared to youth sport participation, significantly less research has focused on these older adults' participation in organized 
sport (Baker et al., 2010). Therefore, this study contributed to the body of knowledge in the context of organized sport participation among older adults aged 55 and over, and provided valuable insight towards understanding the factors that explain older adults' decision to continue to participate in organized sport and increase their level of life satisfaction.

\section{Sample}

To meet the inclusion criteria of participants for this study, the researcher had to visit the research sites where permission was granted to reach out to target participants. Participation in the study was entirely voluntary. Therefore, convenience sampling, as a non-probability sampling method, was utilized to recruit subjects from the older adult population who participated in organized sport or physical activity. Convenience sampling is common in social science research and contributes to the ease of recruiting participants, who are viewed as conveniently based upon their location and accessibility (Gratton \& Jones, 2004). Additionally, snowball sampling, as a form of purposeful sampling, was utilized for recruiting additional survey participants in this study. These survey respondents were asked to recommend other older adult participants who could be surveyed at the research sites (Creswell, 2012). After the survey instrument was finalized, the study sample was selected through the above-mentioned criteria of age, sport activity participation, and location. As noted by Gatton and Jones (2004), non-probability sampling method does not allow generalizability across the target population but does allow for generalization to theories or conceptual models. This means that the current study's sample did not represent the entire older adult population who participate in organized sport and physical activity, but it determined the applicability of SCM to older 
adults. Moreover, it explored the relationships between psychological constructs (sport identity, sport satisfaction and sport commitment) of sport participation and life satisfaction.

\section{Sample Size}

To determine adequate sample size to address the research questions and test the hypotheses, recommendations based on various analyses were reviewed. Creswell (2012) suggests approximately 350 participants are needed for survey research. Other researchers suggest more than 30 participants per variable as an appropriate number for correlation research (VanVoorhis \& Morgan, 2007). This study examined nine variables, including all components of the modified SCM; therefore, a sample size of more than 270 was needed for sufficient statistical power for the hierarchical multiple regression analysis to address the research questions and hypotheses. Additionally, for the multiple regression analysis, Green (1991) suggests a formula for the number of participants: $(N)$ $\geq 50+8 * m$, where $m=$ the number of independent variables (IV). Therefore, the current study needed more than 114 participants. It is important to note that the minimum sample size should not be below 200 cases to compute EFA (Kline, 2016). In sum, a larger sample size could better represent the target population and ensure less sampling error (Robert, 2010). To create a stronger claim in generalizing results from the sample to the population, Creswell (2012) suggested that "a higher response rate creates a stronger claim in generalizing results from the sample to the population" (p.390). Therefore, a minimum of 700 in-person questionnaires were planned to distribute to the target population. With a participant response rate of $50 \%$ or better from the many survey 
studies (Creswell, 2012), this gave a minimum of 350 respondents to meet the suggested sample size for a survey study.

\section{Data Collection Procedures}

The data collection for the study was conducted via a self-reported and paperbased survey. The paper-based questionnaires were directly distributed in person at the research sites. The paper-based questionnaires were either returned directly to the researcher or by mail, or sent electronically via email based by the participants' requests or preferences. Since an adequate response rate for most surveys was 50\% (Creswell, 2012), paper-based surveys were used preferentially to boost the survey response rate for the target age group. Moreover, direct distribution of paper survey suggested as a popular data collection method for managing a large number of questionnaires simultaneously (Andrew, Pedersen \& McEvoy, 2011).

Prior to the data collection procedure, the University of Louisville's Institutional Review Board (IRB) approved the sampling and data collection methods. Written consent, including a brief explanation of the study and survey and contact information, was provided for participants on the front page of the survey instrument. Participation in this study was completely anonymous and voluntary, and participants filled out the inperson survey at their convenience. It took 15-25 minutes on average to complete the in-

person survey. The researcher asked survey respondents to recommend other potential participants or groups after completing their survey and handing it back to the researcher.

\section{Pilot Test of Survey Instrument}

Prior to selecting the measures to addressed the research questions and proposed hypotheses, the researcher and a panel of experts including a research and evaluation 
professor, sport management professors, and health and sport sciences professors (from the physical activity and physiology programs), were asked to review the survey instrument to improve the face validity and content validity. The panel of experts evaluated the relevance, clarity, and representativeness of each item (Chen \& Zhang, 2012; DeVellis, 2017). A pilot test also was conducted with 15 selected older adult participants who represented the target population. These individuals evaluated the face validity along with the readability and completability of the survey instrument (Creswell, 2012). This group provided feedback on the survey instrument. Their comments and suggestions were applied to the survey instrument where appropriate and reviewed by the researchers and experts before recruiting the full-study participants (Creswell, 2012). The pilot test responses were excluded from the final data analyses of the study.

\section{Research Sites}

The researcher and experts determined the research sites which included local YMCA facilities, tennis facilities, golf clubs and courses, a local church's health and sport centers, and the bowling alley. These research locations provided the sport and exercise programs and leagues for older adults. For instance, there are seven tennis facilities around the city of Louisville: Louisville Indoor Racquet Club, Bass-Rudd Tennis Center (University of Louisville), Louisville Tennis Club, Blairwood Tennis, Swim \& Fitness Club, Advantage Tennis \& Fitness and the Tennis Club at Springhurst. In these facilities, there are weekly local women tennis leagues for adults and older adults. In addition, the United States Tennis Association (USTA) hosts adult and senior tournaments (aged 55 and over) every weekend for men and women. In local YMCAs, 
fitness programs and water fitness are provided to older adults. Bowling alleys have regularly scheduled leagues where older adults participate.

The researcher contacted the managers or administrators of the above-mentioned sites to request permission to distribute the paper-based survey to potential participants. After permission was granted from the selected research sites, the researcher visited the research sites to distribute the self-reported paper-and-pencil survey instrument utilizing the intercept survey approach.

\section{Instrument}

The self-report survey instrument was composed of four sections: (1) organized sport activity involvement, (2) the modified Sport Commitment Model (SCM) questionnaire with the addition of sport satisfaction and sport identity, (3) life satisfaction, and (4) demographic characteristics. The survey items were presented in full in Appendix B.

The first section of the survey instrument contained items assessing older adults' involvement in organized group sport activities. The respondents were first asked to identify one organized sport activity in which they currently participated or in which they participated in the last twelve months. Based on this selected sport activity, the respondents were asked to respond to items addressing their years of involvement in this sport activity, average weekly or monthly participation, and average monthly spending on participation. In addition, the open-ended item "What influenced you to first participate in organized sport activity?" was asked to determine which channels (e.g., peers, family, and internet) helped older adults to start participating in organized sport 
The second section of the survey instrument contained the SCM questionnaire items. These items were adapted from Scanlan et al.'s (2016) SCM questionnaire, the modified SCM questionnaire (Casper et al., 2007) of adult tennis participants, and Wilson et al.'s (2004) Exercise Commitment Model (ECM) questionnaire. The survey items of SCM in this section were modified to pertain to older adults and organized sport activity participation. The modifications were minimal to the original questionnaires. The items measured seven SCM constructs: (a) sport commitment, (b) sport enjoyment, (c) involvement alternatives, (d) involvement opportunities, (e) personal investments, (f) social constraints, and (g) social support. Responses to the 30 items of the six predicators of sport commitment were measured using a 5-point Likert-type scale, ranging from not at all (1) to very much (5).

Sport commitment. Sport commitment was measured by Casper et al.'s (2007) sport commitment scale with six items. This scale was used for a sample of adult tennis participants ( $\alpha=0.85)$ which modified the Scanlan and colleagues' (1993a, 1993b) original sport commitment scale assessing participation in youth sport programs. In this study, the sport commitment questionnaire was modified to pertain to organized sport activity participants. The six items assessed the degree to which older adults desire to continue their organized sport activity participation (e.g., "How determined are you to continue participating in this sport activity?" and "How hard would it be to quit this sport activity?"). Responses to the sport commitment items were measured using a 5-point Likert-type scale, ranging from 1 to 5. The anchors differed depending on the items (e.g., not at all dedicated to very dedicated; nothing at all to a lot of things; not hard to very hard; not at all determined to very determined, and not much to very much, etc.). The 
previous study reported that the internal consistency reliability coefficient from a sample of older adult ballroom dancing participants was .88 (Wang \& Chu, 2016) which is deemed acceptable (Nunnally \& Bernstein, 1994).

Sport enjoyment. The sport enjoyment scale was adapted from the SCM questionnaire by Scanlan et al. (2016). In addition, the statement of "I enjoy playing this sport activity" was added in the sport enjoyment scale. This item was consistently used in previous studies (Jeon \& Ridinger, 2009; Lovelock, Jellum, Carr, \& Jowett, 2019). The six items assessed older adults' positive affective responses to participating in organized sport activity (e.g., "Participating in this sport activity makes me happy;" "Participating in this sport activity is fun"). The SCM literature demonstrated that sport enjoyment was the strongest predicator of sport commitment for all age groups. Previous studies indicated that the sport enjoyment scale items were able to accurately measure the construct of sport enjoyment (Scanlan et al., 2016) and also found that internal consistency reliability of the scores from the sport enjoyment scale were viewed acceptable (e.g., $\alpha=0.83$, Casper et al., 2007; $\alpha=0.87$, Wang \& Chu, 2016).

Involvement alternatives. The involvement alternative scale was adapted from Wilson et al. (2004) Exercise Commitment Scale (ECS). The five statements measured how attractive or beneficial other activities or behaviors appeared compared to organized sport activity (e.g., "Compared to participating in sport activity, there are other things I could do which would be more fun;" "Compared to participating in sport activity, there are other things I could do which would be more enjoyable"). The previous study indicated that the scale of involvement alternatives for internal consistency met the 
minimal criterion of acceptability (greater than .70; Nunnally \& Bernstein, 1994), with an alpha score of .81 (Wang \& Chu, 2016).

Involvement opportunities. To measure the involvement opportunities among older adults, the scale was adapted from Casper et al.'s (2007) scale of involvement opportunities for adult tennis participants. The items were employed to assess the anticipated benefits that a participant received through continued participation in a sport activity such as friendship, social interaction, skill mastery, and physical conditioning (e.g., "I would really miss the good times that I had if I discontinued participation;" "I would miss the people and friends that I have met if I quit;" "I would miss the unique experience that I get by participation in this sport activity if I quit") (Casper et al., 2007; Jeon \& Casper, 2016). Previous studies indicated that the scale of involvement alternatives for internal consistency met the minimal criterion of acceptability (greater than .70; Nunnally \& Bernstein, 1994), with an alpha score of .74 for a sample of adult tennis participants (Casper et al., 2007) and with an alpha score of .78 for a sample of Taekwondo participants (Jeon \& Casper 2016). However, based on the definition of involvement opportunities, there were no items to assess health-related opportunities (e.g., physical conditioning) that are only present through continued participation in a sport (Casper et al., 2007; Jeon \& Casper, 2016). Wilson et al. (2004) defined "the involvement opportunities construct reflected the degree to which continued exercise involvement provided social and health related benefits" (p. 409). In the involvement opportunities, six items were measuring the two different benefits. However, the involvement opportunities were eliminated due to the lack of content clarity (Wilson et al., 2004). Even though the construct used the label name, involvement opportunities, but 
social benefits and health benefits are two distant theoretical concepts. In this study, three items that reflected the degree to which organized sport activity involvement provide health related benefits were added to reflect the construct of the involvement opportunities and for the construct representativeness and clarity purposes. Three items of the health benefits were adapted from Wilson et al. (2004) scale of involvement opportunities (e.g., "the sport activity gives me the opportunity to relieve any stress I am feeling;" "the sport activity gives me the opportunity to improve my health and fitness.").

Personal investments. The participants' personal investments was measured by Wilson et al.'s (2004) scale of personal investments that used a sample of participants in group-based exercise classes. The four items were adapted to pertain to organized sport activity among older adults. The items assessed the resources (time, effort, energy, and money) put into sport activity (e.g., "I have invested a lot of time into sport activity;" "I have invested a lot of effort into sport activity;" "I have invested a lot of my own money into sport activity"). Wilson et al. (2004) reported that internal consistency reliability of the score from the personal investments scale was viewed as good $(\alpha=.94)$.

Social constraints. The social constraints scale was adapted from a Wilson et al.'s (2004) social constraint scale (four items). In their study, one item ("People will think I am a quitter if I stop exercising") was dropped based on the exploratory factor analyses (EFA). With three items, Wilson et al. (2004) reported that the internal consistency reliability coefficient from their sample was .82 , which is deemed acceptable (Nunnally \& Bernstein, 1994). In this study, three items were modified to pertain to organized sport activity participation and the participants responded to three statements assessing their perceptions of pressures that create a feeling of obligation to continue participation in 
sport activity (e.g., "I feel pressure from other people to participate in sport activity;" " I have to keep participation in this sport activity to please others," and "People would be disappointed with me if I quit participating in sport activity"). In addition to three items, two additional items were added to improve a score of reliability and construct representativeness. Two items ("I feel that I have to participate in this sport activity to be with my friends" and "I feel that I have to participate in this sport activity more for my friends/spouse than for myself") were adapted from Casper and colleagues' (2007) scale of social constraints ( 4 items). In the previous study, the reliability of the score from the scale (three items) was reported to be acceptable (.72). However, only these two items' factor loadings were greater than .70 (Casper et al., 2007).

Social support. Social support was measured by Casper et al.'s (2007) scale of social support. The four items reflected feelings of encouragement and support that an older adult participant receives from family members and others (e.g., "People say things to make me feel good about participation in sport activity;" "Other people encourage me to participate in sport activity"). Previous research indicated that internal consistency reliability of the scores from the scale were acceptable among adult tennis participants $(\alpha=0.74)$ (Casper et al., 2007) and young and adult Taekwondo participants $(\alpha=0.73)$ (Jeon \& Casper 2016). In addition to the SCM model, two new constructs, sport satisfaction and sport identity, were added separately in this section of the survey instrument.

Sport satisfaction. The sport satisfaction scale was adapted from Bodet's, (2012) measurements of overall consumer satisfaction with a fitness organization. Bodet's (2012) study used items of Oliver's (1980) scale to assess the relationship between the 
respondents and their sport and physical activity participation in clubs. In this study, three statements assessed the degree to which current or past participation in an organized sport activity was perceived as satisfying (e.g., "Overall, I am satisfied with my decision to participate in this sport activity", "I think I did the right thing by deciding to participate in this sport activity", and "My choice to participate in this sport activity is a wise one"). Respondents indicated the extent to which they agreed with each statement on a 5-point Likert style scale anchored by strongly disagree (1) and strongly agree (5). The previous study reported that the internal consistency reliability coefficient from a sample was .88 (Bodet, 2012) which is deemed acceptable (greater than .70; Nunnally \& Bernstein, 1994).

Sport identity. To measure Sport Identity (SID) as a new construct of the SCM, Randel and Jaussi's (2003) identity scale was adapted. Pickett and Cunningham (2018) used Randel and Jaussi's identity scale to measure yoga identification $(\alpha=.85)$. In this study, the four items were modified to reflect the importance of personal identity with the sport activity. A sample item is "Sport activity is an important reflection of who I am," and a 5-point Likert scale was used to allow the participants to express how much they strongly disagree (1) or strongly agree (5) with a particular item. Higher scores indicated a greater level of identification with sport activity.

Life satisfaction. In the third section, to measure participant well-being, the Satisfaction with Life Scale (SWLS) was used to access the global cognitive judgments of satisfaction with older adults' life as a whole (Diener et al., 1985). Researchers have used the SWLS as a component of subjective well-being with positive affect and negative affect, and they also have used it to measure the subjective quality of the life of 
individuals. The SWLS scale contains five statements including "In most ways my life is close to my ideal life", "The conditions of my life are excellent", "I am satisfied with my life", "So far I have gotten the important things I want in life", and "If I could live my life over, I would change almost nothing." Respondents indicated the extent to which they agreed with each statement in a 5-point Likert style scale anchored by strongly disagree (1) and strongly agree (5). Previously SWLS was measured on a 7-point sale. Kobau, Sniezek, Zack, Lucas, and Burns (2010) used a 5-point Likert style scale. The reliability of the score from the scale was reported to be acceptable $(\alpha=0.88)$ among the US adults.

The last section of the survey instrument asked for demographic information. The items included age, gender, retirement (e.g., yes or no), marital status, race and ethnicity, and gross household income in order to have a better understanding of the demographic characteristics of older adults who completed this survey. The adapted and modified major SCM questionnaire, the addition of sport satisfaction and sport identity questionnaire and the life satisfaction questionnaire are presented in Table 2.

\section{Table 2}

The Questionnaire of SCM, Sport Satisfaction, Sport Identity, and Life Satisfaction

\begin{tabular}{ll}
\hline \multicolumn{2}{c}{ Code } \\
\hline Sport commitment (COMMIT) \\
COMMIT_1 & How dedicated are you to participate in this sport activity? \\
COMMIT_2 & What would you be willing to do to be able to keep participating in this sport activity? \\
COMMIT_3 & How determined are you to continue participating in this sport activity? \\
COMMIT_4 & Do you want to keep participating in this sport activity? \\
COMMIT_5 & How proud are you to tell other people that you participate in this sport activity? \\
COMMIT_6 & How hard would it be to quit this sport activity? \\
Sport enjoyment (ENJ) \\
ENJ_1
\end{tabular}


$\begin{array}{ll}\text { ENJ_2 } & \text { I love to play this sport activity. } \\ \text { ENJ_3 } & \text { I like playing this sport activity. } \\ \text { ENJ_4 } & \text { Playing this sport activity is fun. } \\ \text { ENJ_5 } & \text { Playing this sport activity makes me happy. } \\ \text { ENJ_6 } & \text { Playing this sport activity is very pleasurable. } \\ \text { Involvement opportunities (OPP) } & \text { I would miss being considered an athlete (e.g., golfer) if I quit this sport activity. } \\ \text { OPP_1 } & \text { I would miss the people that I have met if I quit this sport activity. } \\ \text { OPP_2 } & \text { I would miss the good times that I had if I quit this sport activity. } \\ \text { OPP_3 } & \text { This sport activity gives me the opportunity to relieve any stress I am feeling. } \\ \text { OPP_4 } & \text { This sport activity gives me the opportunity to improve my health and fitness. } \\ \text { OPP_5 } & \text { This sport activity gives me the opportunity to improve my physical skills. } \\ \text { OPP_6 } & \text { I have invested a lot of effort into this sport activity. } \\ \text { Personal investments (INV) } \\ \text { INV_1 } \\ \text { INV_2 } & \text { I have invested a lot of energy into this sport activity. } \\ \text { INV_3 } & \text { I have invested a lot of time into this sport activity. } \\ \text { INV_4 } & \text { I have invested a lot of my own money into this sport activity. } \\ \text { Social support (SUP) }\end{array}$

SUP_1 People say things to make me feel good about participation in this sport activity.

SUP_2 Other people encourage me to participate in this sport activity.

SUP_3 Significant others (e.g., family or friends) say things to keep me participating in this sport activity.

SUP 4 I feel that I receive support from significant others (e.g., family or friends) about this sport activity.

Social constraints (SOC)

SOC_1 I feel pressure from other people to participate in this sport activity.

SOC_2 I have to keep participating in this sport activity to please others.

SOC_3 People will be disappointed with me if I quit this sport activity.

SOC_4 I feel that I have to participate in this sport activity to be with my friends.

SOC 5 I feel that I have to participate in this sport activity more for my friends/spouse than for myself.

Involvement alternatives (ALT)

ALT_1 Compared to participating in this sport activity, there are other things I could do which would be more fun.

ALT_2 Compared to participating in this sport activity, there are other things I could do which would be more enjoyable.

ALT_3 Compared to participating in this sport activity, there are other things I could do which 
would be more worthwhile.

ALT_4 I would be happier doing something else instead of participating in this sport activity.

ALT_5 I would like to do something else instead of participating in this sport activity.

Sport identity (SID)

SID_1 In general, this sport activity is an important part of my self-image.

SID_2 This sport activity is important to my sense of what kind of a person I am.

SID_3 This sport activity is an important reflection of who I am.

SID_4 Overall, this sport activity has little to do with how I feel about myself. (R)

Sport satisfaction (SAT)

SAT_1 Overall, I am satisfied with my decision to participate in this sport activity.

SAT_2 I think I did the right thing by deciding to participate in this sport activity.

SAT_3 My choice to participate in this sport activity is a wise one.

Life satisfaction (SWLS)

SWLS_1 In most ways my life is close to my ideal life.

SWLS_2 The conditions of my life are excellent.

SWLS_3 I am satisfied with my life.

SWLS_4 So far I have gotten the important things I want in life.

SWLS_5 If I could live my life over, I would change almost nothing.

$(\mathrm{R})=$ Reverse

\section{Data Analysis Procedures}

Each research question included a series of four steps for data analysis. First, descriptive statistics were calculated to describe obtained data from the target sample in the study. In the second step, reliability and validity of measures were performed by Principal Component and Analysis (PCA) for the first research question, Principal Axis Factoring (PAF) analysis for the second research, and Cronbach's alpha. Next, correlation analysis was conducted to represent the values of the strength of relationship among independent and dependent variables. Last, a three stage hierarchical multiple regression analysis was performed to address the first research question with specific three questions (RQ1a, RQ1b, and RQ1c) and three hypotheses testing the proposed 
regression models. Simultaneous multiple regression analysis was performed to address the second research question with specific three questions (RQ2a, RQ2b, and RQ2c) and three hypotheses testing the proposed regression models. Prior to assessing the statistical data analyses, initial data clearing was performed. This included (a) visually inspecting the data for errors, (b) identifying outliers, and (c) dealing with missing data (Creswell, 2012; Odom \& Henson, 2002).

\section{Descriptive Statistics}

Descriptive statistics for the items or measures and major variables were obtained, including means (to measure of general tendency), standard deviations (to measure variability), and frequencies (Creswell, 2012; Gratton \& Jones, 2004). In addition, skewness and kurtosis were calculated to test normality (distribution of variables). This study used the criterion that a variable is non-normal when skewness is above 3 and kurtosis is above 10 (Kline, 2016). It was important to evaluate the measures and assumptions through the descriptive statistics prior to the PCA and PAF.

\section{Reliability and Validity of Measurements}

To assess the reliability and validity of the modified SCM measures for the first research questions, a principal component analysis (PCA) and Cronbach's alpha coefficient were estimated. The PCA were conducted to determine the items of the SCM and two additional variables (sport satisfaction and sport identity) that account for a significant proportion of variance in the original set of variables (Pituch \& Stevens, 2016). Prior to the PAC, the Kaiser-Meyer-Olkin (KMO) measure of sampling adequacy using the 0.70 cut-off (Kaiser, 1974) and Bartlett's test of sphericity were performed to ensure that the data were appropriate for the PAC. Bartlett's test of sphericity indicated a 
sufficient amount of correlation between variables in the population to proceed with the analysis. Next, based on the assumption of correlation of factors, oblique rotation (promax) was performed. After rotation, communalities $\left(h^{2}\right)$ were examined using criterion of the number of variables is $<30$ and the communalities are $>0.70$, or $\mathrm{N}>250$ and the mean communality is $>=0.60$ (Mertler \& Reinhart, 2016). Communalities refer to the proportion of an item's variance that can be explained by the factors. A larger communality score is better because it indicates the item is closer to measuring the construct (Gorsuch, 1983; Pituch \& Stevens, 2016). Three criteria were used to determine how many components should be retained: (1) eigenvalues are greater than 1 (Kaiser, 1960), (2) the scree test (Cattell, 1966), and (3) parallel analysis (Horn, 1965). First, only the factors with eigenvalues greater 1 are considered significant and any individual factor should account for the variance of at least a single item (variable) if it is to be retained for interpretation (Kaiser, 1960). The scree plot determined a sharp drop and retains factors that lie above the elbow (before the first on the line where they start to level off) (Cattell, 1966). It matched with the observation derived from the Total Variance Explained. The parallel analysis was based on (a) the eigenvalues in the column table that are greater than the average eigenvalues in the PA column, and (b) the dashed line in the graph crosses the solid the raw data line before reaching the specific component (Horn, 1965).

The results of the rotation will be interpreted based on structure and pattern coefficients (loadings) of unique relationship (uncontaminated by overlap among factors) between each factor and each item. Costello and Osborne (2005) suggested that the "cleanest" factor structure included item loadings above .40 , no or few item cross 
loadings, no factors with fewer than three items may adequately fit to the data (p.3). In addition, Cronbach's alpha was calculated to measure the strength of internal consistency of each factor based on the items that contributed over 0.4 loading to the factors. The Cronbach's alpha coefficient obtained for the internal consistency reliability of a group of items (predictor variable) uses a recommended score at or above .70 as the cut-off (Nunnally \& Bernstein, 1994).

The Principal Component Analysis (PCA) was conducted to determine the items of sport satisfaction, sport identity, sport commitment and life satisfaction and account for most of the variance of an instrument. Prior to PCA, the Kaiser-Meyer-Olkin (KMO) measure of sampling adequacy and Bartlett's test of sphericity were performed to ensure that the data were appropriate for the PCA analysis. Next, based on assumption of correlation of factors, oblique rotation was performed. Three criteria were used to determine how many components should be able to retain: (1) eigenvalues are greater than 1 (Kaiser, 1960), (2) the scree test (Cattell, 1966), and (3) parallel analysis (Horn, 1965). The results of principal axis factoring with oblique rotation were based on the structure and pattern coefficients (loadings). In addition, Cronbach's alpha was calculated to measure the strength of internal consistency of each factor based on the items that contributed over 0.4 loading to the factors.

\section{Correlation Analysis}

Correlation analysis was obtained to examine the interrelationships among the major variables, which include antecedents of sport commitment, sport commitment, sport satisfaction, sport identity and life satisfaction. Pearson correlation coefficients were computed to present the values of the strength of relationship among variables. The 
closer the correlation coefficients $(r)$ are to +1.0 and -1.0 , the greater the strength of the relationship between the variables (Goodwin \& Leech, 2003). The correlation matrix determined multicollinearity problematic among predictor variables (interrelations were greater than .80) (Pituch \& Stevens, 2016).

\section{Hierarchical Multiple Regression}

Prior to the hierarchical multiple regression analyses, general rules and a specific set of model assumptions (e.g., linear relationship, normality, no auto-correlation, homoscedasticity), and multicollinearity (e.g., Tolerance or Variance Inflation Factor) must be met for the statistical test for the data.

In the first set of analyses, a three-stage hierarchical multiple regression analysis was performed to determine significant and positive or negative predictors of sport commitment sequentially from the following reasons for committing to the sport activity: sport enjoyment, involvement alternatives, involvement opportunities, personal investments, social constraints, social support, sport satisfaction, and sport identity (Figure. 1, in Chapter 1). With sport commitment as the dependent variable, six antecedents (sport enjoyment, involvement opportunities, personal investments, involvement alternatives, social constraints and social support) were entered into the equation in the first block in order to examine the applicability of the initial SCM to the sample of older adults. Sport satisfaction was entered at the second block based on the Exercise Commitment Model (ECM). Wilson et al. (2004) replaced Scanlan's (1993) sport enjoyment construct with the satisfaction construct in the ECM. This ECM determined that satisfaction was one of the strongest predictors of exercise commitment. This study employed sport satisfaction as a distinct construct which separated from other 
original constructs of the SCM. In the last block, sport identity was added as a new variable to examine the statistical significance of the variable and improvement of the regression model after controlling all other variables.

In the first block, the regression model-data fit and the statistical relationship of each independent variable (Independent Variable [IV]: six antecedents) to the dependent variable (Dependent Variable [DV]: sport commitment) were determined by the $F$-test and $p$-value. To measure the effect size, the practical significance of the model was identified by $R^{2}$, which explained the amount of variance accounted for by the combination of independent variables in the model. The Cohen's guidelines for reporting $R^{2}$ are as follows: small (0.02), moderate (0.13) and large (0.26; Cohen, 1988). In each

block, the change in $R^{2}\left(\Delta R^{2}\right)$ indicated whether sport satisfaction and sport identity were important and significant predictors of sport commitment. The change in $R^{2}$ adj also was used to test statistical significance of the variables in the regression models. In order to address three research questions and determine important and significant predictors among the independent variables, the statistical significance of each predictor variable was determined by standard regression coefficients ( 6$)$ and $t$-tests of the beta weights along with standard errors, $t$-statistics, and $p$-value.

\section{Multiple Regression Analysis}

In the second set of analyses, multiple regression analysis was carried out to address the second research question that the combination of independent variables, including sport identity, sport satisfaction, and sport commitment, significantly and positively predicted older adults' level of life satisfaction (Figure. 2, in Chapter 1). The regression model-data fit and the statistical relationship of combination of independent 
variables to the dependent variable (DV: life satisfaction) were determined by the $F$-test and $p$-value. To measure the effect size, the practical significance of the model was identified by $R^{2}$. In order to test the research hypotheses and determine important and significant predictors among the independent variables, statistical significance of each predictor variable was determined by the regression coefficients and $t$-tests of the beta weights along with standard errors, $t$-statistics, and $p$-value. To address the three specific questions (2a, 2b, and $2 \mathrm{c})$ and test the research hypotheses (2a, 2b, and $2 \mathrm{c})$ that how each independent variable, including sport identity, sport satisfaction, and sport commitment, positively and uniquely relate to older adults' level of life satisfaction, squared semipartial correlation coefficients $\left(s r^{2}\right)$ was determined.

For the overall statistical data analyses, the alpha level of 0.05 (95\% confidence level) was used as the accepted level of significance for the study and a series steps of analyses were conducted using the latest version of IBM Statistical Package for the Social Sciences (SPSS) for windows.

In sum, this chapter described the research method employed to address the research questions and proposed hypotheses. The next chapter, Chapter IV, will demonstrate the methodology presented in Chapter III and describe the results of obtained data and statistical analyses. 


\section{CHAPTER IV}

\section{RESULTS}

This results chapter provides the following specific sections: (a) two overarching research questions (with specific questions); (b) pretest; (c) demographic characteristics of the sample; (d) results of first research question including principal component analysis with oblique rotation method, descriptive statistics, correlation analysis, and a three stage hierarchical multiple regression analysis; and (e) results of second research question including factor analysis with oblique rotation method, descriptive statistics, correlation analysis, and simultaneous multiple regression.

This chapter contains the results of the data collection and data analyses to address two overarching research questions (with specific questions) of this study as follows:

RQ1. Do the antecedent factors (i.e., sport enjoyment, involvement opportunities, personal investments, involvement alternatives, social constraints, and social support), sport satisfaction, and sport identity predict the level of sport commitment toward organized sport activity for older adults? Specifically:

1a. Which of the antecedent factors are the strongest predictors of older adults' sport commitment toward organized sport activity?

1b. Does sport satisfaction explain a significant incremental variance in sport commitment over and above the six antecedent factors among older adults? 
1c. Does sport identity explain a significant incremental variance in sport commitment over and above the seven antecedent factors including sport satisfaction among older adults?

In the first purpose, the following hypothesizes are proposed:

Hypothesis 1a: Sport enjoyment, involvement opportunities, personal investments, social constraints, and social support positively predict sport commitment, and involvement alternative negatively predicts sport commitment.

Hypothesis $1 \mathrm{~b}$ : Sport satisfaction positively predicts sport commitment. Hypothesis 1c: Sport identity positively predicts sport commitment.

RQ2. Is there a significant relationship between the level of life satisfaction and sport satisfaction, sport identity, and sport commitment among older adults who participate in organized sport activity regularly? Specifically:

2a. Is sport satisfaction significantly related to older adults' level of life satisfaction?

$2 \mathrm{~b}$. Is sport identity significantly related to older adults' level of life satisfaction?

2c. Is sport commitment significantly related to older adults' level of life satisfaction?

Based on the second research questions, three hypotheses were examined as follows:

Hypothesis 2a: Sport satisfaction positively and uniquely relates to older adults' level of life satisfaction.

Hypothesis $2 \mathrm{~b}$ : Sport identity positively and uniquely relates to older adults' level of life satisfaction. 
Hypothesis 2c: Sport commitment positively and uniquely relates to older adults' level of life satisfaction.

\section{Pretest}

Prior to the pilot test, a panel of experts reviewed the survey instrument. Based on the expert panel's suggestions, minor modifications were made to assess the content validity of the instrument. An initial set of 15 participants were selected to conduct the pilot test. The average age of 13 respondents was 64 years old and 10 respondents were male. The majority of respondents were Caucasian/White $(N=13)$ and 14 respondents played tennis as an organized sport activity. Eleven respondents were not retired yet. The demographic characteristics for the pilot test are presented in Table 3.

\section{Table 3}

The Pilot Test's Demographics Characteristics

\begin{tabular}{llc}
\hline & Classification & $n$ \\
\hline Sport Type & Tennis & 14 \\
& Water Fitness & 1 \\
Gender & Female & 5 \\
& Male & 10 \\
Age & $55-59$ & 4 \\
& $60-64$ & 5 \\
& $65-69$ & 1 \\
& $70-74$ & 2 \\
& $75-79$ & 1 \\
Ethnicity & Prefer not to answer & 2 \\
& & \\
& African-American/Black & 1 \\
& Caucasian/White & 13 \\
Retired & Hispanic & 1 \\
& Yes & 3 \\
& No & 11 \\
\hline
\end{tabular}


Note. $N=15$

This group was also asked to provide feedback on the readability, completability, and face validity of the survey instrument. Their feedback indicated no major concerns but spelling errors were detected and yearly spending categories were minimized. The reliability of each construct was reviewed by the score of Cronbach's alpha. The pilot test responses were excluded from the data analyses of the main study. The results are reported in Table 4.

\section{Table 4}

Reliability Statistics

\begin{tabular}{lcc}
\hline \multicolumn{1}{c}{ Variable } & Items \# & Cronbach's Alpha \\
\hline Dependent Variable & 5 & .78 \\
Life Satisfaction & 6 & .68 \\
Sport Commitment & 6 & \\
Independent Variable (Sport Commitment Model) & .89 \\
Sport Enjoyment & 6 & .82 \\
Social Support & 4 & .89 \\
Social Constraints & 5 & .86 \\
Involvement Alternatives & 5 & .87 \\
Personal Investments & 4 & .77 \\
Involvement Opportunities & 6 & .81 \\
Additional Independent Variable & & .96 \\
Sport Identity & 4 & \\
Sport Satisfaction & 3 & \\
\hline
\end{tabular}

Note. $N=15$ 


\section{Demographic Characteristics of the Sample}

The paper-based questionnaires were directly distributed in person at the research sites. The paper-based questionnaires were either returned directly to the researcher or by mail, or sent electronically via email based by the participants' requests or preferences. A total of 705 questionnaires were distributed at 13 different locations (e.g., indoor tennis courts, community centers). Of these, 399 questionnaires were returned (56\%). Of the returned surveys, 111 surveys were excluded due to respondents not meeting the age criterion (under 55 years old). Additionally, 12 incomplete surveys were also excluded. Overall, a total of 276 surveys were usable and this number exceeded the minimum threshold of the sample size for the data analysis. In general, about 15 subjects per predictor will be needed for multiple regression analysis (e.g., with 9 predictors, 135 subjects are needed) and the minimal sample size of 200 are needed for factor analysis (Pituch \& Stevens, 2016). The average age of the respondents was 68 years old ( $M$ $=67.6, S D=7.44)$. A total of 149 respondents were male $(54 \%)$ and $74 \%$ of respondents were married or had a partner. The majority of respondents were Caucasian/White $(82 \%)$ and retired (67\%). For annual household income, 56\% of respondents reported an annual household income greater than $\$ 50,000$. The sample demographics are presented in Table 5.

Table 5

Sample Demographics

\begin{tabular}{llcc}
\hline & Classification & Frequency $(n)$ & Percent $(\%)$ \\
\hline Gender & Female & 122 & 44.2 \\
& Male & 149 & 54.0 \\
& Prefer not to answer & 2 & 0.7
\end{tabular}


Missing

Age

55-59

60-64

65-69

70-74

75-79

80-84

85-90

Prefer not to answer

Marital

Ethnicity

Retired

(Annual)
Single

Married/Partner

Divorced

Widowed

Other

Prefer not to answer

Missing

African-American/Black

Caucasian/White

Asian

Hispanic

Other

Prefer not to answer

Missing

Yes

No

Other

Missing

Less than $\$ 29,999$

$\$ 30,000-\$ 49,999$

$\$ 50,000-\$ 79,999$

$\$ 80,000-\$ 99,999$

$\$ 100,000$ and more

Prefer not to answer

Missing
3

1.1

41

14.9

49

17.8

55

19.9

70

25.4

21

7.6

4.0

2.2

8.3

23

15

5.4

74.3

205

8.3

23

23

8.3

0.4

2.9

0.4

1

16

5.8

238

86.2

5

1.8

0.7

2.9

2.2

0.4

187

67.8

87

29.7

2.2

0.4

6

19

6.9

$43 \quad 15.6$

$42 \quad 15.2$

$\begin{array}{ll}35 & 12.7\end{array}$

$78 \quad 28.3$

$58 \quad 21.0$

$1 \quad 0.4$

Note. $N=276$ 
Among the 276 respondents, $43 \%$ played tennis as an organized sport activity. The majority of respondents were influenced by significant others (e.g., family, peers, and friends) to participate in organized sport activities (64\%) and had participated in organized sport activities for more than 10 years (64\%). Of these, $48 \%$ of respondents participated in organized sport activities once or twice per week and $47 \%$ of respondents participated in organized sport activities three to five times per week. Only $7 \%$ of respondents paid no fees for membership or participation. Complete organized sport activity involvement profiles are reported in Table 6 .

\section{Table 6}

Organized Sport Activity Involvement

\begin{tabular}{llcc}
\hline & Classification & Frequency $(n)$ & Percent (\%) \\
\hline Sport Type & Tennis & 119 & 43.1 \\
& Bowling & 64 & 23.2 \\
& Indoor softball & 39 & 14.1 \\
& Water fitness & 14 & 5.1 \\
& Fitness Program & 14 & 5.1 \\
& Pickleball & 9 & 3.3 \\
Swimming & 6 & 2.2 \\
& Basketball & 4 & 1.4 \\
& Cycling & 2 & 0.7 \\
Golf & 2 & 0.7 \\
& Volleyball & 1 & 0.4 \\
& Dancing & 1 & 0.4 \\
Rock Steady Boxing & 1 & 0.4 \\
Influenced by & & & \\
(First Participation) & Family & 67 & 24.3 \\
& Peers & 61 & 22.1 \\
& Friends & 48 & 17.4 \\
& Health / Fitness & 33 & 12.0 \\
& Fun / Interested in sport & 28 & 10.1 \\
& Prior experience / Career & 14 & 5.1 \\
& Retirement / Social & 11 & 4.0 \\
& Advertisement & 3 & 1.1 \\
Weekly Participation: & Myself & 2 & 0.7 \\
per week & Medical Doctor & 1 & 0.4 \\
& Other & 8 & 2.9 \\
& 1-2 Time(s) & 131 & 47.5 \\
3-5 & 129 & 46.7 \\
& & &
\end{tabular}




\begin{tabular}{llcc} 
& $6-7$ & 13 & 4.7 \\
& 8 and more & 2 & 0.7 \\
& Missing & 1 & 0.4 \\
Participation Length: & Less than a year & 9 & 3.3 \\
year (s) & $1-3$ & 34 & 12.3 \\
& $4-6$ & 31 & 11.2 \\
& $7-9$ & 11 & 4.0 \\
& $10-19$ & 52 & 18.8 \\
& $20-29$ & 37 & 13.4 \\
& $30-39$ & 26 & 9.4 \\
& $40-49$ & 36 & 13.0 \\
& 50 and more & 38 & 13.8 \\
Missing & 2 & 0.7 \\
Membership and/or & No Fee & & \\
Participation Fee(s) & Less than \$99.99 & 19 & 6.9 \\
Annually & \$100.00-\$49.99 & 25 & 9.1 \\
& \$500.00-\$999.99 & 69 & 25.0 \\
& \$1000.00-\$499.99 & 70 & 25.4 \\
& \$5000.00 and more & 66 & 23.9 \\
& Too Much & 6 & 2.2 \\
& Missing & 2 & 0.7 \\
& & 19 & 6.9 \\
\hline
\end{tabular}

Note. $N=276$

\section{First Research Question}

To assess the first research question along with the three specific questions above, a three stage hierarchical multiple regression analysis was conducted. This section starts with descriptive statistics of each item, reviewing the mean, standard deviation, and assumption of normality. Second, a series of principal component extractions and oblique rotation method were conducted to determine the applicability of SCM measures based on the factor structure of the SCM obtained from a sample of senior population. Third, descriptive statistics of constructs and correlation analysis were conducted. Lastly, a three stage hierarchical multiple regression analysis was conducted.

Prior to the factor analysis, measures of central tendency (e.g., mean) and variability (standard deviation) and normality (using measure of Skewness and Kurtosis) were examined for 43 items from the sport commitment questionnaire (36 items) and two 
adapted measures of sport satisfaction (three items) and sport identity (four items). All items were normally distributed except three items (ENJ_1, ENJ_4 and SAT_1) for which the skewness was greater than 3 and Kurtosis was greater than 10 (Kline, 2016). Two items (ENJ_1 and ENJ_4) of the sport enjoyment scale were eliminated from the factor analysis. The item (SAT_1) from the sport satisfaction scale was retained to maintain three items in the factor (Costello \& Osborne, 2005). Means, standard deviation, skewness, and kurtosis are reported in Table 7.

\section{Table 7}

Descriptive statistics of each item: Mean, SD, and Skewness and Kurtosis

\begin{tabular}{|c|c|c|c|c|c|}
\hline Code & Item & Mean & $\begin{array}{c}\text { Std. } \\
\text { Deviation }\end{array}$ & Skewness & Kurtosis \\
\hline \multicolumn{6}{|c|}{ Sport commitment (COMMIT) } \\
\hline COMMIT_1 & $\begin{array}{l}\text { How dedicated are you to participate } \\
\text { in this sport activity? }\end{array}$ & 4.70 & 0.51 & -1.43 & 1.11 \\
\hline COMMIT_2 & $\begin{array}{l}\text { What would you be willing to do to be } \\
\text { able to keep participating in this sport } \\
\text { activity? }\end{array}$ & 4.55 & 0.68 & -1.63 & 3.15 \\
\hline COMMIT_3 & $\begin{array}{l}\text { How determined are you to continue } \\
\text { participating in this sport activity? }\end{array}$ & 4.71 & 0.61 & -2.51 & 7.81 \\
\hline COMMIT_4 & $\begin{array}{l}\text { Do you want to keep participating in } \\
\text { this sport activity? }\end{array}$ & 4.84 & 0.45 & -2.99 & 8.27 \\
\hline COMMIT_5 & $\begin{array}{l}\text { How proud are you to tell other people } \\
\text { that you participate in this sport } \\
\text { activity? }\end{array}$ & 4.57 & 0.73 & -1.71 & 2.64 \\
\hline COMMIT_6 & $\begin{array}{l}\text { How hard would it be to quit this sport } \\
\text { activity? }\end{array}$ & 4.45 & 0.94 & -1.87 & 3.15 \\
\hline \multicolumn{6}{|c|}{ Sport enjoyment $(\mathrm{ENJ})$} \\
\hline ENJ 1 & I enjoy playing this sport activity. & 4.86 & 0.42 & -3.37 & 13.15 \\
\hline ENJ_2 & I love to play this sport activity. & 4.73 & 0.61 & -2.79 & 9.23 \\
\hline ENJ_3 & I like playing this sport activity. & 4.80 & 0.50 & -2.75 & 7.53 \\
\hline ENJ_4 & Playing this sport activity is fun. & 4.83 & 0.49 & -3.65 & 17.43 \\
\hline ENJ_5 & $\begin{array}{l}\text { Playing this sport activity makes me } \\
\text { happy. }\end{array}$ & 4.64 & 0.69 & -2.05 & 4.29 \\
\hline ENJ_6 & $\begin{array}{l}\text { Playing this sport activity is very } \\
\text { pleasurable. }\end{array}$ & 4.68 & 0.63 & -2.14 & 5.17 \\
\hline
\end{tabular}


I would miss being considered an

\begin{tabular}{|c|c|c|c|c|c|}
\hline OPP_1 & $\begin{array}{l}\text { athlete (e.g., golfer) if I quit this sport } \\
\text { activity. }\end{array}$ & 3.91 & 1.28 & -0.88 & -0.37 \\
\hline OPP_2 & $\begin{array}{l}\text { I would miss the people that I have } \\
\text { met if I quit this sport activity. }\end{array}$ & 4.70 & 0.61 & -2.19 & 4.57 \\
\hline OPP_3 & $\begin{array}{l}\text { I would miss the good times that I had } \\
\text { if I quit this sport activity. }\end{array}$ & 4.68 & 0.69 & -2.74 & 9.06 \\
\hline OPP_4 & $\begin{array}{l}\text { This sport activity gives me the } \\
\text { opportunity to relieve any stress I am } \\
\text { feeling. }\end{array}$ & 4.26 & 1.01 & -1.40 & 1.52 \\
\hline OPP_5 & $\begin{array}{l}\text { This sport activity gives me the } \\
\text { opportunity to improve my health and } \\
\text { fitness. }\end{array}$ & 4.68 & 0.61 & -1.75 & 1.83 \\
\hline OPP_6 & $\begin{array}{l}\text { This sport activity gives me the } \\
\text { opportunity to improve my physical } \\
\text { skills. }\end{array}$ & 4.46 & 0.82 & -1.44 & 1.41 \\
\hline \multicolumn{6}{|c|}{ Personal investments (INV) } \\
\hline INV_1 & $\begin{array}{l}\text { I have invested a lot of effort into this } \\
\text { sport activity. }\end{array}$ & 4.35 & 0.98 & -1.55 & 1.86 \\
\hline INV_2 & $\begin{array}{l}\text { I have invested a lot of energy into this } \\
\text { sport activity. }\end{array}$ & 4.45 & 0.83 & -1.46 & 1.74 \\
\hline INV_3 & $\begin{array}{l}\text { I have invested a lot of time into this } \\
\text { sport activity. }\end{array}$ & 4.36 & 0.97 & -1.53 & 1.74 \\
\hline INV_4 & $\begin{array}{l}\text { I have invested a lot of my own money } \\
\text { into this sport activity. }\end{array}$ & 3.80 & 1.41 & -0.79 & -0.76 \\
\hline \multicolumn{6}{|c|}{ Social support (SUP) } \\
\hline SUP_1 & $\begin{array}{l}\text { People say things to make me feel } \\
\text { good about participation in this sport } \\
\text { activity. }\end{array}$ & 3.91 & 1.10 & -0.76 & -0.11 \\
\hline SUP_2 & $\begin{array}{l}\text { Other people encourage me to } \\
\text { participate in this sport activity. } \\
\text { Significant others (e.g., family or }\end{array}$ & 3.23 & 1.30 & -0.23 & -0.98 \\
\hline SUP_3 & $\begin{array}{l}\text { friends) say things to keep me } \\
\text { participating in this sport activity. }\end{array}$ & 3.03 & 1.43 & -0.10 & -1.26 \\
\hline SUP_4 & $\begin{array}{l}\text { I feel that I receive support from } \\
\text { significant others (e.g., family or } \\
\text { friends) about this sport activity. }\end{array}$ & 3.79 & 1.16 & -0.68 & -0.46 \\
\hline \multicolumn{6}{|c|}{ Social constraints (SOC) } \\
\hline SOC_1 & $\begin{array}{l}\text { I feel pressure from other people to } \\
\text { participate in this sport activity. }\end{array}$ & 1.66 & 1.03 & 1.58 & 1.80 \\
\hline SOC_2 & $\begin{array}{l}\text { I have to keep participating in this } \\
\text { sport activity to please others. }\end{array}$ & 1.62 & 1.07 & 1.87 & 2.82 \\
\hline SOC_3 & $\begin{array}{l}\text { People will be disappointed with me if } \\
\text { I quit this sport activity. }\end{array}$ & 2.77 & 1.37 & 0.24 & -1.14 \\
\hline SOC_4 & $\begin{array}{l}\text { I feel that I have to participate in this } \\
\text { sport activity to be with my friends. }\end{array}$ & 2.67 & 1.28 & 0.25 & -0.90 \\
\hline SOC_5 & $\begin{array}{l}\text { I feel that I have to participate in this } \\
\text { sport activity more for my }\end{array}$ & 1.50 & 1.00 & 2.22 & 4.30 \\
\hline
\end{tabular}


friends/spouse than for myself.

Involvement alternatives (ALT)

Compared to participating in this sport

\begin{tabular}{|c|c|c|c|c|c|}
\hline $\mathrm{ALT}_{-} 1$ & $\begin{array}{l}\text { activity, there are other things I could } \\
\text { do which would be more fun. }\end{array}$ & 2.40 & 1.11 & 0.41 & -0.55 \\
\hline ALT_2 & $\begin{array}{l}\text { Compared to participating in this sport } \\
\text { activity, there are other things I could } \\
\text { do which would be more enjoyable. }\end{array}$ & 2.21 & 1.11 & 0.64 & -0.35 \\
\hline ALT_3 & $\begin{array}{l}\text { Compared to participating in this sport } \\
\text { activity, there are other things I could } \\
\text { do which would be more worthwhile. } \\
\text { I would be happier doing something }\end{array}$ & 2.31 & 1.13 & 0.44 & -0.73 \\
\hline $\mathrm{ALT}_{-} 4$ & $\begin{array}{l}\text { else instead of participating in this } \\
\text { sport activity. }\end{array}$ & 1.60 & 0.87 & 1.46 & 1.65 \\
\hline $\mathrm{ALT}_{2} 5$ & $\begin{array}{l}\text { I would like to do something else } \\
\text { instead of participating in this sport } \\
\text { activity. }\end{array}$ & 1.49 & 0.86 & 1.73 & 2.18 \\
\hline \multicolumn{6}{|c|}{ Sport identity (SID) } \\
\hline SID_1 & $\begin{array}{l}\text { In general, this sport activity is an } \\
\text { important part of my self-image. }\end{array}$ & 3.60 & 1.19 & -0.46 & -0.61 \\
\hline SID_2 & $\begin{array}{l}\text { This sport activity is important to my } \\
\text { sense of what kind of a person I am. }\end{array}$ & 3.34 & 1.26 & -0.25 & -0.86 \\
\hline SID_3 & $\begin{array}{l}\text { This sport activity is an important } \\
\text { reflection of who I am. }\end{array}$ & 3.24 & 1.27 & -0.15 & -0.92 \\
\hline SID_4 & $\begin{array}{l}\text { Overall, this sport activity has little to } \\
\text { do with how I feel about myself. (R) }\end{array}$ & 3.05 & 1.38 & -0.07 & -1.16 \\
\hline \multicolumn{6}{|c|}{ Sport satisfaction (SAT) } \\
\hline $\mathrm{SAT}_{-} 1$ & $\begin{array}{l}\text { Overall, I am satisfied with my } \\
\text { decision to participate in this sport } \\
\text { activity. }\end{array}$ & 4.79 & 0.53 & -3.03 & 11.66 \\
\hline SAT_2 & $\begin{array}{l}\text { I think I did the right thing by deciding } \\
\text { to participate in this sport activity. }\end{array}$ & 4.74 & 0.59 & -2.49 & 6.14 \\
\hline SAT_3 & $\begin{array}{l}\text { My choice to participate in this sport } \\
\text { activity is a wise one. }\end{array}$ & 4.74 & 0.57 & -2.71 & 9.24 \\
\hline
\end{tabular}

\section{Principal Component Analysis}

For the factor extraction, principal component analysis (PCA) was conducted with 41 items used to make a decision about the number of factors underlying a set of items (Green \& Salkind, 2013). The Kaiser-Meyer-Olkin (KMO) measure of sampling adequacy was 0.88 (which was greater than 0.70 ; Kaiser, 1974), indicating that the 
present data was suitable for the analysis. The Bartlett's test of sphericity was significant (approximate chi square $=6105.41, p<0.001$ ), indicating that there was a sufficient amount of correlation among variables to proceed with the factor analysis. Communalities after extraction ranged from a low of $h^{2}=0.45$ (OPP_1) to a high of $h^{2}=$ 0.86 (SID_2). Based on an eigenvalue greater than 1 criterion, the initial 10 factors explained $67.20 \%$ of the total variance which accounts for satisfactory (Hair et al., 2006).

The oblique rotation (promax) was performed based on the assumption that the underlying factors will be correlated. A previous study using a sample of tennis players indicated that all variables were intercorrelated (Casper \& Stellino, 2008). After rotation, 41 items with structure and pattern coefficient of 0.40 or greater loaded significantly onto their respective factors, except four items. These four items were problematic in that three items (OPP_1, OPP_2, and OPP_3) from the involvement opportunities scale was loaded onto the sport enjoyment factor and the loading was lower than 0.40 . In addition, the one item (SOC_3) from the social constraints scale loaded onto the social support factor. A previous study indicated that the involvement opportunities factor was uninterpretable due to aberrant loadings associated with the involvement opportunities items on other factors (e.g., social support and satisfaction) in the exercise commitment model (Wilson et al., 2004). This study also indicated that these items did not meet the simple structure and exhibited factor interpretability (Thurstone, 1947). Therefore, these items were removed one by one and the principal component analysis (PCA) was rerun using the promax rotation method to enhance factors' interpretability to the sample of older adults and be acceptable in both theoretical and empirical standpoints in line with the SCM literature (Park, Yoh, \& Park, 2015; Thurstone, 1947; Wilson et al., 2004). 
The Kaiser-Meyer-Olkin (KMO) measure of sampling adequacy was 0.87 and the Bartlett's test of sphericity was significant (approximate chi square $=5561.14, p<$ 0.001). Communalities after extraction ranged from a low of $h^{2}=0.53$ (SUP_4) to a high of $h^{2}=0.83$ (SID_3). Based on an eigenvalue greater than 1 criterion, the nine factors emerged with 37 items explaining $67.40 \%$ of the total variance. Additionally, a parallel analysis was conducted to determine how many components to retain, and the result indicated that nine components should be retained. Nine of the eigenvalues in the PCA column are greater than 1 and the dashed line for parallel analysis in the graph reaching the nine components was based on an eigenvalue greater than 1 criterion (see Appendix C)

After applying the promax rotation, 37 items with structure and pattern coefficient of 0.40 or greater loaded significantly onto their respective factors as follows: sport commitment (6 items), sport enjoyment (4 items), involvement alternatives (5 items), involvement opportunities ( 3 items), personal investments ( 4 items), social constraints (4 items), social support (4 items), sport satisfaction (3 items), and sport identity (4 items). All items loaded on their respective factors. It is important to note that the results of the PCA, social related benefits items (OPP_1, OPP_2, and OPP_3) in involvement opportunities were eliminated due to the above-mentioned aberrant loadings (OPP_1, OPP_2, and OPP_3). Therefore, involvement opportunities represented the construct that specifically related to health benefits (e.g., this sport activity gives me the opportunity to improve my health and fitness) as valuable opportunities present only through continued involvement in organized sport activity (Scanlan et al., 1993). In addition, Cronbach's alpha, which measures how a set of items closely associated as a group, was calculated to 
measure the strength of internal consistency, or reliability, of each factor based on a set of items that contributed over 0.40 loading to the factors. Except for involvement opportunities scale $(\alpha=0.69)$, all factors' Cronbach's alpha were greater than 0.70 which are acceptable internal consistency of scales (Nunnally \& Bernstein, 1994). This study kept the involvement opportunities scale because a score just slightly below 0.70 score is considered to be acceptable if not below 0.65 (Hair, et al., 2006). The results of factor loading (structure and pattern coefficients), communities, and Cronbach's alpha are represented in Table 8 and Table 9.

\section{Table 8}

Results of the Pattern Coefficients, Communities, and Cronbach's alpha

\begin{tabular}{|c|c|c|c|c|c|c|c|c|c|c|}
\hline Item & COMMIT & ALT & INV & SUP & SID & ENJ & SAT & SOC & OPP & $h^{2}$ \\
\hline COMMIT_3 & 0.92 & 0.05 & 0.02 & -0.04 & -0.07 & -0.08 & 0.10 & 0.01 & -0.05 & 0.76 \\
\hline COMMIT_2 & 0.82 & -0.09 & 0.14 & 0.01 & -0.04 & -0.07 & -0.09 & 0.00 & 0.02 & 0.71 \\
\hline COMMIT_4 & 0.73 & 0.07 & -0.09 & -0.05 & 0.05 & 0.11 & 0.28 & -0.03 & -0.16 & 0.69 \\
\hline COMMIT_1 & 0.69 & 0.10 & 0.19 & 0.00 & 0.10 & 0.04 & 0.01 & -0.07 & -0.19 & 0.58 \\
\hline COMMIT_6 & 0.62 & -0.04 & 0.03 & 0.00 & -0.10 & 0.26 & -0.06 & 0.02 & 0.01 & 0.54 \\
\hline COMMIT_5 & 0.54 & -0.03 & -0.37 & 0.18 & 0.25 & 0.08 & -0.16 & -0.04 & 0.13 & 0.52 \\
\hline ALT_2 & 0.14 & 0.80 & -0.06 & 0.04 & -0.11 & -0.05 & 0.01 & 0.00 & -0.03 & 0.66 \\
\hline $\mathrm{ALT}_{-} 1$ & -0.09 & 0.80 & 0.02 & 0.05 & 0.03 & -0.17 & 0.06 & -0.22 & 0.15 & 0.62 \\
\hline ALT_3 & -0.06 & 0.74 & 0.10 & -0.10 & -0.14 & -0.03 & 0.06 & 0.06 & 0.15 & 0.56 \\
\hline ALT_4 & 0.02 & 0.66 & 0.03 & -0.15 & -0.02 & 0.01 & -0.03 & 0.23 & -0.03 & 0.59 \\
\hline ALT_5 & 0.07 & 0.63 & -0.01 & -0.12 & 0.10 & 0.01 & -0.12 & 0.27 & -0.05 & 0.63 \\
\hline INV_3 & -0.03 & 0.07 & 0.85 & 0.08 & 0.04 & 0.10 & 0.02 & -0.09 & -0.03 & 0.81 \\
\hline INV_4 & 0.05 & -0.08 & 0.84 & -0.09 & 0.01 & -0.07 & -0.05 & 0.25 & -0.15 & 0.69 \\
\hline INV_1 & 0.09 & 0.03 & 0.71 & 0.07 & 0.09 & 0.16 & -0.06 & 0.01 & 0.02 & 0.81 \\
\hline INV_2 & 0.00 & 0.09 & 0.67 & 0.11 & 0.06 & 0.06 & -0.03 & -0.13 & 0.17 & 0.71 \\
\hline SUP_3 & 0.05 & -0.08 & 0.07 & 0.84 & -0.08 & -0.19 & -0.01 & 0.15 & -0.06 & 0.71 \\
\hline SUP_2 & -0.10 & -0.07 & -0.02 & 0.75 & 0.05 & 0.00 & 0.05 & 0.13 & -0.10 & 0.59 \\
\hline SUP_4 & 0.06 & -0.08 & 0.17 & 0.68 & -0.13 & -0.28 & 0.20 & -0.01 & 0.05 & 0.53 \\
\hline SUP_1 & 0.04 & -0.01 & -0.07 & 0.65 & 0.02 & 0.16 & -0.08 & 0.03 & 0.11 & 0.57 \\
\hline SID_2 & -0.02 & -0.08 & 0.03 & -0.02 & 0.87 & -0.10 & 0.07 & 0.11 & 0.14 & 0.85 \\
\hline SID_3 & 0.04 & -0.08 & 0.06 & -0.05 & 0.86 & -0.14 & 0.12 & 0.17 & 0.05 & 0.83 \\
\hline SID_1 & 0.07 & -0.06 & 0.09 & -0.09 & 0.73 & -0.03 & -0.01 & 0.23 & 0.16 & 0.77 \\
\hline SID_4 & -0.13 & 0.12 & 0.03 & 0.05 & 0.71 & 0.14 & -0.05 & -0.55 & -0.29 & 0.68 \\
\hline
\end{tabular}




\begin{tabular}{|c|c|c|c|c|c|c|c|c|c|c|}
\hline ENJ_2 & 0.16 & -0.06 & 0.03 & -0.14 & 0.03 & 0.80 & 0.01 & 0.00 & -0.02 & 0.79 \\
\hline ENJ_3 & -0.02 & -0.10 & 0.03 & -0.11 & -0.08 & 0.77 & 0.13 & 0.11 & 0.03 & 0.68 \\
\hline ENJ_6 & -0.06 & -0.03 & 0.08 & 0.04 & -0.08 & 0.74 & -0.01 & -0.04 & 0.27 & 0.77 \\
\hline ENJ_5 & 0.24 & 0.00 & 0.05 & -0.01 & -0.12 & 0.52 & 0.08 & 0.05 & 0.16 & 0.61 \\
\hline SAT_2 & -0.02 & -0.03 & -0.05 & 0.03 & 0.06 & 0.09 & 0.85 & 0.02 & 0.05 & 0.82 \\
\hline SAT_3 & 0.08 & 0.05 & -0.03 & 0.03 & 0.13 & -0.07 & 0.84 & -0.04 & 0.07 & 0.78 \\
\hline SAT_1 & 0.02 & 0.00 & 0.00 & 0.04 & -0.03 & 0.18 & 0.78 & -0.06 & -0.04 & 0.75 \\
\hline SOC_4 & 0.03 & -0.10 & 0.13 & -0.03 & 0.14 & -0.02 & -0.06 & 0.67 & 0.12 & 0.55 \\
\hline SOC_5 & 0.06 & 0.28 & -0.06 & 0.10 & 0.03 & -0.17 & 0.00 & 0.61 & 0.04 & 0.64 \\
\hline SOC_2 & -0.18 & 0.15 & -0.05 & 0.32 & 0.07 & 0.21 & 0.01 & 0.58 & -0.07 & 0.62 \\
\hline SOC_1 & -0.13 & 0.11 & 0.00 & 0.27 & 0.02 & 0.30 & 0.01 & 0.55 & -0.29 & 0.59 \\
\hline OPP 5 & -0.08 & 0.11 & -0.10 & -0.02 & 0.08 & 0.10 & 0.03 & 0.01 & 0.85 & 0.68 \\
\hline OPP_6 & -0.14 & 0.00 & 0.07 & -0.08 & 0.03 & 0.16 & 0.07 & 0.06 & 0.81 & 0.73 \\
\hline OPP_4 & 0.24 & 0.08 & 0.02 & 0.29 & 0.05 & 0.07 & -0.13 & -0.09 & 0.41 & 0.54 \\
\hline Eigenvalues & 9.59 & 4.57 & 2.26 & 1.98 & 1.64 & 1.44 & 1.23 & 1.15 & 1.08 & \\
\hline$\%$ of Variance & 25.91 & 12.36 & 6.12 & 5.36 & 4.43 & 3.88 & 3.33 & 3.11 & 2.92 & \\
\hline Cumulative \% & 25.91 & 38.26 & 44.38 & 49.74 & 54.17 & 58.05 & 61.38 & 64.49 & 67.41 & \\
\hline $\begin{array}{l}\text { Cronbach's } \\
\text { alpha }(\alpha)\end{array}$ & .82 & .81 & .84 & .75 & .81 & .87 & .87 & .74 & .69 & \\
\hline
\end{tabular}

Table 9

Results of Structure Coefficients

\begin{tabular}{lccccccccc}
\hline \multicolumn{1}{c}{ Item } & COMMIT & ALT & INV & SUP & SID & ENJ & SAT & SOC & OPP \\
\hline COMMIT_3 & $\mathbf{0 . 8 6}$ & -0.12 & 0.31 & 0.19 & 0.22 & 0.34 & 0.39 & 0.06 & 0.35 \\
COMMIT_2 & $\mathbf{0 . 8 2}$ & -0.22 & 0.44 & 0.26 & 0.29 & 0.36 & 0.25 & 0.05 & 0.43 \\
COMMIT_4 & $\mathbf{0 . 7 6}$ & -0.13 & 0.21 & 0.17 & 0.25 & 0.45 & 0.53 & -0.02 & 0.25 \\
COMMIT_1 & $\mathbf{0 . 7 2}$ & -0.04 & 0.43 & 0.25 & 0.37 & 0.39 & 0.26 & 0.03 & 0.26 \\
COMMIT_6 & $\mathbf{0 . 7 0}$ & -0.19 & 0.33 & 0.22 & 0.20 & 0.51 & 0.27 & 0.02 & 0.37 \\
COMMIT_5 & $\mathbf{0 . 5 8}$ & -0.11 & 0.06 & 0.39 & 0.42 & 0.32 & 0.09 & 0.05 & 0.34 \\
ALT_2 & -0.09 & $\mathbf{0 . 7 9}$ & -0.16 & 0.01 & -0.10 & -0.22 & -0.19 & 0.22 & -0.23 \\
ALT_1 & -0.20 & $\mathbf{0 . 7 4}$ & -0.08 & 0.00 & -0.01 & -0.27 & -0.17 & 0.01 & -0.09 \\
ALT_3 & -0.16 & $\mathbf{0 . 7 1}$ & -0.02 & -0.08 & -0.13 & -0.19 & -0.14 & 0.20 & -0.08 \\
ALT_4 & -0.15 & $\mathbf{0 . 7 3}$ & -0.08 & -0.09 & -0.05 & -0.21 & -0.25 & 0.37 & -0.23 \\
ALT_5 & -0.10 & $\mathbf{0 . 7 3}$ & -0.06 & 0.00 & 0.08 & -0.20 & -0.31 & 0.44 & -0.22 \\
INV_3 & 0.37 & -0.06 & $\mathbf{0 . 8 8}$ & 0.33 & 0.39 & 0.43 & 0.18 & 0.01 & 0.40 \\
INV_4 & 0.28 & -0.05 & $\mathbf{0 . 7 7}$ & 0.17 & 0.29 & 0.18 & 0.03 & 0.30 & 0.21 \\
INV_1 & 0.49 & -0.09 & $\mathbf{0 . 8 6}$ & 0.39 & 0.48 & 0.50 & 0.15 & 0.10 & 0.47 \\
INV_2 & 0.40 & -0.06 & $\mathbf{0 . 8 0}$ & 0.36 & 0.41 & 0.41 & 0.15 & -0.02 & 0.52
\end{tabular}




\begin{tabular}{llllllllll} 
SUP_3 & 0.20 & 0.02 & 0.22 & $\mathbf{0 . 8 0}$ & 0.27 & 0.05 & -0.01 & 0.35 & 0.15 \\
SUP_2 & 0.14 & 0.00 & 0.16 & $\mathbf{0 . 7 4}$ & 0.32 & 0.16 & 0.04 & 0.29 & 0.10 \\
SUP_4 & 0.28 & -0.10 & 0.30 & $\mathbf{0 . 6 5}$ & 0.21 & 0.08 & 0.22 & 0.14 & 0.29 \\
SUP_1 & 0.32 & -0.03 & 0.24 & $\mathbf{0 . 7 3}$ & 0.36 & 0.35 & 0.05 & 0.18 & 0.32 \\
SID_2 & 0.36 & -0.09 & 0.41 & 0.40 & $\mathbf{0 . 9 0}$ & 0.23 & 0.15 & 0.21 & 0.40 \\
SID_3 & 0.38 & -0.07 & 0.40 & 0.37 & $\mathbf{0 . 8 8}$ & 0.19 & 0.17 & 0.27 & 0.33 \\
SID_1 & 0.42 & -0.06 & 0.46 & 0.36 & $\mathbf{0 . 8 2}$ & 0.27 & 0.11 & 0.31 & 0.42 \\
SID_4 & 0.00 & 0.03 & 0.12 & 0.14 & $\mathbf{0 . 5 6}$ & 0.20 & -0.03 & -0.40 & -0.08 \\
ENJ_2 & 0.53 & -0.28 & 0.38 & 0.15 & 0.26 & $\mathbf{0 . 8 7}$ & 0.36 & -0.11 & 0.35 \\
ENJ_3 & 0.39 & -0.29 & 0.31 & 0.12 & 0.14 & $\mathbf{0 . 7 9}$ & 0.40 & -0.04 & 0.32 \\
ENJ_6 & 0.43 & -0.27 & 0.44 & 0.28 & 0.23 & $\mathbf{0 . 8 3}$ & 0.32 & -0.13 & 0.54 \\
ENJ_5 & 0.57 & -0.22 & 0.39 & 0.24 & 0.19 & $\mathbf{0 . 7 0}$ & 0.39 & -0.02 & 0.48 \\
SAT_2 & 0.39 & -0.28 & 0.18 & 0.14 & 0.16 & 0.41 & $\mathbf{0 . 8 9}$ & -0.09 & 0.34 \\
SAT_3 & 0.43 & -0.20 & 0.19 & 0.15 & 0.22 & 0.31 & $\mathbf{0 . 8 6}$ & -0.10 & 0.35 \\
SAT_1 & 0.38 & -0.26 & 0.18 & 0.11 & 0.08 & 0.45 & $\mathbf{0 . 8 5}$ & -0.17 & 0.27 \\
SOC_4 & 0.20 & 0.06 & 0.28 & 0.26 & 0.32 & 0.05 & -0.06 & $\mathbf{0 . 6 8}$ & 0.19 \\
SOC_5 & 0.01 & 0.47 & -0.02 & 0.24 & 0.13 & -0.23 & -0.18 & $\mathbf{0 . 7 3}$ & -0.07 \\
SOC_2 & 0.00 & 0.31 & 0.08 & 0.46 & 0.25 & 0.10 & -0.10 & $\mathbf{0 . 6 7}$ & -0.05 \\
SOC_1 & -0.01 & 0.28 & 0.05 & 0.38 & 0.18 & 0.14 & -0.10 & $\mathbf{0 . 6 3}$ & -0.20 \\
OPP_5 & 0.34 & -0.10 & 0.31 & 0.24 & 0.29 & 0.34 & 0.24 & -0.01 & $\mathbf{0 . 8 0}$ \\
OPP_6 & 0.37 & -0.22 & 0.45 & 0.20 & 0.27 & 0.42 & 0.31 & -0.02 & $\mathbf{0 . 8 3}$ \\
OPP_4 & 0.51 & -0.07 & 0.39 & 0.50 & 0.39 & 0.38 & 0.12 & 0.02 & $\mathbf{0 . 6 0}$ \\
\hline & & & & & & & &
\end{tabular}

\section{Descriptive Statistics and Correlation Analysis}

Table 9 represented the measures of central tendency (mean) and variability (standard deviation), skewness, and kurtosis of variables. For normality, measures of skewness $(<3)$ and kurtosis $(<10)$, which assess normality of sample distribution, supported a normal distribution (Kline, 2016). A correlation analysis determined that there was no discernable multicollinearity between the variables indicating interrelations were less than 0.80 among variables (Pituch \& Stevens, 2016). Most correlations were statistically significant. In particular, sport commitment (COMMIT) and sport enjoyment (ENJ) were strongly correlated, $r=0.60$, compared to other variables: personal investments (INV) $(r=.45, p<0.01)$, involvement opportunities (OPP) $(r=0.52, p<$ 
$0.01)$, and social support (SUP) $(r=0.31, p<0.01)$. In the association with involvement alternatives (ALT) and sport commitment $(r=-0.21, p<0.01)$, there was a negative correlation, but there was no correlation between social constraints (SOC) and sport commitment $(r=0.09, p>0.05)$. Additionally, sport satisfaction (SAT) $(r=0.46, p<$ $0.01)$ and sport identity (SID) $(r=0.38, p<0.01)$ were also positively related with sport commitment. Overall, all of the assumptions regarding independence, normality, multicollinearity were met for the current study. A summary correlation matrix is presented in Table 10

\section{Table 10}

Descriptive Statistics and Correlation Matrix

\begin{tabular}{|c|c|c|c|c|c|c|c|c|c|c|c|c|c|}
\hline Variable & Mean & SD & $\begin{array}{l}\text { Skew } \\
\text { ness }\end{array}$ & $\begin{array}{l}\text { Kurto } \\
\text { sis }\end{array}$ & $\begin{array}{l}\text { COM } \\
\text { MIT }\end{array}$ & ENJ & INV & SUP & ALT & SOC & OPP & SAT & SID \\
\hline COMMIT & 4.64 & 0.49 & -2.18 & 7.02 & 1 & - & - & - & - & - & - & - & - \\
\hline ENJ & 4.71 & 0.51 & -2.36 & 6.58 & $.60^{* *}$ & 1 & - & - & - & - & - & - & - \\
\hline INV & 4.24 & 0.88 & -1.20 & 0.91 & $.45^{* *}$ & $.46^{* *}$ & 1 & - & - & - & - & - & - \\
\hline SUP & 3.49 & 0.95 & -0.17 & -0.74 & $.31^{* *}$ & $.21^{* *}$ & $.35^{* *}$ & 1 & - & - & - & - & - \\
\hline ALT & 2.00 & 0.77 & 0.71 & 0.20 & $-.21^{* *}$ & $-.33^{* *}$ & -.08 & -.05 & 1 & - & - & - & - \\
\hline SOC & 1.86 & 0.82 & 1.35 & 1.93 & .09 & -.04 & $.22^{* *}$ & $.43^{* *}$ & $.33^{* *}$ & 1 & - & - & - \\
\hline OPP & 4.47 & 0.65 & -1.34 & 1.21 & $.52^{* *}$ & $.52^{* *}$ & $.51^{* *}$ & $.34^{* *}$ & $-.18^{* *}$ & .10 & 1 & - & - \\
\hline SAT & 4.76 & 0.50 & -2.37 & 5.84 & $.46^{* *}$ & $.50^{* *}$ & $.20^{* *}$ & $.15^{*}$ & $-.29^{* *}$ & -.11 & $.36^{* *}$ & 1 & - \\
\hline SID & 3.31 & 1.02 & -0.24 & -0.56 & $.38^{* *}$ & $.27^{* *}$ & $.47^{* *}$ & $.36^{* *}$ & -.10 & $.24^{* *}$ & $.41^{* *}$ & $.17^{* *}$ & 1 \\
\hline
\end{tabular}

personal investments, SUP $=$ social support, ALT $=$ involvement alternatives, $\mathrm{SOC}=$ social constraints, OPP = involvement opportunities, SAT = sport satisfaction, and SID = sport identity.

\section{A Three Stage Hierarchical Multiple Regression}

For RQ1, the hierarchical multiple regression analysis was conducted to analyze which antecedent factors (sport enjoyment, involvement opportunities, personal investments, involvement alternatives, social constraints and social support), sport 
satisfaction and sport identity were most influential in predicting older adults' sport commitment toward organized sport activity.

For the first block, the regression model indicated that the regression equation of six antecedent factors was significantly related to sport commitment, $R^{2}=0.44, R^{2} a d j=$ $0.42, F(6,269)=35.25, p<0.001$. The six predictor variables in combination accounted for $44 \%$ of the variance in sport commitment. The results showed that sport enjoyment $(\beta$ $=0.40, \mathrm{t}=7.01, p<0.001)$, social support $(\beta=0.10, t=1.98, p<0.05)$, and involvement opportunities $(\beta=0.20, t=3.49, p<0.01)$ were significant positive predictors of sport commitment. The model shows that with every increase of one standard deviation (SD) in older adults' sport enjoyment, the level of sport commitment increases by 0.40 standard deviation (SD) with all other independent variables held constant. For each one SD increase in the social support, the level of sport commitment will increase by 0.10 SD. For each one SD increase in the involvement opportunities, the level of sport commitment will increase by $0.20 \mathrm{SD}$. Therefore, for RQ1a, sport enjoyment was the strongest predictor $(\beta=0.40)$ followed by involvement opportunities $(\beta=0.20)$ and social support $(\beta=0.10)$. However, the results did not support that personal investments, social constraints, and involvement alternative were significant predictors of the sport commitment.

Sport satisfaction was entered into the next block. The second step regression model indicated that a significant increase in incremental variance $\left[R^{2}\right.$ change $=0.03, F(1$, $268)=14.23, p<0.001]$ with the standardized coefficient of $0.19(t=3.77, p<0.001)$. The model shows that with every increase of one SD in older adults' sport satisfaction, the level of sport commitment increases by $0.19 \mathrm{SD}$, holding all other variables constant. 
The $\mathrm{R}^{2}$ adj was increased from 0.42 (in step 2) to 0.45 . The change in variance accounted for $\left(\Delta R^{2}\right)$ was 0.03 and this increase $(3 \%)$ was statistically significant $(p<0.001)$ over and above the combination of the six antecedent factors. Therefore, for RQ1b, the results indicated sport satisfaction does explain a significant incremental variance in sport commitment over and above the six antecedent factors among older adults. Moreover, the linear combination of six antecedent factors and sport satisfaction were significantly related to sport commitment, $R^{2}=0.46, R^{2} a d j=0.45, F(7,268)=33.73, p<0.001$. The six predictor variables and sport satisfaction in combination accounted for $46 \%$ of the variance in sport commitment. With sport satisfaction, sport enjoyment $(\beta=0.33, t=5.44$, $p<0.001)$, personal investments $(\beta=0.12, t=2.25, p<0.05)$, and involvement opportunities $(\beta=0.17, t=2.99, p<0.01)$ were significant positive predictors of sport commitment. The model shows that with every increase of one SD in older adults' sport enjoyment, the level of sport commitment increases by $0.33 \mathrm{SD}$, holding all other variables constant. For each one SD increase in the personal investments, the level of sport commitment will increase by $0.12 \mathrm{SD}$. For each one SD increase in the involvement opportunities, the level of sport commitment will increase by $0.17 \mathrm{SD}$. Therefore, sport satisfaction $(\beta=0.19)$ was the second strongest predictor. Sport enjoyment $(\beta=0.33)$ was the strongest predictor. However, social support was no longer a significant predictor in the regression equation and did not support that social constraints and involvement alternatives were significant predictors of the sport commitment.

In the last block, sport identity was entered and it indicated a significant increase in incremental variance $\left[R^{2}\right.$ change $\left.=0.01, F(1,267)=4.42, p<0.05\right]$ with the standardized coefficient of $0.11(t=2.10, p<0.05)$. The model shows that with every 
increase of one SD in older adults' sport identity, the level of sport commitment increases by $0.11 \mathrm{SD}$, holding all other variables constant. The $R^{2} a d j$ was increased from 0.45 (in step 2) to 0.46 . The change in variance accounted for $\left(\Delta R^{2}\right)$ was 0.01 , and this increase $(1 \%)$ was statistically significant $(p<0.01)$. For RQ1c, the results indicated that sport identity did explain a significant incremental variance in sport commitment over and above the seven antecedent factors including sport satisfaction among older adults. Furthermore, the linear combination of six antecedent factors, sport satisfaction and sport identity were significantly related to sport commitment, $R^{2}=0.47, R^{2} a d j=0.46, F(8,267)$ $=30.44, p<0.001$. The six predictor variables, sport satisfaction and sport identity in combination accounted for $47 \%$ of the variance in sport commitment. With sport identity, sport enjoyment $(\beta=0.33, t=5.55, p<0.001)$, involvement opportunities $(\beta=0.15, t=$ 2.63, $p<0.01)$, and sport satisfaction $(\beta=0.19, t=3.64, p<0.001)$ were significant positive predictors of sport commitment. The model shows that with every increase of one SD in older adults' sport enjoyment, the level of sport commitment increases by 0.33 $\mathrm{SD}$, holding all other variables constant. For each one SD increase in the involvement opportunities, the level of sport commitment will increase by $0.15 \mathrm{SD}$. For each one SD increase in the sport satisfaction, the level of sport commitment will increase by 0.19 SD. However, social support and personal investments were no longer significant predictors in the regression equation and did not support that social constraints and involvement alternatives were significant predictors of the sport commitment.

Overall, based on the results, sport enjoyment was the strongest predictor of sport commitment followed by involvement opportunities among the sample of older adults. Additionally, sport satisfaction and sport identity appeared to offer additional predictive 
power beyond that contributed by six antecedent factors in SCM. Therefore, Hypothesis 1a was partially supported in that personal investments, social constraints and involvement alternatives did not predict the sport commitment in the sample of older adults. Hypothesis $1 \mathrm{~b}$ and $1 \mathrm{c}$ were supported. The results of hierarchical linear regression analysis for sport commitment were reported in Table 11.

\section{Table 11}

The Results of Hierarchical Linear Regression Analysis for Sport Commitment

\begin{tabular}{|c|c|c|c|c|c|c|c|c|}
\hline Predictor & B & $S E$ & $\beta$ & $t$ & $p$ & $F$ & $R^{2}\left(R^{2} a d j\right.$ & $\Delta R^{2}$ \\
\hline \multicolumn{6}{|c|}{ Step 1 (Model 1) } & $35.25 * * *$ & $0.44(0.42)$ & \\
\hline ENJ & .38 & .05 & .40 & 7.01 & $.00 * * *$ & & & \\
\hline INV & .06 & .03 & .11 & 1.94 & .05 & & & \\
\hline SUP & .05 & .02 & .10 & 1.98 & $.04 *$ & & & \\
\hline ALT & -.01 & .03 & -.02 & -.52 & .59 & & & \\
\hline SOC & .01 & .03 & .02 & .43 & .66 & & & \\
\hline OPP & .15 & .04 & .20 & 3.49 & $.00 * *$ & & & \\
\hline \multicolumn{6}{|c|}{ Step 2 (Model 2) } & $33.73 * * *$ & $0.46(0.45$ & $0.03 * * *$ \\
\hline ENJ & .31 & (.05) & .33 & 5.44 & $.00 * * *$ & & & \\
\hline INV & .06 & $(.03)$ & .12 & 2.25 & $.02 *$ & & & \\
\hline SUP & .04 & $(.02)$ & .09 & 1.76 & .07 & & & \\
\hline ALT & -.00 & $(.03)$ & -.00 & -.13 & .89 & & & \\
\hline SOC & .02 & $(.03)$ & .04 & .78 & .43 & & & \\
\hline OPP & .12 & (.04) & .17 & 2.99 & $.01 * *$ & & & \\
\hline SAT & .19 & (.05) & .19 & 3.77 & $.00 * * *$ & & & \\
\hline \multicolumn{6}{|c|}{ Step 3 (Model 3) } & $30.44^{*}$ & $0.47(0.46)$ & $0.01 * *$ \\
\hline ENJ & .31 & .05 & .33 & 5.55 & $.00 * * *$ & & & \\
\hline INV & .05 & .03 & .09 & 1.59 & .11 & & & \\
\hline SUP & .04 & .03 & .07 & 1.47 & .14 & & & \\
\hline ALT & .00 & .03 & .00 & .01 & .99 & & & \\
\hline SOC & .01 & .03 & .03 & .54 & .58 & & & \\
\hline OPP & .11 & .04 & .15 & 2.63 & $.01 * *$ & & & \\
\hline SAT & .18 & .05 & .19 & 3.64 & $.00 * * *$ & & & \\
\hline
\end{tabular}




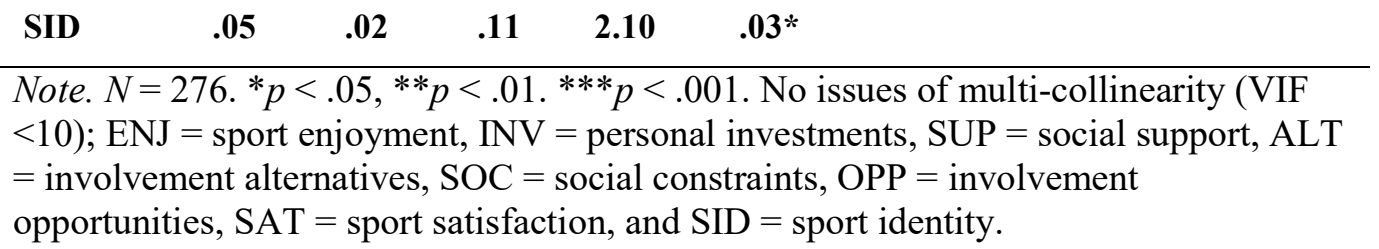

\section{Second Research Questions}

To address the second purpose of the current study along with the second research question, a multiple regression analysis was conducted to evaluate how well the combination of sport satisfaction, sport identity, and sport commitment predicted level of life satisfaction among older adults. Prior to simultaneous multiple regression, principal axis factoring with oblique rotation was conducted to identify dimensions from SCM (specifically, items from sport identity, sport satisfaction, and sport commitment) and life satisfaction measures, and Cronbach's alpha $(\alpha)$ was used to assess the internal consistency reliability of four scales.

\section{Principal Component Analysis}

In the previous correlation analysis, sport identity, sport satisfaction, and sport commitment were correlated with one another (see the Table 10). Therefore, Principal Component Analysis (PCA) with promax rotation was conducted on the sample of 276 older adults. The Kaiser-Meyer-Olkin measure of sampling adequacy was .84 (greater than 0.70; Kaiser, 1974) and similarly, Bartlett's test of sphericity was significant (approximate chi square $=2570.15, p<0.001)$, indicating sufficient evidence to proceed with the factor analysis. Communalities after extraction ranged from a low of $h^{2}=0.26$ (SID_4) to a high of $h^{2}=0.87$ (SID_2). 
The results of principal component analysis with the oblique rotation (promax) indicated four factors had eigenvalues $>1$. The scree plot test further suggested four factors, which respectively accounted for $29.37 \%, 17.50 \%, 11.34 \%$, and $7.77 \%$ of the variance. Additionally, the parallel analysis indicated that four components should be retained. Four of the eigenvalues in the PCA column are greater than 1 and the dashed line for parallel analysis in the graph indicated the four components met the eigenvalue greater than 1 criterion (see Appendix D).

According to the factor pattern matrix, 18 items with a pattern coefficient of 0.40 or greater loaded significantly onto their respective factors, sport identity (loadings ranging from 0.55 to 0.93 ), sport satisfaction (loadings ranging from 0.85 to 0.91 ), sport commitment (loadings ranging from 0.52 to 0.90 ) and life satisfaction (loadings ranging from 0.67 to 0.85 ) in promax rotation. The four rotated factors accounted for $65.98 \%$ of the total variance (Hair et al., 2006). It is important to note that extracted factors usually explain only $50 \%$ to $60 \%$ in social science research (UCLA: Statistical Consulting Group, 2020). In addition, Cronbach's alpha was calculated to measure the strength of internal consistency of each factor based on the items that contributed over 0.40 loading to the factors. These four factors' Cronbach's alpha scores were greater than 0.80 which indicates good internal consistency of scales (Nunnally \& Bernstein, 1994). The factor loading (structure and pattern coefficients) and Cronbach's alpha results from this analysis are reported in Table 12.

\section{Table 12}

Structure \& Pattern Coefficients, Communalities and Cronbach's alpha

\begin{tabular}{lllllllllll} 
Factor & Items & F1 & F2 & F3 & F4 & F1 & F2 & F3 & F4 & $h^{2}$ \\
\hline
\end{tabular}




\begin{tabular}{lllllllllll}
\hline & & \multicolumn{3}{c}{ Pattern Coefficients } & \multicolumn{3}{c}{ Structure Coefficients } \\
\hline \multirow{3}{*}{ F1.Sport } & COMMIT_3 & $\mathbf{0 . 9 0}$ & -0.07 & -0.14 & 0.05 & $\mathbf{0 . 8 6}$ & 0.05 & 0.23 & 0.42 & 0.76 \\
Commitment & COMMIT_2 & $\mathbf{0 . 8 8}$ & 0.02 & -0.01 & -0.11 & $\mathbf{0 . 8 3}$ & 0.11 & 0.33 & 0.29 & 0.70 \\
& COMMIT_6 & $\mathbf{0 . 7 3}$ & -0.04 & -0.08 & 0.04 & $\mathbf{0 . 7 1}$ & 0.06 & 0.22 & 0.35 & 0.66 \\
& COMMIT_1 & $\mathbf{0 . 7 0}$ & 0.04 & 0.09 & -0.03 & $\mathbf{0 . 7 3}$ & 0.13 & 0.37 & 0.31 & 0.54 \\
& COMMIT_4 & $\mathbf{0 . 6 8}$ & -0.08 & -0.08 & 0.28 & $\mathbf{0 . 7 7}$ & 0.05 & 0.24 & 0.56 & 0.52 \\
& COMMIT_5 & $\mathbf{0 . 5 2}$ & 0.21 & 0.22 & -0.14 & $\mathbf{0 . 5 7}$ & 0.26 & 0.41 & 0.17 & 0.42 \\
\hline \multirow{3}{*}{ F2.Life } & SWLS_3 & 0.00 & $\mathbf{0 . 8 5}$ & 0.01 & 0.07 & 0.14 & $\mathbf{0 . 8 6}$ & 0.05 & 0.24 & 0.75 \\
Satisfaction & SWLS_2 & 0.08 & $\mathbf{0 . 8 4}$ & -0.03 & -0.02 & 0.16 & $\mathbf{0 . 8 4}$ & 0.03 & 0.17 & 0.71 \\
& SWLS_1 & 0.03 & $\mathbf{0 . 8 0}$ & 0.01 & 0.06 & 0.16 & $\mathbf{0 . 8 2}$ & 0.06 & 0.23 & 0.67 \\
& SWLS_4 & -0.09 & $\mathbf{0 . 7 9}$ & 0.00 & 0.06 & 0.03 & $\mathbf{0 . 7 9}$ & 0.00 & 0.17 & 0.63 \\
& SWLS_5 & -0.02 & $\mathbf{0 . 6 7}$ & -0.07 & -0.11 & -0.01 & $\mathbf{0 . 6 5}$ & -0.07 & 0.00 & 0.44 \\
\hline \multirow{3}{*}{ F3.Sport Identity } & SID_2 & 0.00 & -0.01 & $\mathbf{0 . 9 3}$ & 0.03 & 0.39 & 0.03 & $\mathbf{0 . 9 4}$ & 0.18 & 0.87 \\
& SID_3 & 0.02 & -0.05 & $\mathbf{0 . 9 0}$ & 0.04 & 0.39 & 0.00 & $\mathbf{0 . 9 1}$ & 0.19 & 0.84 \\
& SID_1 & 0.15 & -0.04 & $\mathbf{0 . 8 1}$ & -0.05 & 0.45 & 0.00 & $\mathbf{0 . 8 6}$ & 0.15 & 0.75 \\
& SIDr_4 & -0.23 & 0.00 & $\mathbf{0 . 5 5}$ & 0.05 & 0.02 & 0.01 & $\mathbf{0 . 4 7}$ & 0.05 & 0.26 \\
\hline \multirow{2}{*}{ F4.Sport } & SAT_2 & -0.03 & 0.02 & 0.05 & $\mathbf{0 . 9 1}$ & 0.40 & 0.19 & 0.19 & $\mathbf{0 . 9 1}$ & 0.76 \\
Satisfaction & SAT_1 & 0.03 & 0.02 & -0.06 & $\mathbf{0 . 8 7}$ & 0.39 & 0.19 & 0.10 & $\mathbf{0 . 8 7}$ & 0.83 \\
& SAT_3 & 0.01 & 0.02 & 0.09 & $\mathbf{0 . 8 5}$ & 0.43 & 0.19 & 0.24 & $\mathbf{0 . 8 7}$ & 0.77 \\
\hline Eigenvalues & & 5.29 & 3.15 & 2.04 & 1.40 & & & & &
\end{tabular}

Note. $N=276$

\section{Descriptive Statistics and Correlation Matrix}

Prior to multiple regression analysis, measures of central tendency and variability, and the assumptions of normality and multicollinearity, were examined. For normality, measures of skewness $(<3)$ and kurtosis $(<10)$, which assess normality of sample distribution, confirmed a normal distribution (Kline, 2016). The correlation matrix indicated no multicollinearity among predictor variables (interrelations were less than .80) (Pituch \& Stevens, 2016). Specifically, life satisfaction was significantly associated with sport commitment $(r=0.13, p<0.05)$ and sport satisfaction $(r=0.21, p<0.01)$ but not with sport identity $(r=-0.01 p>0.05)$. Furthermore, values of VIF (less than 10) were also confirmed with multicollinearity violation in a regression analysis (Pituch \& Stevens, 2016). Descriptive statistics and the correlation matrix are reported in Table 13. 


\section{Table 13}

Descriptive Statistics and Correlation Matrix

\begin{tabular}{|c|c|c|c|c|c|c|c|c|}
\hline Variable & Mean & $\mathrm{SD}$ & Skewness & Kurtosis & 1 & 2 & 3 & 4 \\
\hline 1.Life Satisfaction & 4.05 & 0.68 & -0.43 & -0.38 & 1 & $0.13 *$ & -0.01 & $0.21 * *$ \\
\hline 2. Sport Commitment & 4.64 & 0.49 & -2.18 & 7.02 & - & 1 & $0.38 * *$ & $0.46^{* *}$ \\
\hline 3.Sport Identity & 3.31 & 1.02 & -0.24 & -0.56 & - & - & 1 & $0.20 * *$ \\
\hline 4. Sport Satisfaction & 4.76 & 0.50 & -2.37 & 5.84 & - & - & - & 1 \\
\hline
\end{tabular}

\section{Multiple Regression Analysis}

For RQ2, a multiple regression analysis was conducted to predict older adults' level of life satisfaction from sport satisfaction, sport identity, and sport commitment simultaneously. The results indicated a statistically significant relationship between sport satisfaction, sport identity, sport commitment, and life satisfaction, $F(3,272)=4.59, p<$ 0.01 . The three variables in combination accounted for approximately $5 \%$ of the variance, a relatively small effect size, in life satisfaction, $R^{2}=0.05$.

For RQ2a, sport satisfaction was a statistically significant predictor of life satisfaction $(b=0.25, p<0.05)$ and uniquely accounted for approximately $3 \%$ of the variance. (See Table 14). This regression coefficient indicates that if sport commitment increases by one unit, the level of life satisfaction increased by 0.25 , holding all other variables constant. Therefore, it supports that sport satisfaction is significantly and positively related to older adults' level of life satisfaction (Hypothesis 2a). According to results of multiple regression analysis, sport identity and sport commitment were not significant predators of older adults' life satisfaction. Therefore, the Hypothesis $2 \mathrm{~b}$ and 
Hypothesis $2 \mathrm{c}$ were not supported. Interestingly, the correlation matrix indicated that life satisfaction was significantly associated with sport commitment $(r=0.13, p<0.05)$. This result indicated that there is a statistical relationship between sport commitment and life satisfaction However, this is a small effect $(r=0.13)$ that would not be significant if the sample size was smaller. Therefore, the result should be interpreted with caution. The results are reported in Table 14.

Table 14

Results of Multiple Regression for Life Satisfaction

\begin{tabular}{|c|c|c|c|c|c|c|c|}
\hline Variable & $B$ & $S E B$ & $\beta$ & $t$ & $p$ & $s r^{2}$ & VIF \\
\hline Sport Commitment & .10 & .10 & .07 & 1.01 & .31 & .00 & 1.43 \\
\hline Sport Identity & -.05 & .04 & -.07 & -1.07 & .29 & .00 & 1.17 \\
\hline Sport Satisfaction & .25 & .09 & .19 & $2.80 *$ & .01 & .03 & 1.27 \\
\hline
\end{tabular}

\section{Summary of Results}

In sum, a three stage hierarchical multiple regression analysis revealed that the SCM with sport identity and sport satisfaction was a valid theoretical framework to examine the older adults population. The results using the original SCM indicated that sport enjoyment, involvement opportunities and social support were significant predictors of sport commitment for the sample of older adults who participated in organized sport activities. It is important to note that the construct of involvement opportunities was specifically related to health benefits in the current study. 
The SCM revealed that sport satisfaction was a distinct construct form sport enjoyment, and both sport satisfaction and sport identity were significant predictors of sport commitment among older adults. The regression model with life satisfaction indicated that only $5 \%$ of the variation can be explained by spot satisfaction, sport identity, and sport commitment. The findings suggested that sport satisfaction was an important factor which contributed not only to sport commitment but also to life satisfaction among older adults.

Chapter 5 will highlight insights into what the results means, illustrate how the findings contribute to the literature, and discuss theoretical and practical implications of the findings related to promoting regular and consistent organized sport participation in later life. In addition, recommendations of the future research will be presented. 


\section{CHAPTER V \\ DISCUSSION}

People are living longer, and the size of the aging population in the U.S. is showing significant growth. For instance, U.S. Census Bureau projections indicate that by 2050 , the elderly (aged 65 years and above) will make up a full quarter of all people living in the US. This does not mean, however, that older adults are necessarily living healthier lives (Brockman, 2019). Public health representatives suggest that regular participation in sport, exercise, and physical activities may improve positive emotional experiences, self-esteem, quality of life, and psychological and social well-being, including mental health (U.S. Department of Health and Human Services, 2018). However, the proportion of the population which participates in sport, exercise, and physical activity declines as people age (Jenkin et al., 2018). Unfortunately, health reports indicated that approximately 80 percent of U.S. adults (including older adults) are insufficiently active, meaning they participate for fewer than 150 minutes ( 2 hours and 30 minutes) in moderate-intensity physical activity (e.g., brisk walking, dancing, swimming, bicycling, tennis [doubles], or gardening) per week (U.S. Department of Health and Human Services, 2018). Therefore, to promote sport engagement, public health representatives and sport and fitness facility managers need a better understanding of older adults' attitudes toward participation in organized sport and physical activity.

The primary purpose of this dissertation was to gain a better understanding of participation in organized sport activities among adults over 55 years of age, referred to 
as "older adults." Specifically, this purpose was twofold: (1) use the Sport Commitment Model (SCM) to identify antecedent factors that influence levels of sport commitment toward organized sport activity among older adults (Figures 1 and 2, see Chapter I), and (2) investigate the relationships between sport satisfaction, sport identity, and sport commitment in the well-being of older adults who regularly participate in organized sport activity (Figure 3, see Chapter I). Specifically, two overarching questions were addressed and for each overarching question, there was a set of more specific questions.

RQ1. Do the antecedent factors (i.e., sport enjoyment, involvement opportunities, personal investments, involvement alternatives, social constraints and social support), sport satisfaction, and sport identity predict the level of sport commitment toward organized sport activity for older adults? Specifically:

1a. Which of the antecedent factors are the strongest predictors of older adults' sport commitment toward organized sport activity?

1b. Does sport satisfaction explain a significant incremental variance in sport commitment over and above the six antecedent factors among older adults?

1c. Does sport identity explain a significant incremental variance in sport commitment over and above the seven antecedent factors including sport satisfaction among older adults?

In the first purpose, (using the SCM to identify antecedent factors that influence levels of sport commitment toward organized sport activity among older adults) the following hypotheses were proposed:

Hypothesis 1a: Sport enjoyment, involvement opportunities, personal investments, social constraints, and social support positively 
predict sport commitment, and involvement alternative negatively predicts sport commitment.

Hypothesis 1b: Sport satisfaction positively predicts sport commitment.

Hypothesis 1c: Sport identity positively predicts sport commitment.

RQ2. Is there a significant relationship between the level of life satisfaction and sport satisfaction, sport identity, and sport commitment among older adults who participate in organized sport activity regularly? Specifically:

2a. Is sport satisfaction significantly related to older adults' level of life satisfaction?

2b. Is sport identity significantly related to older adults' level of life satisfaction?

2c. Is sport commitment significantly related to older adults' level of life satisfaction?

Based on the second study purpose (to investigate the relationships between sport satisfaction, sport identity, and sport commitment in the well-being of older adults who regularly participate in organized sport activity), three hypotheses were examined as follows:

Hypothesis 2a: Sport satisfaction positively and uniquely relates to older adults' level of life satisfaction.

Hypothesis $2 \mathrm{~b}$ : Sport identity positively and uniquely relates to older adults' level of life satisfaction.

Hypothesis 2c: Sport commitment positively and uniquely relates to older adults' level of life satisfaction. 
This chapter includes (a) a discussion of major findings as related to the above research questions and the literature on the SCM and sport participation among older adults, and (b) a discussion on connecting the activity theory of aging and Snyder's (1981) concept of commitment to promote organized sport activity participation among older adults. Also included is a discussion of future research possibilities. The chapter concludes with a discussion on what practical implications may be valuable to practitioners who provide sport and physical activities and services to older adults (e.g., public and private sport facility and fitness club administrators) and an overview of the importance of research regarding regular participation in organized sport activity among older adults.

\section{Theoretical Implications of First Research Question}

Theoretically, sport commitment is a psychological construct for assessing individuals' desire and resolve to persist in a sport and physical activity over time. It has been widely examined with different contexts of participants (e.g., youth athletes, college athletes, recreational and exercise participants) to understand individuals' behavior toward sport and physical activities. Previous studies have empirically demonstrated that highly committed sport participants are more likely to frequently engage in and spend considerable time, effort, and money on sport (Chang \& Gibson, 2015; Mullin et al., 2014; Tokuyama \& Greenwell, 2011). Moreover, previous studies indicated that older adults were more committed to their sport and physical activity (e.g., tennis and windsurfing) based on the length of time of participation, but their commitment levels can vary depending on the type of sport and physical activities (Casper \& Stellino, 2008). Therefore, sport commitment is an important psychological state influencing older adults in their decisions to continue to participate in organized sport activities. Specifically, the 
SCM explores how committed participants are to participating in their sport activity.

Furthermore, determining the factors related to sport commitment is important because that information will help researchers, health professionals, and organized sport providers to promote organized sport participation among older adults. Specifically, increased organized sport participation among older adults could lead to increased life satisfaction and improved health outcomes. Thus, the first research question used the SCM to identify significant predictors of sport commitment in order to explain the reasons why older adults regularly participate in organized sport activities. Moreover, the current study suggested two additional constructs, sport satisfaction and sport identity, be examined in order to explore how these factors were able to predict sport commitment among older adults.

To address the first research question adequately, three subquestions (RQ1a, RQ1b, and RQ 1c) were addressed using hierarchical multiple regression analysis. A three stage hierarchical multiple regression was conducted to determine which antecedent factors of sport commitment (Step 1; RQ1a), sport satisfaction (Step 2; RQ1b), and sport identity (Step 3; RQ1c) significantly predicted the level of sport commitment toward organized sport activity among older adults. Table 15 presents a basic overview of the findings for RQ1. Explanations for each level of the table are provided in the sections that follow.

Table 15

Summary of Significant Findings from RQ1

\begin{tabular}{ll}
\hline Antecedent & $\begin{array}{l}\text { Was this antecedent a significant predictor } \\
\text { of sport commitment? }\end{array}$
\end{tabular}




\begin{tabular}{ll}
\hline Sport enjoyment & Yes \\
Involvement opportunities & Yes \\
Personal investment & $\mathrm{Yes}^{2} / \mathrm{No}^{3}$ \\
Involvement alternatives & No \\
Social constraints & No \\
Social support & Yes $^{1} / \mathrm{No}^{3}$ \\
Sport satisfaction & Yes \\
Sport identity & Yes \\
\hline Note. $1=$ Step $1,2=$ Step $2,3=$ Step 3
\end{tabular}

\section{Original Sport Commitment Model}

For RQ1a, Step 1 (see Model 1 in Table 11) indicated a linear relationship between a combination of antecedent factors and sport commitment. The six antecedent factors (sport enjoyment, involvement opportunities, personal investments, involvement alternatives, social constraints and social support) in combination accounted for $44 \%$ of the variance in sport commitment. Therefore, Model 1 supported the premise that the SCM is a good fit with the sample data of older adults and the model significantly predicts sport commitment. This study provided empirical evidence regarding the applicability of the SCM to the older adult population's participation in organized sport and physical activity. It also supported previous studies claiming that SCM is a valid measure in comparing age groups' similarities and differences on the level of sport commitment and its significant predictors (Casper \& Andrew, 2008; Casper et al, 2007; Jeon \& Casper, 2016). A percentage of variance in sport commitment (44\%) was similar 
to a previous study among older adults aged 55 and over who were tennis players (49\%) (Casper \& Stellino, 2008). However, this study also indicated that the adult and older adult models explain less variance of sport commitment by predictors compared to youth and younger adult samples (range between 50\% to 98\%) (Casper \& Stellino, 2008; Casper et al., 2007).

In Model 1, the regression model determined that sport enjoyment, social support, and involvement opportunities were the only significant predictors of sport commitment. Sport enjoyment was the strongest predictor $(\beta=0.40)$ followed by involvement opportunities $(\beta=0.20)$ and social support $(\beta=0.10)$. Therefore, Hypothesis 1a was partially supported as the results did not support that personal investments and involvement alternatives were significant predictors of sport commitment.

The findings suggested that sport enjoyment has a larger effect on the level of sport commitment toward organized sport activities, and as involvement opportunities and social support respectively increase, the level of sport commitment also increases. Specifically, if older adults experience positive feelings such as pleasure, happiness, and love through their participation in organized sport, they may be less likely to quit. Moreover, valuable opportunities attained by participating in organized sport activities such as relieving stress and improving overall health and fitness, are important aspects in increasing willingness to continue to participate in organized sport activity. Furthermore, if older adults feel supported and encouraged to participate by significant others (e.g., family and friends), they are likely to have an increased level of commitment to their sport. These findings are consistent with a previous study which found that sport enjoyment, and involvement opportunities (except personal investment) were important 
and significant predictors of sport commitment among older adult ballroom dancers (Wang \& Chu, 2016). However, social support was not a determinant of sport commitment for older adults to remain active in ballroom dancing. Likewise, Casper and Stellino (2008) also indicated that sport enjoyment, involvement opportunities, and personal investments were important determinants of sport commitment for a sample of tennis players aged 55 and older. These previous studies each focused on one particular sport, tennis or ballroom dancing, requiring specific skills and training to perform. Compared to walking or running, organized sport activity (e.g., tennis league) may require significant investment in resources such as court or membership fees, equipment purchases, and lessons to participate. Therefore, personal investments were an important determinant rather than social support. In the current study, participants participated in 13 different sports and physical activities (e.g., fitness program, water fitness and basketball). However, it is important to note that mean score on personal investments (4.24) among older adults was higher than social support (3.49) in the descriptive statistics. This means that older adults very much felt they were spending considerable time, effort, energy, and money participating in their organized sport activity.

This study indicated that social support is an important and significant factor; if older adults receive greater support from family and friends or peers to participate in the organized sport activity, they are more likely to participate and may be less likely to quit. This finding is in line with previous studies' findings that support from family members, friends or exercise program staff are significant factors associated with participation in physical activity by older adults (Allender, Cowburn, \& Foster 2006; Lim \& Tylor, 2004; Smith, Banting, Eime, O’Sullivan, \& Van Uffelen, 2017). Allender et al. (2006) 
determined that strong social networks encouraged older adults (aged 50 and over) in maintaining participation in sport and physical activities (e.g., social ballroom dancing). Another review of quantitative studies also determined that family support of physical activity significantly increased physical activity levels among older adults (Smith et al, 2017). Allender et al. also determined that health benefits and enjoyment were significant motivations for regular and consistent sport and physical activity in later life.

Overall, the findings of the current study contribute to SCM literature and illustrated that sport enjoyment and involvement opportunities explained significant amounts of variance in sport commitment regardless of age or type of sports and activities (Crocker \& Augaitis, 2010; Jeon \& Casper, 2016). In general, positive participation experiences and valuable opportunities (e.g., social and health benefits) are important aspects for all age groups involved in regular sport and physical activity. Therefore, the findings of this study are not surprising, and rather the results (a) demonstrate that the original SCM is appropriate for a sample of older adults in the context of organized sport activity and (b) add empirical evidence to support the importance of sport enjoyment and involvement opportunities in a variety of sport contexts and ages (Jeon \& Casper, 2016).

However, it is important to note that the construct of involvement opportunities was specifically related to health benefits (e.g., this sport activity gives me the opportunity to improve my health and fitness) in the current study. Previous studies adapted measures of valued opportunities that specifically focused on social-related benefits (e.g., I would miss the people that I have met if I quit this sport activity) of continued involvement (Scanlan et al., 1993). In the current study, three items that 
reflected the degree to which organized sport activity involvement provided health related benefits were added to reflect the construct of involvement opportunities and for the construct representativeness purpose (Wilson et al., 2004). The results from the principal component analysis (PCA) eliminated social related benefits items due to measurement issues (e.g., factor loadings were lower than .40 and aberrant loadings occurred). Similarly, a previous study also utilized involvement opportunities that measured both social and health benefits together, but the construct was dropped in the analysis due to comparable measurement issues as mentioned above (Wilson et al., 2004). The results confirmed that social benefits and health benefits are two distinct theoretical concepts and could not be measured using the same label, involvement opportunities. Additional empirical evidence is needed to support the construct and items and clarify the role of involvement opportunities (both social and health related benefits) in the context of older adults' participation in sport and physical activities.

\section{SCM with Sport Satisfaction}

Sport satisfaction is defined as the positive perceptions or feelings an individual gains as a result of engaging in sport activities and choices. It determines the degree to which an individual is currently satisfied with their experiences with sport activities (Beard \& Ragheb, 1980). Previously, sport satisfaction was examined interchangeably with various constructs such as enjoyment, pleasure, fun, and intrinsic and extrinsic rewards (Casper et al., 2007; Eklund \& Tenenbaum, 2013, Granero-Gallegos et al., 2014; Snyder 1981). For instance, Casper et al. (2007) added the item, "Are you satisfied with tennis as your choice of an activity?" in the tennis enjoyment scale. However, the current study assumed that sport satisfaction and sport enjoyment were two different factors in 
predicting older adults' sport commitment. The results of the PCA indicated that the sport satisfaction items were not related to the sport enjoyment items. It is important to note that the sport satisfaction scale was adapted from Bodet's (2012) measurements of overall consumer satisfaction with a fitness organization. Three statements assessed the degree to which current or past participation in an organized sport activity was perceived as satisfying (e.g., "Overall, I am satisfied with my decision to participate in this sport activity", "I think I did the right thing by deciding to participate in this sport activity", and "My choice to participate in this sport activity is a wise one").

For RQ1b, sport satisfaction was entered into Model 2 (see Table 10) and the $R^{2} a d j$ increased from .42 (in the model 2) to .45 . This increase (3\%) was statistically significant $(p<0.001)$. Therefore, the results indicated that sport satisfaction explained a significant incremental variance in sport commitment over and above the six antecedent factors among older adults meaning that sport satisfaction significantly contributed to sport commitment after controlling for the other antecedent factors in the regression model. Specifically, an older adult who is highly satisfied with their choice to participate in organized sport activities is more likely to continue to participate and would not quit their sport.

Model 2 determined that sport enjoyment, personal investments, involvement opportunities, and sport satisfaction were significant predictors of sport commitment. Therefore, Hypothesis $1 \mathrm{~b}$ was supported. Sport enjoyment $(\beta=0.33)$ was the strongest predictor and sport satisfaction $(\beta=.19)$ was the second strongest predictor. These findings support the idea that sport satisfaction is a distinct construct from the constructs of sport enjoyment and fun. The current study employed sport satisfaction as a distinct 
construct which separated it from other original constructs of the SCM (Wilson et al., 2004). The results were consistent with previous researchers' findings that sport satisfaction is one of the strongest predictors of sport and exercise commitment (Bodet, 2012; Eklund \& Tenenbaum, 2013; Snyder 1981; Wilson et al., 2004).

Additionally, it is important to note that personal investment was an important predictor of sport commitment in this model. Older adults who spend considerable time, effort, energy, and money participating in their organized sport activity are more likely to have increased levels of sport commitment. This finding is in agreement with that of previous studies that personal investment was an important factor for increasing sport commitment and participation behaviors (frequency and consumptions) among older adults (Casper, 2007; Wang \& Chu, 2016).

\section{SCM with Sport Identity}

Sport identity represents how sport and physical activity are "incorporated into one's sense of self" and "involves internalizing the meanings associated with" the specific sport or exercise (e.g., golf, swimming) (Eklund \& Tenenbaum, 2013, p.366). In the literature, many theoretical constructs have been utilized (e.g., athletic identity, exercise identity, and leisure identity) to measure active sport participants' identity with a specific sport and physical activity. Studies utilizing the above constructs demonstrated that sport related identity strengthens an individual's sport choice and behavior (Abbott et al, 1999; Lau et al., 2004). In the context of the SCM, previous studies suggested more research is needed to investigate relationships between sport identity and sport commitment to support the notion that sport identity is positively related to sport commitment (Frayeh \& Lewis, 2017; Hall, 1993; Zahariadis et al., 2006). In the current 
study, sport identity reflected the importance of personal identity with the sport (Pickett \& Cunningham, 2018). For instance, older adults were asked how much they agreed with the following statement: "Sport activity is an important reflection of who I am and sport activity is an important part of my self-image." Higher scores indicated a greater level of identification with the sport activity.

For RQ1c, sport identity was entered into the last block for Step 3 (see Model 3 in Table 10) and the $R^{2}$ adj increased from .45 (in the model 2) to .46 . This increase (1\%) was statistically significant $(p<0.01)$. Therefore, the results supported that sport identity does explain a significant incremental variance in sport commitment over and above the seven antecedent factors, including sport satisfaction, among older adults. This means that sport identity significantly contributes to sport commitment after controlling for the other antecedent factors as well as sport satisfaction in the regression model. Specifically, an older adult who highly identified with their organized sport activity is more likely to continue to participate in the organized sport activity and they would not quit easily.

Older adults who indicated a greater level of identification with sport activity agreed that organized sport activity is an important reflection of both who they are and their self-image; moreover, their organized sport activity has a lot to do with how they feel about themselves. Therefore, sport participation is an integral aspect of personal identity for older adults who are retired or soon will be retired. Model 3 determined that sport enjoyment, involvement opportunities, sport satisfaction and sport identity were significant predictors, and therefore, Hypothesis 1c was supported. This finding supports the idea that regular participation may help form and maintain as well as strengthen an individual's identity with sport and physical activity (Klenin et al, 1993; Laverie, 1998; 
Lau et al., 2004). Studies also support the notion that sport identity is a significant predictor of sport commitment (Frayeh \& Lewis, 2017; Hall, 1993; Yair 1990) and highly identified sport and physical participants are willing to frequently participate in sport and physical activities (Jun \& Kyle, 2012; Kay \& Jackson, 1991; Klenin et al., 1993; Laverie, 1998; Lau et al., 2004; Won \& Hwang, 2008).

Social support (from Model 1) and personal investments (from Model 2) were no longer significant predictors of sport commitment in Model 3. Sport enjoyment was the strongest predictor $(\beta=0.33)$ followed by sport satisfaction $(\beta=0.18)$, involvement opportunities $(\beta=0.15)$, and sport identity $(\beta=0.11)$. Hence, the level of sport commitment increases when sport enjoyment, sport satisfaction, involvement opportunities, and sport identity respectively increase. These findings are also consistent with the prior results (RQ1a) and previous studies that determined sport enjoyment and involvement opportunities were strong predictors and explained significant amounts of variance in sport commitment regardless of age or type of sports or activities (Crocker \& Augaitis, 2010; Jeon \& Casper, 2016). Moreover, this model confirmed that sport satisfaction and sport identity were additional predictors of the SCM with the sample of older adults in this study. Although the extended SCM with sport satisfaction and sport identity appears to be a sufficient theoretical framework for the study of older adults and organized sport activity, it should be re-evaluated for the items that contribute directly to its constructs such as involvement opportunities, sport satisfaction, and sport identity. Previous studies used different items (e.g. "I find exercising to be very rewarding") for the satisfaction construct, and other theoretical constructs (e.g., athletic identity) to 
examine the SCM model (Brewer et al., 1993; Wilson et al., 2004, p. 419). Therefore, more empirical research is needed to support the expanded SCM for older adults.

\section{Summary}

In sum, the SCM was utilized in this study to explore the underlying psychological characteristics and behaviors of older adults, as well as to determine the reasons they continue to participate in organized sport and physical activities. The results of this study provided empirical evidence regarding sport commitment and predictors of sport commitment toward participating in organized sport and physical activity among older adults in the United States. The findings suggested that the extended SCM (with two additional constructs, sport identity and sport satisfaction) is a valid theoretical framework to examine the older adult population. Understanding how an older adult makes a decision to participate in sport and physical activity is critical to researchers, health professionals and sport program providers who want to know the reasons why some people are physically active whereas others are not (Molanorouzi et al, 2015). Using the SCM with sport identity and satisfaction assists in determining how decisions are made to keep older adults participating in organized sports activities. The results of this study revealed that sport enjoyment, sport satisfaction involvement opportunities, and sport identity were important sport commitment factors for the sample of older adults to maintain and continue to participate in organized sport activity. For older adults, experiencing positive feelings, such as pleasure, happiness, and love, through their organized sport and valuable opportunities attained by participating in organized sport activity, such as relieving stress and improving overall health and fitness, were important to increasing the willingness to continue to participate in organized sport and physical 
activity. Moreover, high identification with their organized sport activity and high satisfaction with their organized sport activity led to increased commitment. Since there is still relatively little sport commitment literature in the context of organized sport activity for older adults, more empirical research will reveal the robust determinants of sport commitment among older adults. The current study extends the literature on older adults' sport commitment and sport participation behavior, by incorporating the SCM, the concept of sport satisfaction and sport identity

\section{Theoretical Implications of Second Research Question}

Theoretically, the importance of involvement in sport and physical activity for well-being and life satisfaction among older adults can be understood through activity theory (Havighurst, 1961). Activity theory proposes that successful aging occurs when individuals continue to intensively participate in social and leisure activities from middle adulthood into old age, and then adapt when life roles change (e.g., retirement) (Adams et al., 2011; Snyder, 1981). Many studies have empirically demonstrated a significant relationship between participation in sport, exercise, and physical activities and life satisfaction among older adults (Jenkin et al., 2017; Jenkin et al., 2018; McPhee et al., 2016; Ryu et al., 2018). Snyder (1981) argued, however, that activity theory is limited in explaining why older adults are active or inactive and why they continue or discontinue participating. Furthermore, Snyder stated that "the configuration and depth of commitment will be more critical in determining quality of life and well-being in old age" (p.115). Snyder suggested that the concept of commitment might be incorporated into activity theory to explore sport participation behavior in middle and old age. Specifically, it would be important to know how individuals achieve life satisfaction from commitment 
and its components (e.g., identity, and satisfaction). However, the relationships among life satisfaction, sport commitment and components of commitment have not been fully studied empirically. Furthermore, an examination of the literature revealed no studies on the relationship between the SCM and life satisfaction.

\section{Life Satisfaction}

Life satisfaction represents "a cognitive evaluation of the quality of an individual's life as a whole" (Eklund \& Tenenbaum, 2013, p.609). As a psychosocial benefit, life satisfaction is one of the elements that determine successful aging (Ryu et al., 2018; Siegenthaler \& O’Dell, 2003). More research is needed to have a better understanding of the factors that contribute to life satisfaction through participation in sport or leisure activities (Ryu et al., 2018). Thus, the current study suggests that the life satisfaction regression model can help examine the relationship between important psychological factors (i.e., sport identity, sport satisfaction, and sport commitment) that significantly relate to sport behavior and life satisfaction. It is important to note that predictors (e.g., sport enjoyment) in the SCM were excluded in this study because of no specific literature to examine the direct relationships between sport life satisfaction and the sport commitment with its antecedents simultaneously. Table 16 presents a basic overview of the findings for RQ2 which examined life satisfaction. Explanations for each level of the table are provided in the sections that follow.

Table 16 Summary of Significant Findings from RQ2 of life satisfaction? 


\begin{tabular}{ll}
\hline Sport satisfaction & Yes \\
Sport identity & No \\
Sport commitment & No \\
\hline
\end{tabular}

Simultaneous regression, as a multiple regression method, was conducted to determine the extent of the influence of sport satisfaction, sport identity, and sport commitment on the level of life satisfaction among older adults who regularly participate in organized sport activities. The results indicated a linear relationship between variables, and the life satisfaction model was a good fit for the sample data in this study. However, approximately only $5 \%$ of the variance in life satisfaction was explained by sport satisfaction, sport identity, and sport commitment for older adults who regularly participate in organized sport activity. This means that about $95 \%$ of the variance can be explained by factors other than sport satisfaction, sport identity, and sport commitment in the life satisfaction model. This finding is not surprising because a previous study determined that levels of life satisfaction vary from day to day based on changes in sedentary behavior and physical activity across the adult life span (Maher \& Conroy, 2015). Importantly, leisure activities can include sedentary behaviors, such as reading, listening to music, and watching TV, along with other more physical activities. These physically low-demand leisure activities significantly contribute to improving mental health status later in life (Everard, Lach, Fisher, \& Baum, 2000; Ryu et al., 2018). Moreover, previous studies have also suggested that an individual's life satisfaction may relate to numerous different aspects such as participation in social activities, important 
life events, health conditions, and demographic characteristics (e.g., age, gender, retirement, education level, income level, marital status, family life and societal life) (Lapa, 2013; Sener et al., 2007). Surprisingly, Baird et al. (2010) indicated that most adults (between age 40 and 70 years old) feel satisfied with their lives even though they may experience an increase in physical problems and illnesses in later life. These findings suggest life satisfaction can be enhanced through a multifaceted experience (Ryu et al., 2018).

\section{Life Satisfaction and Sport Satisfaction}

In the present study, the results of the simultaneous regression analysis indicated that of the three proposed predictors, only sport satisfaction $(b=.25)$ was a significant predictor of life satisfaction, supporting Hypothesis 2a. This means that after controlling for sport identity and sport commitment in the regression model, only sport satisfaction positively increased the level of life satisfaction among older adults who regularly participate in organized sport activities. The finding suggests that among older adults, high levels of satisfaction in an organized sport activity significantly and positively contributes to life satisfaction. This finding is consistent with previous studies where sport and leisure satisfaction were significantly associated with life satisfaction (Baudin, Aluja, Rolland, \& Blanch, 2011; Lapa, 2013; Ragheb, \& Griffith, 1982). Ragheb and Griffith (1982) found older adults who have higher levels of leisure satisfaction experienced greater satisfaction with life. Lapa (2013) carried out a study on recreation sports activity participants and found a positive linear association between life satisfaction and leisure satisfaction obtained from positive experiences of leisure activity. Likewise, life satisfaction and sport satisfaction were moderately associated for the adult 
sport participants (e.g., Handball, football, US football, rugby) (Baudin et al, 2013). Therefore, recognizing the factors that significantly contribute to sport satisfaction are crucial to enhancing life satisfaction among older adults who participate in organized sport and physical activities.

Importantly, literature related to physical activity and exercise participation suggested that people who have meaningful social interactions through physical activity and exercise participation were more likely to have higher levels of sport satisfaction (Eklund \& Tenenbaum, 2013). The findings of the present study also suggest positive experiences of organized sport participation that provide greater social interaction with other participants (e.g., teammates or opponents) can lead to greater sport satisfaction, increased desire to continue to participating in sport, and improved life satisfaction. Currently sport policies and programs for organized sport and physical activity typically prioritize participation by younger age populations (Jenkin et al., 2018). More sport and physical activity programs should be available for older adults who are insufficiently active.

\section{Life Satisfaction and Sport Identity}

The study results revealed that sport identity was not a significant predictor of life satisfaction. Therefore, Hypothesis $2 \mathrm{~b}$ was not supported, and sport identity did not contribute to life satisfaction among older adults who participated in organized sport activity and physical activity. This finding did not support previous studies reporting that individuals with strong sport and exercise identity experience greater satisfaction with life (Hardcastle \& Tayler, 2005; Strachan et al., 2010). However, these studies utilized physical identity or athletic identity measurements (Brewer et al, 1993) to assess the level 
of older adults' identity with specific physical acidity or exercise. It is important to note that many theoretical constructs have been utilized to measure active sport participants' identity toward a specific sport and physical activity (e.g., athletic identity, sport identity, exercise identity and leisure identity). Thus, caution should be taken with the findings of this study because the results may be different or vary depending on which theoretical constructs and measures were selected in other studies in the literature.

\section{Life Satisfaction and Sport Commitment}

Furthermore, results revealed that sport commitment was not a significant predictor of life satisfaction, and Hypothesis 2c was not supported. Despite the results of the multiple regression, it is important to note that the correlation matrix indicated a significant correlation between life satisfaction and sport commitment $(r=.13)$. However, this small effect would not be significant if the sample size was smaller. Therefore, the result should be interpreted with caution since in the current study the results were not statistically significant.

No study has examined the direct and positive relationship between sport commitment and life satisfaction. However, a previous study indicated that participation frequency in physical activity and exercise is an important contributor to increasing the level of life satisfaction in older adults (McAuley et al., 2000). Sport commitment has been determined to be an important contributor to increasing participation frequency among sport participants in variety of sport contexts (e.g., tennis, windsurfing, and taekwondo) (Casper et al., 2007; Jeon \& Casper 2016; Jeon, \& Ridinger, 2009). Despite the fact that the regression analysis indicated that sport commitment was not a significant contributor, the current study is an important first step in understanding the relationship 
between sport commitment and life satisfaction for participation in organized sport participation among older adults. Therefore, it would be fruitful to consider more research on these relationships among these antecedents and older adults participating in organized sport and physical activity.

\section{Summary}

In sum, the results of this study provided empirical evidence regarding the relationships between sport satisfaction, sport identity, sport commitment and life satisfaction among older adults in the United States. Sport management scholars have noted the importance of organized sport events and programing (e.g., distance running events, family swim nights) in increasing the rate of participation in physical activity by establishing links between organized sport participation and public health benefits (e.g., life satisfaction) (Sato, Jordan, \& Funk, 2016). To contribute to overcoming the decline in physical activity among older adults, this study highlighted the importance of understanding theoretical relationships among important psychological factors (i.e., sport identity, sport satisfaction, and sport commitment). The findings of the current study indicated that older adults who are currently satisfied with their organized sport activity and its experiences experience greater life satisfaction. Therefore, the current study suggested that sport satisfaction is an important factor which contributes not only to sport

commitment but also to life satisfaction among older adults. The findings also support the view of the activity theory of aging that suggests active lifestyles lead to successful aging (Havighurst, 1961; Ryu et al., 2018). However, there is still relatively little literature on the theoretical relationships among important psychological factors on the well-being of older adults who regularly participate in organized sport and physical activity. 
Specifically, much more empirical evidence needs to be explored to support Snyder's claim of the significant relationships among sport commitment, elements of the sport commitment (e.g., sport satisfaction, sport identity) in the well-being of older adults.

\section{Recommendations for Future Research}

The current study determined important factors predicting older adults' sport commitment toward organized sport activity and their satisfaction with life. The findings determined that older adults who continue to participate in organized sport activity over time do so because they experienced positive feelings along with perceived health benefits from sport, satisfaction with his or her choice of sport, and an increased sense of self through sport (e.g., self-image). Moreover, older adults who are highly satisfied with their choice of organized sport activity were more likely to be satisfied with their life. Therefore, these findings contributed to the understanding of participation in organized sport activities among older adults and prompted some suggestions for further research.

Three areas need to be explored: (a) demographic differences in participation by older adults, (b) additional variables which may influence greater sport commitment and increase levels of life satisfaction, and (c) different theoretical constructs and measures of sport identity and sport satisfaction among older adults.

First, future research could examine demographic differences, specifically age and gender differences. Based on previous health promotion and competitive sport participation studie, this study defined older adults as those who were aged 55 and older (Dionigi, 2002; Lyons \& Dionigi, 2007; Walker et al., 1988). However, there are different age classifications or ranges for defining older adults. For instance, the Centers for Disease Control and Prevention (2020) defined the older adult group as people 64 and 
older. Moreover, the number of people in the age group of 65 to 75 years is significantly increasing and that group is at a higher risk of contracting diseases and illnesses globally (World Health Organization, 2013). As people live longer, researchers suggest that individuals between 65 and 75 should be considered middle aged. For those aged 75 and older, chronic disease appears significantly more likely (Pinsker, 2020). Therefore, future studies could evaluate how sport commitment and determinants of sport commitment (including sport identity and sport satisfaction) differ based on three different older age groups - adults (55 to 64 years old), middle-aged (65 to 74 years old), and older adults (75 years old and over).

For gender differences, previous studies indicated a significant gender gap in sport and physical activity participation (Lee, 2005; Lim \& Tylor, 2004; Murphy, 2018). In general, approximately $19 \%$ of the U.S. population was involved in sports, exercise, and recreational activities per day in 2018. Specifically, men (about 21\%) were more likely to participate in sport, exercise, and recreational activities each day compared to women (about 17\%) although this same report indicated the rate of women's participation increased from 15\% in 2010 to $19 \%$ in 2016 (Gough, 2019). For the older adult population, older women were generally more sedentary and less involved in regular physical activities compared to older men (Lee, 2005). Researchers report significant gender differences in types of sport and physical activity, motives, constraints, attitudes and behaviors (Hanlon, Morris, \& Nabbs, 2010, 2014; Koivula, 1999; Lee, 2005; Lim \& Tylor, 2004; Lim, Warner, Dixon, Berg, Kim, \& Newhouse-Bailey, 2011; Wiley, Shaw, \& Havitz, 2000). Therefore, future researchers could consider examining gender differences for older adults using the SCM and suggested life satisfaction model. These 
results would be valuable and would contribute to further understanding the trends in regular participation in organized sport activity among older adults.

Additionally, researchers previously investigated demographic differences (e.g., age, income, sex, and skill level) of sport commitment and the determinants of sport commitment among adults (Casper, 2007; Casper \& Stellino, 2008; Jeon \& Casper, 2016). To get to a more sophisticated understanding of attitudes and behaviors toward organized sport activity participation, researchers need to evaluate how sport commitment and the determinants of sport commitment, including sport identity and sport satisfaction, differ based on demographic characteristics among older adults.

Second, this study indicated that the original SCM explained less variance in sport commitment among older adults (range between 50 to 98) compared to youth and younger adult samples (Casper \& Stellino, 2008; Casper et al., 2007). Therefore, a number of other variables may influence sport commitment and levels of life satisfaction. The current study did not take into account organizational or program-based factors (e.g., resources, affordability, accessibility, type of sport and physical activity) or environmental influences (e.g., safe footpaths, safe neighborhoods, and weather) which may also contribute to or inhibit regular participation in sport and physical activities among older adults (Lim \& Taylar, 2005). Sport enjoyment was the strongest predictor of sport commitment and it may also contribute to increasing the level of life satisfaction among older adults who regularly participate in organized sport activities (Snyder, 1981). Therefore, future researchers could consider examining those additional variables to explore the relationships with both sport commitment and life satisfaction using regression models. 
Third, future researchers could evaluate different theoretical constructs and measures of sport identity and sport satisfaction among older adults. Many theoretical constructs have been utilized (e.g., athletic identity, exercise identity, and leisure identity) to measure active sport participants' identity with a specific sport and physical activity. For sport satisfaction, Beard and Ragheb's (1980) Leisure Satisfaction Scale has been employed to assess "the perceptions or feelings which an individual forms, elicits, or gains as a result of engaging in leisure activities and choice and reflecting the degree to which one is presently content or pleased with his/her general leisure experiences and situations" (Ragheb \& Tate, 1993, p. 65). The scale has been widely used in the context of sport, recreation, and physical activities (Lapa, 2013; Rejeski \& Mihalko, 2001; Strachan et al., 2010). Depending on different constructs and measures, the results may vary on which theoretical constructs and measures are selected and may produce more robust empirical results.

These recommendations for follow-up studies could contribute to a more detailed understanding of organized sport participation among older adults. These recommendations can assist recreational sport managers and program/league directors for older adults to maintain and increase adequate sport and physical activity programs. These programs will help older adult meet the previously recommended activity guidelines from the Centers for Disease Control and Prevention (2020) to improve their physical and mental health as well as social health and well-being. With significantly less literature on effects associated with older adults' participation in organized sport activities, (Joseph et al., 2010), more studies and empirical evidence are needed to support the statistically significant relationships among the determinants of sport 
commitment, including sport satisfaction and sport identity, and sport commitment in the well-being of older adults.

\section{Practical Implications}

Previous studies indicated the rates of participation in sport and physical activity by older adults decreases significantly as people age (Jenkin et al., 2017; Tischer et al., 2011). The U.S. Bureau of Labor Statistics indicated that individuals aged 55 and over were less likely to engage in team or group sport and exercise activities compared to other age groups (those aged 15 to 24 years and aged 25 to 54) (Woods, 2017). In order to attract inactive older adults to regularly participate in organized sport activity, it is important to understand how current organized sport participants are committed to their organized sport activities. Using the extended SCM with sport satisfaction and sport identity, the current study determined important factors that may increase the level of sport commitment among older adults. These findings will provide practical suggestions that may guide activities and programming aimed at promoting organized sport activity among older adults. The findings suggest the following actions: (a) emphasizing the positive aspects of participation, (b) offering a variety of sports which would interest older adults, (c) providing health and fitness information, (d) offering activities which help older adults enrich their identity, and (e) evaluating older adults' satisfaction with current activity offerings.

The findings of this study suggested positive feelings (such as pleasure, liking, happy, and love) and experiences such as relieving stress and improving overall health contribute to increasing an individual's degree of sport commitment and willingness to continue to participate. Thus, public or private sport and physical activity facilities and 
service providers should emphasize the positive experiences and the physical and social health benefits of participating in group sport activities (e.g., tennis, bowling, golf, and pickleball) that are popular sports for older adults. For instance, facility and service providers can offer family and friends opportunities to participate in mini trainings, tournaments or events. These activities should focus on promoting enjoyable experiences that can be obtained only through participation with family and friends rather than competition. The current study found that the majority of respondents $(64 \%)$ were influenced to participate by significant others (e.g., family, peers, and friends) and had participated in organized sport activities for more than 10 years. Therefore, these trainings, tournaments or events should encourage regular participants to bring along their friends and family members who are less active. They could be rewarded with free training programs to improve sport skills as well so as to encourage their friends and family members to participate in organized sport activities.

More different types of organized sport and physical activities need to be made available for older adults. Promoting and emphasizing the valuable opportunities that are present only through continued involvement (e.g., health benefits) may help increase their level of commitment. Medicareful (2019) suggested three sports (tennis, soccer, and basketball) as good possibilities for seniors who want to begin to participate and maintain an active lifestyle. These sports can provide a fun and enjoyable environment with others while improving health and fitness (Medicareful, 2019). These suggestions are in line with the findings of this study. If older adults enjoy these sports, they would be willing to do what they are able in order to keep participating. For instance, the game of pickleball is a newly introduced racket sport that has seen significant growth and become popular 
with older adults. It can be played on the same size court as a badminton court at a basketball gym. Scholars suggest that pickleball participation can be used as a strategy to cope with life transition for retirees to spend their free time productively (Ryu et al., 2018). Other sports that can be suggested to older adults include walking, soccer/football, (United States Adult Soccer Association, 2020), and FootGolf (American FootGolf Federation, 2020). Facility and service providers need to develop appropriate promotion and marketing strategies showcasing positive experiences and health related benefits to introduce these newly formed sports to attract inactive or insufficiently active older adults. Additionally, public or private health administrators and personal trainers working in clinical health settings should provide older adults with adequate health and fitness information. Previous studies found that some older adults were not aware of the right amount of time to spend on participating in sport and physical activity (Dergance et al., 2003; Hirvensalo \& Lintunen, 2011). Therefore, public or private health administrators and personal trainers can provide resources on how much exercise time is appropriate and on proper nutrition to increase physical health and fitness. This information may provide both active and insufficiently active older adults a better understanding of the importance of the health and fitness benefits gained through organized sport participation. Thus, as findings of this study suggested, acknowledging health and fitness benefits of organized sport participation may help enhance involvement opportunities and increase levels of sport commitment among older adults.

The current study suggested that sport identity is an important contributing factor for increasing sport commitment among older adults. If older adults increase their selfimage and reflect on who they are through organized sport activities, they become more 
willing to keep participating in their sport. Moreover, older adults can strengthen their personal identity through participating in organized sport activities. No matter what age, people feel the need to be connected to others. Some reports indicate people do not consider taking retirement early because of three common fears: "running out of money, loss of community, and loss of identity" (Hoffower, 2019, para. 1). These fears can apply to anyone who is ready to retire. To address these fears, people working in recreational settings should offer people nearing retirement the opportunity to participate in organized or group sport activities mentioned above. These sport activities may replace the time and meaning they gained from recent or previous work (Hoffower, 2019). Specifically these organized or group sport activities help people to (a) maintain their health in order to save health costs, (b) meet new friends and gain a new community group for social interaction, and (c) develop a new identity through a new activity (Hoffower, 2019). If people join a sport group or team (e.g., Derby City tennis league, senior baseball or softball league), they are not only playing the game and practicing together but also celebrating a specific day together. People can develop and value an identity by being a team member (Symes, 2010). Previous studies suggested that positive feelings, social connections, atmosphere, and physical and psychological benefits influenced participants' continued participation in sport activities and enhanced feelings of identity (Laverie, 1998). Therefore, it can be assumed that organized sport participation which results in building sport identity leads to a strong feeling or sense of self. Therefore, public or private sport and physical activity facilities and service providers should offer a diverse group of leagues and tournaments. These offerings can emphasize and maintain team and group sport participation. For instance, the city of New Albany Parks and Recreation provides the use of its indoor turf 
facility (known as Silver Street Park) to host adult and senior sport leagues such as a senior softball league, indoor "pick-up" ultimate frisbee, indoor slow pitch softball leagues and tournaments, and indoor adult co-ed kickball (7 on 7) during the winter (City of New Albany Parks \& Recreation, 2020). The leagues have registration fees and championship matches. These leagues help participants develop and form their identity through competition and social connections with teammates and opponents.

Lastly, this study demonstrated that older adults who are satisfied with their decision to participate in organized sport activities are more likely to have increased levels of sport commitment, higher participation frequency, and are more likely satisfied with their life in general. Therefore, facility and service providers need to evaluate older adult participants' level of sport satisfaction with their choice of above-mentioned programs and sports, such as mini trainings and events, health clinic programs, and more as well as newly formed sports. These self-evaluations need to examine enjoyment, health benefits, and identity to observe how willing older adults are to continue to participate in the sport. This information can be used to inform strategy for facility and service providers to encourage both active and insufficiently active older adults to not only increase their organized sport participation but also meet recommended activity guidelines to improve their physical, mental, and social health and well-being (Centers for Disease Control and Prevention, 2020; Jenkin et al., 2017; World Health Organization, 2018b). These guidelines include a combination of at least 150 minutes a week of moderate intensity activity such as brisk walking and at least two days a week of activities that strengthen muscles (Centers for Disease Control and Prevention, 2020). 


\section{Summary of the Study}

In sum, the findings of this study provide both scholars and practitioners with valuable insights into understanding the relationship among sport satisfaction, sport identity, sport commitment, and life satisfaction among older adults. From a theoretical perspective, this study expanded and advanced knowledge on sport participation among older adults by addressing the theoretical relationships among sport participation and life satisfaction based on activity theory, identity theory, and the SCM. From a practical perspective, the findings provide helpful resources for public or private sport and physical activity service providers and other practitioners working closely with older adults. They will gain a better understanding of (a) the importance of psychological aspects which help people to continue to participate in organized sport activity; (b) the importance of the role of sport identity, sport satisfaction and level of sport commitment toward organized sport participation; and (c) the significant positive relationship between levels of sport satisfaction and sport commitment at the level of one's life satisfaction. Therefore, these findings would help older adult sport and physical activity service providers or practitioners to understand why older adults participate in organized sport activities. Knowing this could help practitioners develop effective marketing and promotion plans to attract and sustain current participants and encourage beginners or inactive older adults to participate in organized sport activities. 


\section{REFERENCES}

Abbott, C. L., Weinmann, C. A., Bailey, C. I., \& Laguna, P. L. (1999). The relationship between sport salience and choice behaviour in Division I collegiate baseball players. International Journal of Sport Psychology, 30(3), 369-380.

Adams, K. B., Leibbrandt, S., \& Moon, H. (2011). A critical review of the literature on social and leisure activity and wellbeing in later life. Ageing \& Society, 31(4), 683-712.

Alexandris, K., \& Carroll, B. (1998). The relationship between selected demographic variables and recreational sport participation in Greece. International Review for the Sociology of Sport, 33(3), 291-297.

Alexandris, K., Zahariadis, P., Tsorbatzoudis, C., \& Grouios, G. (2002). Testing the sport commitment model in the contest of exercise and fitness participation. Journal of Sport Behavior, 25(3), 217-230.

Alexandris, K., Zahariadis, P., Tsorbatzoudis, C., \& Grouios, G. (2004). An empirical investigation of the relationships among service quality, customer satisfaction and psychological commitment in a health club context. European Sport Management Quarterly, 4(1), 36-52.

Allender, S., Cowburn, G., \& Foster, C. (2006). Understanding participation in sport and physical activity among children and adults: a review of qualitative studies. Health Education Research, 21(6), 826-835.

American FootGolf Federation. (2020). American footGolf league footGolf in the United States. Retrieved from https://www.footgolf.us/about-footgolf

Anderson, D. F., \& Cychosz, C. M. (1994). Development of an exercise identity scale. Perceptual and Motor Skills, 78(3), 747-751.

Andrew, D., Pedersen, P., \& McEvoy, C. (2011). Research methods and design in sport management. Champaign, IL: Human Kinetics.

Andriot, A., \& Owens, T. J. (2012, April 24). Identity. Oxford Bibliographies. Retrieved from https://www.oxfordbibliographies.com/view/document/obo9780199756384/obo-9780199756384-0025.xml 
Baird, B. M., Lucas, R. E., \& Donnellan, M. B. (2010). Life satisfaction across the lifespan: Findings from two nationally representative panel studies. Social Indicators Research, 99(2), 183-203.

Baker, J., Fraser-Thomas, J., Dionigi, R. A., \& Horton, S. (2010). Sport participation and positive development in older persons. European Review of Aging and Physical Activity, 7(1), 3-12. Do: https://doi.org/10.1007/s11556-009-0054-9

Balaska, P., \& Kouthouris, C. (2014). Promoting sport participation in Greece: issues and challenges. International Journal of Sport Management, Recreation and Tourism, $13,63-84$.

Barratt, J. (2017, February 14). We are living longer than ever. But are we living better? STAT. Retrieved from https://www.statnews.com/2017/02/14/living-longer-livingbetter-aging/

Baudin, N., Aluja, A., Rolland, J. P., \& Blanch, A. (2011). The role of personality in satisfaction with life and sport. Behavioral Psychology /Psicologia Conductual, 19(2), 333-345.

Beard, J. G., \& Ragheb, M. G. (1980). Measuring leisure satisfaction. Journal of leisure Research, 12(1), 20-33.Bennett, G., Henson, R., \& Zhang, J. (2002). Action sports sponsorship recognition. Sport Marketing Quarterly, 11(3), 174-185.

Bloom, M., Grant, M., \& Watt, D. (2005). Strengthening Canada: The socio-economic benefits of sport participation in Canada. Ottawa, Ontario: The Conference Board of Canada.

Bodet, G. (2012). Loyalty in sport participation services: An examination of the mediating role of psychological commitment. Journal of Sport Management, 26(1), 30-42.

Brewer, B. W., van Raalte, J. L., \& Linder, D. E. (1993). Athletic identity: Hercules' muscles or Achilles heel?. International Journal of Sport Psychology, 24(2), 237254

Brockman, K. (2019, Jun 11). The one retirement risk you're probably not preparing for? Depression. USA Today. Retrieved from https://www.usatoday.com/story/money/2019/06/11/depression-duringretirement-how-cope-and-prepare/1416091001/

Burke, P. J., \& Stets, J. E. (2009). Identity theory. New York: Oxford University Press

Byers, T., Slack, T., \& Parent, M. (2012). Key concepts in sport management. London: SAGE. 
Callero, P. L. (1985). Role-identity salience. Social Psychology Quarterly, 203-215.

Carpenter, P. J., \& Coleman, R. (1998). A longitudinal study of elite youth cricketers' commitment. International Journal of Sport Psychology, 29(3), 195-210.

Carpenter, P. J., Scanlan, T. K., Simons, J. P., \& Lobel, M. (1993). A test of the sport commitment model using structural equation modeling. Journal of Sport and exercise Psychology, 15, 119-133.

Casper, J. (2007). Sport commitment, participation frequency and purchase intention segmentation based on age, gender, income and skill level with us tennis participants. European Sport Management Quarterly, 7(3), 269-282.

Casper, J. M., \& Andrew, D. P. S. (2008). Sport commitment differences among tennis players on the basis of participation outlet and skill level. Journal of Sport Behavior, 31(3), 201-219

Casper, J. M., \& Stellino, M. B. (2008). Demographic predictors of recreational tennis participants' sport commitment. Journal of Park \& Recreation Administration, 26(3), 93-115

Casper, J. M., Gray, D. P., \& Stellino, M. B. (2007). A sport commitment model perspective on adult tennis players' participation frequency and purchase intention. Sport Management Review, 10(3), 253-278.

Caspersen, C. J., Powell, K. E., \& Christenson, G. M. (1985). Physical Activity, Exercise, and Physical Fitness: Definitions and Distinctions for Health-Related Research. Public Health Reports, 126-131.

Cattell, R. B. (1966). The scree test for the number of factors. Multivariate Behavioral Research, 1(2), 245-276.

Centers for Disease Control and Prevention (2020, January 31). Physical activity recommendations for different age groups. Retrieved from https://www.cdc.gov/physicalactivity/basics/age-chart.html

Chang, S., \& Gibson, H. J. (2015). The relationships between four concepts (involvement, commitment, loyalty, and habit) and consistency in behavior across leisure and tourism. Tourism Management Perspectives, 13, 41-50.

Chen, K. K., \& Zhang, J. J. (2012). To name it or not name it: Consumer perspectives on facility naming rights sponsorship in collegiate athletics. Journal of Issues in Intercollegiate Athletics, 5, 119-148. 
Chu, A. Y., \& Wang, C. H. (2012). Differences in level of sport commitment among college dance sport competitors. Social Behavior and Personality: an international journal, 40(5), 755-766.

City of New Albany Parks \& Recreation. (2020). Recreation brochure. Retrieved from https://cityofnewalbany.com/residents/parks-a-recreation/

Clopton, A. W. (2011). Social capital and college sport: In search of the bridging potential of intercollegiate athletics. Journal of Intercollegiate Sport, 4, 174-189.

Cohen, J. (1988). Statistical power analysis for the behavioral sciences (2nd ed.). Hillsdale, NJ: Erlbaum.

Costello, A. B., \& Osborne, J. W. (2005). Best practices in exploratory factor analysis: Four recommendations for getting the most from your analysis. Practical Assessment, Research, \& Evaluation, 10, 1-9

Crandall, R. (1980). Motivations for leisure. Journal of Leisure Research, 12(1), 45-54.

Creswell, J. W. (2012). Educational research: Planning, conducting, and evaluating quantitative and qualitative research (4th ed.). Upper Saddle River, NJ: Prentice Hall. Pearson

Creswell, J. W. (2013). Educational research (4 ${ }^{\text {th }}$ ed.). Thousand Oaks, CA: Sage Publications, Inc.

Crocker, P. R., \& Augaitis, L. (2010). Commitment in age class adult triathletes: examining gender differences in the sport commitment model. International Journal of Sport Psychology, 41(2), 177-194.

Crompton, J. L., Jackson, E. L., \& Witt, P. (2005). Integrating benefits to leisure with constraints to leisure. In E. L. Jackson (Ed.), Constraints to leisure (pp. 245-260). State College, PA: Venture Publishing.

Curry, T. J., \& Parr, R. (1988). Comparing commitment to sport and religion at a Christian college. Sociology of Sport Journal, 5(4), 369-377.

Curry, T. J., \& Weaner, J. S. (1987). Sport identity salience, commitment, and the involvement of self in role: Measurement issues. Sociology of Sport Journal, 4(3), 280-288.

Curry, T. J., \& Weiss, O. (1989). Sport identity and motivation for sport participation: A comparison between American college athletes and Austrian student sport club members. Sociology of Sport Journal, 6(3), 257-268. 
Deaux, K. (1992). Personalizing identity and socializing self. In G. Breakwell (Ed.), Social psychology of identity and the self-concept (pp. 9-33). New York: Surrey University Press.

Deaux, K. (1993). Reconstructing social identity. Personality and Social Psychology Bulletin, 19(1), 4-12.

Dergance, J. M., Calmbach, W. L., Dhanda, R., Miles, T. P., Hazuda, H. P., \& Mouton, C. P. (2003). Barriers to and benefits of leisure time physical activity in the elderly: differences across cultures. Journal of the American Geriatrics Society, 51(6), $863-868$.

DeVellis, R. F. (2017). Scale development : theory and applications (4th ed., Ser. Applied social research methods series, v. 26). Los Angeles: Sage Publications.

Dionigi, R. (2002). Leisure and identity management in later life: Understanding competitive sport participation among older adults. World Leisure Journal, 44(3), 4-15.

Dionigi, R. A., \& Son, J. S. (2017). Introduction to critical perspectives on physical activity, sport, play and leisure in later life. Annals of Leisure Research, 20(1), 1-6.

Eklund, R. C., \& Tenenbaum, G. (2013). Encyclopedia of sport and exercise psychology. Sage Publications.

Fernandes, N. E., Correia, A. H., Abreu, A. M., \& Biscaia, R. (2013). Relationship between sport commitment and sport consumer behavior. Motricidade, 9(4), 2-11.

Fraenkel, J., \& Wallen, N. (2009). How to design and evaluate research in education (7th ed. ed.). New York, NY: McGraw-Hill.

Frayeh, A. L., \& Lewis, B. (2017). Sport commitment among adult recreational soccer players: Test of an expanded model. International Journal of Exercise Science, $10(1), 4-24$.

Frederick, C. M., Morrison, C., \& Manning, T. (1996). Motivation to participate, exercise affect, and outcome behaviors toward physical activity. Perceptual and Motor Skills, 82(2), 691-701.

Funk, D. C., Alexandris, K., \& McDonald, H. (2016). Sport consumer behaviour: Marketing strategies. New York, NY: Routledge.

Everard, K. M., Lach, H. W., Fisher, E. B., \& Baum, M. C. (2000). Relationship of activity and social support to the functional health of older adults. The Journals of Gerontology Series B: Psychological Sciences and Social Sciences, 55(4), S208S212. 
Gladych, P. A. (2016, Febryary 26). How employers can help workers deal with longevity risk. Employee Benefit News. Retrieved from https://www.benefitnews.com/news/how-employers-can-help-workers-deal-withlongevity-risk

Goodwin, L. D., \& Leech, N. L. (2003). The meaning of validity in the new standards for educational and psychological testing: Implications for measurement courses. Measurement \& Evaluation In Counseling \& Development (American Counseling Association), 36(3), 181-191.

Gorsuch, R. L. (1983). Factor analysis (2nd Ed.). Hillsdale, NJ: Erlbaum.

Gough, C. (2019, July 3). Percentage of U.S. population engaged in sports and exercise per day 2010-2018. Retrieved from https://www.statista.com/statistics/189562/daily-engagement-of-the-uspoppulation-in-sports-and-exercise/

Granero-Gallegos, A., Baena-Extremera, A., Gómez-López, M., \& Abraldes, J. A. (2014). Psychometric properties of the "Sport Satisfaction Instrument (SSI)" in female athletes: predictive model of sport commitment. Psychological Reports, 115(1), 148-164.

Gratton, C., \& Jones, I. (2004). Research methods for sport studies. London: Routledge.

Green, S. B. (1991). How many subjects does it take to do a regression analysis? Multivariate Behavioral Research, 26, 499-510.

Green, S. B., \& Salkind, N. J. (2013). Using SPSS for Windows and Macintosh: Analyzing and understanding data (7th ed.). Hillsdale, NJ: Pearson.

Guadagnoli, E., \& Velicer, W.F. (1988). Relation of sample size to the stability of component patterns. Psychological Bulletin, 103, 265-275.

Hair, J., Black, W., Babin, B., Anderson, R., \& Tatham, R. (2006). Multivariate data analysis (6th ed.). New Jersey: Pearson Educational, Inc.

Hall, T. K. (1993). Determinants of elite athletes' commitment to sport: Examination of the sport commitment model in the professional sport domain (Master's thesis, Portland State University, Portland, USA). Retrieved from https://pdxscholar.library.pdx.edu/open_access_etds/3551/

Hanlon, C., Morris, T., \& Nabbs, S. (2010). Establishing a successful physical activity program to recruit and retain women. Sport Management Review, 13(3), 269-282. 
Hanlon, C., Morris, T., \& Nabbs, S. (2014). Program providers' perspective: Recruitment and retention strategies for women in physical activity programs. Sport Management Review, 17(2), 133-144.

Hardcastle, S., \& Taylor, A. H. (2005). Finding an exercise identity in an older body: "It's redefining yourself and working out who you are". Psychology of Sport and Exercise, 6(2), 173-188.

Havighurst, R. J. (1961). Older people: A test of life satisfaction. Gerontologist, 1, 8-13.

Havighurst, R. J., \& Albrecht, R. (1953). Older people. Longmans, Green.

Hennigs, B., \& Hallmann, K. (2015). A motivation-based segmentation study of kitesurfers and windsurfers. Managing Sport and Leisure, 20(2), 117-134.

Heo, J., Stebbins, R. A., Kim, J., \& Lee, I. (2013). Serious leisure, life satisfaction, and health of older adults. Leisure Sciences, 35(1), 16-32.

Hidalgo, J. L. T. (2019). Effectiveness of physical exercise in the treatment of depression in older adults as an alternative to antidepressant drugs in primary care. $B M C$ Psychiatry, 19(1), 21(1-7).

Hightower, R., Brady, M. K., \& Baker, T. L. (2002). Investigating the role of the physical environment in hedonic service consumption: an exploratory study of sporting events. Journal of Business Research, 55(9), 697-707.

Hillier S.M. \& Barrow G.M. (2007). Aging, the individual, and society (8th ed.). California: Thomson Wadsworth.

Hirvensalo, M., \& Lintunen, T. (2011). Life-course perspective for physical activity and sports participation. European Review of Aging and Physical Activity, 8(1), 13-22. doi: https://doi.org/10.1007/s11556-010-0076-3

Hoelter, J. W. (1983). The effects of role evaluation and commitment on identity salience. Social Psychology Quarterly, 140-147.

Hoffower, H. (2019, September 22). Two world travelers who retired at 31 as millionaires say there's a 'dark side' to early retirement. Here's how they tackled the 3 biggest downsides. Business Insiders. Retrieved from https://www.businessinsider.com/early-retirement-downsides-challenges-losingmoney-community-identity-2019-9

Hogg, M. A., Terry, D. J., \& White, K. M. (1995). A tale of two theories: A critical comparison of identity theory with social identity theory. Social Psychology Quarterly, 58(4), 255-269. 
Horn, J. L. (1965). A rationale and test for the number of factors in factor analysis. Psychometrika, 30(2), 179-185.

Jackson, S. E. (1981). Measurement of commitment to role identities. Journal of Personality and Social Psychology, 40(1), 138.

Jacobson, B. (2003). The social psychology of the creation of a sports fan identity: A theoretical review of the literature. The Online Journal of Sport Psychology, 5(2).1-14.

James, W. (1890). Principles of psychology. New York, NY: Holt Rinehart and Winston.

Jenkin, C. R., Eime, R. M., Westerbeek, H., O’Sullivan, G., \& Van Uffelen, J. G. (2017). Sport and ageing: a systematic review of the determinants and trends of participation in sport for older adults. BMC public health, 17(1), 976 (1-20). Doi: https://doi.org/10.1186/s12889-017-4970-8

Jenkin, C. R., Eime, R. M., Westerbeek, H., \& van Uffelen, J. G. (2018). Sport for adults aged 50+ years: Participation benefits and barriers. Journal of Aging and Physical activity, 26(3), 363-371.

Jeon, J. H. (2012). Participants' psychological connection to recreational sports: An examination of the psychological continuum model framework (unpublished doctoral dissertation). North Carolina State University: Raleigh.

Jeon, J. H., \& Casper, J. (2016). Psychological antecedents of youth versus adult participation: An examination based on the sport commitment model. Journal of Amateur Sport. doi: http://dx.doi.org/10.17161/jas.v0i0.5049

Jeon, J. H., \& Ridinger, L. L. (2009). An examination of sport commitment of windsurfers. Journal of Sport Behavior, 32(3), 325-338.

Jun, J., \& Kyle, G. T. (2011). The effect of identity conflict/facilitation on the experience of constraints to leisure and constraint negotiation. Journal of Leisure Research, 43(2), 176-204.

Kaiser, H. F. (1960). The application of electronic computers to factor analysis. Educational and Psychological Measurement, 20(1), 141-151.

Kaiser, H. F. (1974). An index of factorial simplicity. Psychometrika, 39(1), 31-36.

Kay, T., \& Jackson, G. (1991). Leisure despite constraint: The impact of leisure constraints on leisure participation. Journal of Leisure Research, 23(4), 301-313.

Kelley, S.W., \& Davis, M.A. (1994). Antecedents to customer expectations for service recovery. Journal of the Academy of Marketing Science, 22, 52-61. 
Kelley, S.W., Hoffman, K.D., \& Davis, M.A. (1993). A typol-ogy of retail failures and recoveries. Journal of Retailing, 69, 429-452.

Kellner, D. (1992). Popular culture and the construction of postmodern identities. In L. Friedman (Ed.), Modernity and identity (pp. 141177). Oxford: Blackwell.

Kim, A. C. H., Park, S. H., Kim, S., \& Fontes-Comber, A. (2019). Psychological and social outcomes of sport participation for older adults: A systematic review. Ageing \& Society, 1-21.

Kim, J., Dattilo, J., \& Heo, J. (2011). Taekwondo participation as serious leisure for life satisfaction and health. Journal of Leisure Research, 43(4), 545-559.

Kleine, R. E., Kleine, S. S., \& Kernan, J. B. (1993). Mundane consumption and the self: A social-identity perspective. Journal of Consumer Psychology, 2(3), 209-235. https://doi.org/10.1207/s15327663jcp0203_01

Kline, R. B. (2016). Principles and practice of structural equation modeling (4th ed.). New York: Guilford.

Kobau, R., Sniezek, J., Zack, M. M., Lucas, R. E., \& Burns, A. (2010). Well-being assessment: An evaluation of well-being scales for public health and population estimates of well-being among US adults. Applied Psychology: Health and WellBeing, 2(3), 272-297. doi:http://dx.doi.org/10.1111/j.1758-0854.2010.01035.x

Koivula, N. (1999). Sport participation: Differences in motivation and actual. Journal of Sport Behavior, 22(3), 360-380.

Lapa, T. Y. (2013). Life satisfaction, leisure satisfaction and perceived freedom of park recreation participants. Procedia-Social and Behavioral Sciences, 93, 1985-1993.

Laverie, D. A. (1998). Motivations for ongoing participation in a fitness activity. Leisure Sciences, 20(4), 277-302.

Lau, P. W., Cheung, M. W., \& Ransdell, L. (2007). Sport identity and sport participation: A cultural comparison between collective and individualistic societies. International Journal of Sport and Exercise Psychology, 5(1), 66-81.

Lau, P. W., Fox, K. R., \& Cheung, M. W. (2004). Psychosocial and socio-environmental correlatesof sport identity and sport participationin secondary school-age children. European Journal of Sport Science, 4(3), 1-21.

Lee, Y. S. (2005). Gender differences in physical activity and walking among older adults. Journal of Women \& Aging, 17(1-2), 55-70. 
Lerch, S. (1984). Athletic retirement as social death: An overview. In N. Theberge \& P. Donnelly (Eds.), Sport and the sociological imagination (pp. 259-272). Fort Worth, Texas: Christian University Press.

Lim, K., \& Taylor, L. (2005). Factors associated with physical activity among older people-a population-based study. Preventive Medicine, 40(1), 33-40.

Lim, S. Y., Warner, S., Dixon, M., Berg, B., Kim, C., \& Newhouse-Bailey, M. (2011). Sport participation across national contexts: A multilevel investigation of individual and systemic influences on adult sport participation. European Sport Management Quarterly, 11(3), 197-224.

Lovelock, B., Jellum, C., Carr, A., \& Jowett, T. (2019). An exploration of commitment in nature-based recreation, and its relationship with participation and purchase behaviour. Annals of Leisure Research, 22(3), 373-394.

Lyons, K., \& Dionigi, R. (2007). Transcending emotional community: A qualitative examination of older adults and masters' sports participation. Leisure Sciences, 29(4), 375-389.

Maguire, J., \& Mansfield, L. (1998). "No-body's perfect": Women, aerobics, and the body beautiful. Sociology of Sport Journal, 15(2), 109-137.

Maher, J. P., \& Conroy, D. E. (2017). Daily Life Satisfaction in Older Adults as a Function of (In) Activity. The Journals of Gerontology. Series B, Psychological Sciences and Social Sciences, 72(4), 593.

Malm, C., Jakobsson, J., \& Isaksson, A. (2019). Physical activity and sports-Real health benefits: A review with insight into the public health of Sweden. Sports, 7(5), 127.

Mathes, S. A., \& Battista, R. (1985). College men's and women's motives for participation in physical activity. Perceptual and Motor Skills, 61(3), 719-726.

McAuley, E., Blissmer, B., Marquez, D. X., Jerome, G. J., Kramer, A. F., \& Katula, J. (2000). Social relations, physical activity, and well-being in older adults. Preventive Medicine, 31(5), 608-617. doi:10.1006/pmed.2000.0740

McPhee, J. S., French, D. P., Jackson, D., Nazroo, J., Pendleton, N., \& Degens, H. (2016). Physical activity in older age: perspectives for healthy ageing and frailty. Biogerontology, 17(3), 567-580.

Medicareful (2019, April 3). 3 fun \& competitive sports for seniors. Retrieved from https://living.medicareful.com/3-fun-competitive-sports-for-seniors

Mertler, C. A., \& Reinhart, R. V. (2016). Advanced and multivariate statistical methods: Practical application and interpretation (6th ed.). New York, NY: Routledge. 
Meyers, L. S., Gamst, G., \& Guarino, A. J. (2006). Applied multivariate research: Design and interpretation. Thousand Oaks, CA: Sage Publication.

Miller, K. E., \& Hoffman, J. H. (2009). Mental well-being and sport-related identities in college students. Sociology of Sport Journal, 26(2), 335-356.

Miller, K. H., Ogletree, R. J., \& Welshimer, K. (2002). Impact of activity behaviors on physical activity identity and self-efficacy. American Journal of Health Behavior, 26(5), 323-330.

Molanorouzi, K., Khoo, S., \& Morris, T. (2015). Motives for adult participation in physical activity: type of activity, age, and gender. BMC Public Health, 15(1), 66 $(1-12)$.

Mullin, B. J., Hardy, S., \& Sutton, W. (2014). Sport marketing (4th Edition). Champaign, IL: Human Kinetics.

Mura, G., \& Carta, M. G. (2013). Physical activity in depressed elderly. A systematic review. Clinical Practice and Epidemiology in Mental Health: CP \& EMH, 9, 125.

Murphy, M. (2018, November 20). The gender play gap: Why aren't more women playing sport? Retrieved from https://www.rte.ie/brainstorm/2017/1129/923613the-gender-play-gap-why-arent-more-women-playing-sport/

Murrell, A. J., \& Dietz, B. (1992). Fan support of sport teams: The effect of a common group identity. Journal of Sport \& Exercise Psychology, 28-39.

National Institutes of Age (2017). Depression and older adults. Retrieved from https://www.nia.nih.gov/health/depression-and-older-adults

Neulinger, J. 1974. The psychology of leisure. Springfield, IL: Thomas

Nunnally, J. C., \& Bernstein, I. H. (1994). Psychometric theory (3rd ed.). New York: McGraw-Hill.

Ogilvie, B. C., \& Howe, M. (1986). The trauma of termination from athletics. In J. M. Williams (Ed.), Applied sport psychology: Personal growth to peak performance (pp. 365-382). Palo Alto: Mayfield.

Rosenberg, E. (1984). Athletic retirement as social death: Concepts and perspectives. In N. Theberge \& P. Donnelly (Eds.), Sport and the sociological imagination (pp. 245-258). Fort Worth: Texas Christian University Press.

Oliver, R. L. (1980). A cognitive model of the antecedents and consequences of satisfaction decisions. Journal of Marketing Research, 17(4), 460-469. 
Osborne, J., \& Waters, E. (2002). Four assumptions of multiple regression that researchers should always test. Practical Assessment, Research \& Evaluation, $8(2), 1-9$.

Park, Y., Yoh, T., \& Park, M. (2015). Testing a leisure constraints model in the context of Asian international students. International Journal of Sport Management, Recreation and Tourism, 20, 58-83.

Physical Activity Council. (2020). 2020 Physical activity council's overview report on U.S. participation. Retrieved from https://eb6d91a4-d249-47b8-a5cb933f7971db54.filesusr.com/ugd/286de6_c28995b76cf94de2a22ac7a0a4d5264d.p df

Pickett, A. C., \& Cunningham, G. B. (2018). The fat leading the thin: Relative body size, physical activity identification, and behavioral problems. Journal of Applied Sport Management, 10(1), 1-12. DOI: https://doi.org/10.18666/JASM-2018-V10-I18290

Piercy, K. L., Troiano, R. P., Ballard, R. M., Carlson, S. A., Fulton, J. E., Galuska, D. A., ... \& Olson, R. D. (2018). The physical activity guidelines for Americans. JAMA, 320(19), 2020-2028.

Pinsker, J. (2020, January 27). When does someone become 'old'? The Atlantic. Retrieved from https://www.theatlantic.com/family/archive/2020/01/old-peopleolder-elderly-middle-age/605590/

Pituch, K. A., \& Stevens, J. (2016). Applied multivariate statistics for the social sciences: Analyses with SAS and IBM's SPSS, (6th ed.). New York, NY: Routledge.

Pot, N., Schenk, N., \& Van Hilvoorde, I. (2014). School sports and identity formation: Socialisation or selection?. European Journal of Sport Science, 14(5), 484-491.

Ragheb, M. G., \& Griffith, C. A. (1982). The contribution of leisure participation and leisure satisfaction to life satisfaction of older persons. Journal of Leisure Research, 14(4), 295-306.

Ragheb, M. G., \& Tate, R. L. (1993). A behavioural model of leisure participation, based on leisure attitude, motivation and satisfaction. Leisure Studies, 12(1), 61-70.

Rejeski, W. J., \& Mihalko, S. L. (2001). Physical activity and quality of life in older adults. The Journals of Gerontology. Series A, Biological Sciences and Medical Sciences, 56, 23-35.

Rejeski, W. J., Shelton, B., Miller, M., Dunn, A. L., King, A. C., \& Sallis, J. F. (2001). Mediators of increased physical activity and change in subjective well-being: 
Results from the Activity Counseling Trial (ACT). Journal of Health Psychology, 6(2), 159-168.

Ruuskanen, J. M., \& Ruoppila, I. (1995). Physical activity and psychological well-being among people aged 65 to 84 years. Age and Ageing, 24(4), 292-296.

Ryu, J., Yang, H., Kim, A. C. H., Kim, K. M., \& Heo, J. (2018). Understanding pickleball as a new leisure pursuit among older adults. Educational Gerontology, 44(2-3), 128-138.

Saint-Maurice, P. F., Coughlan, D., Kelly, S. P., Keadle, S. K., Cook, M. B., Carlson, S. A., ... \& Matthews, C. E. (2019). Association of Leisure-Time Physical Activity Across the Adult Life Course With All-Cause and Cause-Specific Mortality. JAMA network open, 2(3), e190355-e190355. doi:10.1001/jamanetworkopen.2019.0355

Santee, R. T., \& Jackson, S. E. (1979). Commitment to self-identification: A sociopsychological approach to personality. Human Relations, 32(2), 141-158.

Sato, M., Jordan, J. S., \& Funk, D. C. (2016). A distance-running event and life satisfaction: The mediating roles of involvement. Sport Management Review, 19(5), 536-549.

Scanlan, T. K., Carpenter, P. J., Schmidt, G.W., Simons, J. R., \& Keeler, B. (1993a). An introduction to the sport commitment model. Journal of Sport \& Exercise Psychology, 15, 1-15.

Scanlan, T. K., Chow, G. M., Sousa, C., Scanlan, L. A., \& Knifsend, C. A. (2016). The development of the sport commitment questionnaire-2 (English version). Psychology of Sport and Exercise, 22, 233-246.

Scanlan, T. K., Simons, J. P., Carpenter, P. J., Schmidt, G. W., \& Keeler, B. (1993b). The sport commitment model: Measurement development for the youth-sport domain. Journal of Sport \& Exercise Psychology, 15(1). 16-38.

Shamir, B. (1988). Commitment and leisure. Sociological Perspectives, 31(2), 238-258.

Shamir, B. (1992). Some correlates of leisure identity salience: Three exploratory studies. Journal of Leisure Research, 24(4), 301-323.

Shah, T. M., Weinborn, M., Verdile, G., Sohrabi, H. R., \& Martins, R. N. (2017). Enhancing cognitive functioning in healthly older adults: a systematic review of the clinical significance of commercially available computerized cognitive training in preventing cognitive decline. Neuropsychology Review, 27(1), 62-80. 
Siegenthaler, K. L., \& O'Dell, I. (2003). Older golfers: Serious leisure and successful aging. World Leisure Journal, 45(1), 45-52.

Smith, G. L., Banting, L., Eime, R., O’Sullivan, G., \& Van Uffelen, J. G. (2017). The association between social support and physical activity in older adults: a systematic review. International Journal of Behavioral Nutrition and Physical Activity, 14(1), 56.1-21.

Snyder, E. E. (1981). A reflection on commitment and pattern of disengagement from recreational physical activity. In S. L. Greendorfer 8c A. Yiannakis (Eds.), Proceedings of the First Annual NASS Conference on Sociology of Sport: Diverse Perspectives (pp. 108-117). Westpoint, NY: Leisure Press.

Son, J. S., \& Yarnal, C. M. (2011). An integration of constraints and benefits within an older women's social club: An examination, extension and critique. Leisure Sciences, 33(3), 205-227.

Sousa, C., Torregrosa, M., Viladrich, C., Villamarín, F., \& Cruz, J. (2007). The commitment of young soccer players. Psicothema, 19(2), 256-262.

Stebbins, R. A. (1992). Amateurs, professionals and serious leisure. Montreal, QC: McGill-Queen's University Press.

Stevens, J. P. (2007). Intermediate statistics: A modern approach (3rd ed.). New York: Routledge/Taylor \& Francis Group.

Stone, R. C., Dionigi, R. A., \& Baker, J. (2018). The role of sport in promoting physical activity among older people. In The Palgrave handbook of ageing and physical activity promotion (pp. 673-691). Palgrave Macmillan, Cham.

Strachan, S. M., Brawley, L. R., Spink, K., \& Glazebrook, K. (2010). Older adults' physically-active identity: Relationships between social cognitions, physical activity and satisfaction with life. Psychology of Sport and Exercise, 11(2), 114121.

Stryker, S. (1968). Identity salience and role performance. Journal of Marriage and the Family, 4, 558-564.

Stryker, S. (1980). Symbolic Interactionism: A Social Structural Version. Menlo Park, CA: Benjamin Commings.

Stryker, S., \& Burke, P. J. (2000). The past, present, and future of an identity theory. Social Psychology Quarterly, 63, 284-297. doi:10.2307/2695840 
Stryker, S., \& Serpe, R. T. (1982). Commitment, identity salience, and role behavior: Theory and research example. In Personality, roles, and social behavior (pp. 199218). New York, NY: Springer.

Summers, J. J., Machin, V. J., \& Sargent, G. I. (1983). Psychosocial factors related to marathon running. Journal of Sport and Exercise Psychology, 5(3), 314-331.

Symes, R. (2010, May 24). Understanding athletic identity: “Who am i?" Retrieved from http://www.podiumsportsjournal.com/2010/05/24/understanding-athletic-identitywho-am-i/

Tajfel, H. \& Turner, J. C. (1979). 'An integrative theory of intergroup conflict'. In: Austin, W. G. and Worchel, S. (Eds) The Social Psychology of Intergroup Relations. Monterey, California: Brooks-Cole.

Thurstone, L. L. (1947). Multiple-factor analysis. Chicago, IL: University of Chicago Press.

Tischer, U., Hartmann-Tews, I. \& Combrink, C. (2011). Sport participation of the elderly - the role of gender, age, and social class. European Review of Aging and Physical Activity, 8, 83-91. https://doi.org/10.1007/s11556-011-0087-8

Tokuyama, S., \& Greenwell, T. C. (2011). Examining similarities and differences in consumer motivation for playing and watching soccer. Sport Marketing Quarterly, 20(3), 148-156.

Turner, J. C. (2010). Social categorization and the self-concept: A social cognitive theory of group behavior. In T. Postmes \& N. R. Branscombe (Eds.), Key readings in social psychology. Rediscovering social identity (p. 243-272). Psychology Press.

UCLA: Statistical Consulting Group (2020). A practical introduction to factor analysis: exploratory factor analysis. Retrieved from https://stats.idre.ucla.edu/spss/seminars/introduction-to-factor-analysis/apractical-introduction-to-factor-analysis/

United States Adult Soccer Association. (2020). USASA walking soccer. Retrieved from https://www.usadultsoccer.com/walkingsoccer

U.S. Department of Health \& Human Services. (2019). Physical activity guidelines for Americans. Retrieved from https://www.hhs.gov/fitness/be-active/physicalactivity-guidelines-for-americans/index.html

Ussery, E. N., Fulton, J. E., Galuska, D. A., Katzmarzyk, P. T., \& Carlson, S. A. (2018). Joint prevalence of sitting time and leisure-time physical activity among US adults, 2015-2016. JAMA, 320(19), 2036-2038. 
VanVoorhis, C. W., \& Morgan, B. L. (2007). Understanding power and rules of thumb for determining sample sizes. Tutorials in Quantitative Methods for Psychology, $3(2), 43-50$.

Walker, S. N., Volkan, K., Sechrist, K. R., \& Pender, N. J. (1988). Health-promoting life styles of older adults: Comparisons with young and middle-aged adults, correlates and patterns. Advances in Nursing Science, 11(1), 76-90.

Wang, C. H., \& Chu, A. Y. (2016). Older adults' participation in ballroom dancing: Practical application of the sport commitment model. Social Behavior and Personality: An International Journal, 44(3), 445-452.

Weinfurt, K. P. (1995). Multivariate analysis of variance. In L. G. Grimm, \& P. R. Yarnold (Eds.), Reading and understanding multivariate statistics. Washington, DC: APA

Weiss, M. R., Kimmel, L. A., \& Smith, A. L. (2001). Determinants of sport commitment among junior tennis players: Enjoyment as a mediating variable. Pediatric Exercise Science, 13, 131-144.

Weiss, W. M., \& Weiss, M. R. (2007). Sport commitment among competitive female gymnasts: A developmental perspective. Research Quarterly for Exercise and Sport, 78(2), 90-102.

Wheaton, B. (Ed.). (2004). Understanding lifestyle sport: Consumption, identity and difference. London: Routledge.

Wiley, C. G., Shaw, S. M., \& Havitz, M. E. (2000). Men's and women's involvement in sports: An examination of the gendered aspects of leisure involvement. Leisure Sciences, 22(1), 19-31.

Wilson, P. M., Rodgers, W. M., Carpenter, P. J., Hall, C., Hardy, J., \& Fraser, S. N. (2004). The relationship between commitment and exercise behavior. Psychology of Sport and Exercise, 5(4), 405-421.

Wolff, R., \& Lester, D. (1989). A theoretical basis for counseling the retired professional athlete. Psychological Reports, 64, 1043-1046.

Won, D., \& Hwang, S. (2008). The Course to Tee off: Golfers' Participation Constraints, Age, Income, and Leisure Identity Salience. The ICHPER-SD Journal of Research in Health, Physical Education, Recreation, Sport \& Dance, 3(2), 55-61.

Won, D., Hwang, S., \& Kleiber, D. (2009). How Do Golfers Choose a Course? A Conjoint Analysis of Influencing Factors. Journal of Park \& Recreation Administration, 27(2), 1-16. 
Woods, R. A. (2017). Sports and exercise. U.S. Bureau of Labor Statistics. Retrieved from https:/www.bls.gov/spotlight/2017/sports-and-exercise/home.htm

World Health Organization. (2013). Oral health surveys: Basic methods (5 ${ }^{\text {th }}$ edition). Retrieved from https://apps.who.int/iris/bitstream/handle/10665/97035/9789241548649 eng.pdf? $\underline{\text { sequence }=1 \text {. }}$.

World Health Organization. (2018a, February 5). Ageing and health. Retrieved from https://www.who.int/news-room/fact-sheets/detail/ageing-and-health

World Health Organization. (2018b, February 23). Physical activity. Retrieved from https://www.who.int/news-room/fact-sheets/detail/physical-activity

Wright, J. \& Laverty, J. (2010). Young people, physical activity and transistions. In J. Wright \& D. Macdonald (Eds.), Young people, activity and the everyday (pp. 136149). London and New York: Routledge.

Yair, G. (1990). The commitments to long distance running and levels of activity: Personal or structural? Journal of Leisure Research, 22, 213-227

Yong, A. G., \& Pearce, S. (2013). A beginner's guide to factor analysis: Focusing on exploratory factor analysis. Tutorials in Quantitative Methods for Psychology, 9(2), 79-94.

Zahariadis, P., Tsorbatzoudis, H., \& Alexandris, K. (2006). Self-determination in sport commitment. Perceptual and Motor Skills, 102(2), 405-420. 
APPENDICES 


\title{
APPENDIX A
}

\author{
PROMOTING HEALTHY AGING: AN INVESTIGATION OF THE RELATIONSHIPS AMONG SPORT \\ SATISFACTION, SPORT IDENTITY, AND SPORT COMMITMENT IN THE WELL-BEING OF OLDER \\ ADULTS
}

January 2020

Dear Participants:

You are being invited to participate in a research study by answering questions in the attached survey to explore the relationships between psychological constructs (sport identity, sport satisfaction and sport commitment) of sport participation and life satisfaction among older adults. This study is conducted by Mary Hums, Ph.D., and Seonghun Lee, M.S., of the University of Louisville. There are no known risks for your participation in this research study. The information collected may not benefit you directly. The information learned in this study may be helpful to others. The information you provide will be a helpful resource for older adult sport and physical activity programmers, professionals, and scholars to promote healthy aging. Your completed survey will be stored on a password protected external hard drive and computer. The survey will take approximately 15 minutes to complete.

Individuals from the University of Louisville Department of Health \& Sport Sciences, the Institutional Review Board (IRB), the Human Subjects Protection Program Office (HSPPO), and other regulatory agencies may inspect these records. In all other respects, however, the data will be held in confidence to the extent permitted by law. Should the data be published, your identity will not be disclosed.

Taking part in this study is voluntary. By answering survey questions you agree to take part in this research study. You do not have to answer any questions that make you uncomfortable. You may choose not to take part at all. If you decide to participate in this study you may stop taking part at any time. If you decide not to be in this study or if you stop taking part at any time, you will not lose any benefits for which you may qualify.

If you have any questions, concerns, or complaints about the research study, please contact: Dr. Mary Hums at mhums@louisville.edu.edu or (502) 852-5908 and Seonghun Lee at seonghun.lee@louisville.edu or (502) 852-0549.

If you have any questions about your rights as a research subject, you may call the Human Subjects Protection Program Office at (502) 852-5188. You can discuss any questions about your rights as a research subject, in private, with a member of the Institutional Review Board (IRB). You may also call this number if you have other questions about the research, and you cannot reach the research staff, or want to talk to someone else. The IRB is an independent committee made up of people from the University community, staff of the institutions, as well as people from the community not connected with these institutions. The IRB has reviewed this research study.

If you have concerns or complaints about the research or research staff and you do not wish to give your name, you may call 1-877-852-1167. This is a 24 hour hot line answered by people who do not work at the University of Louisville.

Sincerely,

Mary A. Hums, Ph.D.

Seonghun Lee, PhD Candidate 


\section{APPENDIX B \\ Organized Sport Participation Questionnaire}

1. Please indicate $\mathrm{ONE}$ (1) of the primary organized group sport activities you currently participating in, or participated in the last twelve months, such as a league or club team (e.g., Louisville tennis club, running group), or exercise/fitness program (e.g., YMCA yoga, Louisville cycling, aqua fitness, and swimming):

2. What influenced you to first participate in this sport activity? (e.g., peers, family, internet, etc.):

3. How often do you participate in your organized sport activity? time(s) per week and/or time(s) per month

4. How long have you been participating in this organized sport activity (e.g., joined league, club team, fitness program or facility)?

Year (s) and/or Month (s)

5. How much money, on average, do you yearly spend for this organized sport activity? Please give your best estimate:

- Membership and/or Participation Fees: \$

- Total amount of yearly spending (e.g., Equipment, Apparel, Lessons, Travels, and Other Related Items): \$

Please mark the number which best expresses your opinion about each statement on your commitment to the sport activity you chose above.

1. How dedicated are you to participate in this sport activity?

$\begin{array}{llllllll}\text { Not at all dedicated } & \mathbf{1} & \mathbf{2} & \mathbf{3} & \mathbf{4} & \mathbf{5} & \text { Very dedicated }\end{array}$

2. What would you be willing to do to keep participating in this sport activity? $\begin{array}{llllllll}\text { Nothing at all } & \mathbf{1} & \mathbf{2} & \mathbf{3} & \mathbf{4} & \mathbf{5} & \text { A lot of things }\end{array}$

3. How determined are you to continue participating in this sport activity? 


\section{$\begin{array}{lllllll}\text { Not at all determined } & \mathbf{1} & \mathbf{2} & \mathbf{3} & \mathbf{4} & \mathbf{5} & \text { Very determined }\end{array}$}

4. Do you want to keep participating in this sport activity?

$\begin{array}{lllllll}\text { Not at all } & \mathbf{1} & \mathbf{2} & \mathbf{3} & \mathbf{4} & \mathbf{5} & \text { Very } m \text { much }\end{array}$

5. How proud are you to tell other people that you participate in this sport activity? $\begin{array}{lllllll}\text { Not at all } & \mathbf{1} & \mathbf{2} & \mathbf{3} & \mathbf{4} & \mathbf{5} & \text { Very proud }\end{array}$

6. How hard would it be to quit this sport activity? $\begin{array}{lllllll}\text { Not hard } & \mathbf{1} & \mathbf{2} & \mathbf{3} & \mathbf{4} & \mathbf{5} & \text { Very Hard }\end{array}$

For the following questions, please mark the appropriate number which best expresses how you feel and your opinion about your involvement in the sport activity you chose above.

$\begin{array}{llllllll}\text { Not at all } & 1 & 2 & 3 & 4 & 5 & \text { Very Much }\end{array}$

1. I enjoy playing this sport activity.

2. I would miss being considered an athlete (e.g., golfer) if I quit this sport activity.

3. This sport activity gives me the opportunity to relieve any stress I am feeling.

4. I feel pressure from other people to participate in this sport activity.

5. People say things to make me feel good about participation in this sport activity.

6. Compared to participating in this sport activity, there are other things I could do which would be more fun.

7. I love to play this sport activity.

8. I would miss the people that I have met if I quit this sport activity.

9. This sport activity gives me the opportunity to improve my health and fitness.

10. I have invested a lot of energy into this sport activity.

11. I have to keep participating in this sport activity to please others.

12. Other people encourage me to participate in this sport activity.

13. Compared to participating in this sport activity, there are 
other things I could do which would be more enjoyable.

12345

14. I like playing this sport activity.

12345

15. I would miss the good time that I had if I quit this sport activity.

12345

16. This sport activity gives me the opportunity to improve my physical skills.

12345

17. I have invested a lot of time into this sport activity.

12345

18. People will be disappointed with me if I quit this sport activity.

12345

19. Significant others (e.g., family or friends) say things to keep me participating in this sport activity.

12345

20. Compared to participating in this sport activity, there are other things I could do which would be more worthwhile. 12345

21. Playing this sport activity is fun.

12345

22. I have invested a lot of my own money into this sport activity.

23. I feel that I have to participate in this sport activity to be with my friends.

12345

24. I feel that I receive support from significant others (e.g., family or friends) about this sport activity.

12345

25. I would be happier doing something else instead of participating in this sport activity.

12345

26. Playing this sport activity makes me happy.

12345

27. I feel that I have to participate in this sport activity more for my friends/spouse than for myself.

28. I would like to do something else instead of participating in this sport activity.

29. Playing this sport activity is very pleasurable.

12345

30. I have invested a lot of effort into this sport activity.

12345

Please mark the number which best expresses how your opinion about each statement on your identity with this sport activity. 


\begin{tabular}{|lllllll}
\hline Strongly disagree & 1 & 2 & 3 & 4 & 5 & Strongly agree \\
\hline
\end{tabular}

1. In general, this sport activity is an important part of my self-image.

2. This sport activity is important to my sense of what kind of a person I am.

3. This sport activity is an important reflection of who I am. 12345

4. Overall, this sport activity has little to do with how

I feel about myself.

12345

Please mark the number which best expresses your opinion about each statement on your satisfaction with this organized sport activity.

$\begin{array}{llllllll}\text { Strongly disagree } & 1 & 2 & 3 & 4 & 5 & \text { Strongly agree }\end{array}$

1. Overall, I am satisfied with my decision to participate in this organized sport activity.

2. I think I did the right thing by deciding to participate in this organized sport activity.

3. My choice to participate in this organized sport activity is a wise one.

12345

Please mark the number which best express how you feel and your opinion about each statement on your life satisfaction in general.

$\begin{array}{llllllll}\text { Strongly disagree } & 1 & 2 & 3 & 4 & 5 & \text { Strongly agree }\end{array}$

1. In most ways my life is close to my ideal life.

12345

2. The conditions of my life are excellent.

12345

3. I am satisfied with my life.

12345

4. So far I have gotten the important things I want in life. 12345

5. If I could live my life over, I would change almost nothing. 12345

Please circle the number that best represent your behavioral intentions with the sport activity you chose.

$\begin{array}{lllllll}\text { Not at all } & 1 & 2 & 3 & 4 & 5 & \text { Very Much }\end{array}$

1. I say positive things about this sport activity.

12345

2. I recommend playing this sport activity to others seeking 
my advice.

12345

3. I encourage friends and relatives to play this sport activity. 12345

4. I intend to participate in this sport activity regularly.

12345

5. I intend to participate in this sport activity in the future. $\quad 12345$

The following information is being requested for statistical purposes only. Please answer the following questions by placing a mark or circling the appropriate box.

1. What is your gender? $\square$ Female $\square$ Male $\square$ Prefer not to answer

2. What is your age?

$\square$ Prefer not to answer

3. Are you retired? $\square$ Yes $\square$ No

If yes, when did you retire? (Year)

If no, when do you look forward to retirement? (Year)

4. What is your marital/household status?

$\square$ Single

$\square$ Married/Partner

$\square$ Divorced

$\square$ Widowed

$\square$ Other

5. What is your annual household income?

$\square$ Less than \$19,999 $\square$ \$20,000-\$29,999

$\square \$ 40,000-\$ 49,999 \quad \square \$ 50,000-\$ 59,999$

$\square \$ 30,000-\$ 39,999$

$\square$ \$70,000-\$79,999 $\square \$ 80,000-\$ 89,999 \quad \square \$ 90,000-\$ 99,999$

$\square$ \$100,000-\$109,999 $\square$ \$110,000-\$119,999 $\square$ \$120,000+

6. What is your ethnicity?

$\square$ African-American/Black $\square$ Caucasian/White

$\square$ Asian

American Indian or Alaska Native

$\square$ Hispanic

$\square$ Native Hawaiian or Pacific Islander

Other-

7. Any thoughts or comments...

\section{Thank you for your participation!}




\section{APPENDIX C.}

\section{The Results of the Parallel Analysis for the First Research Question.}

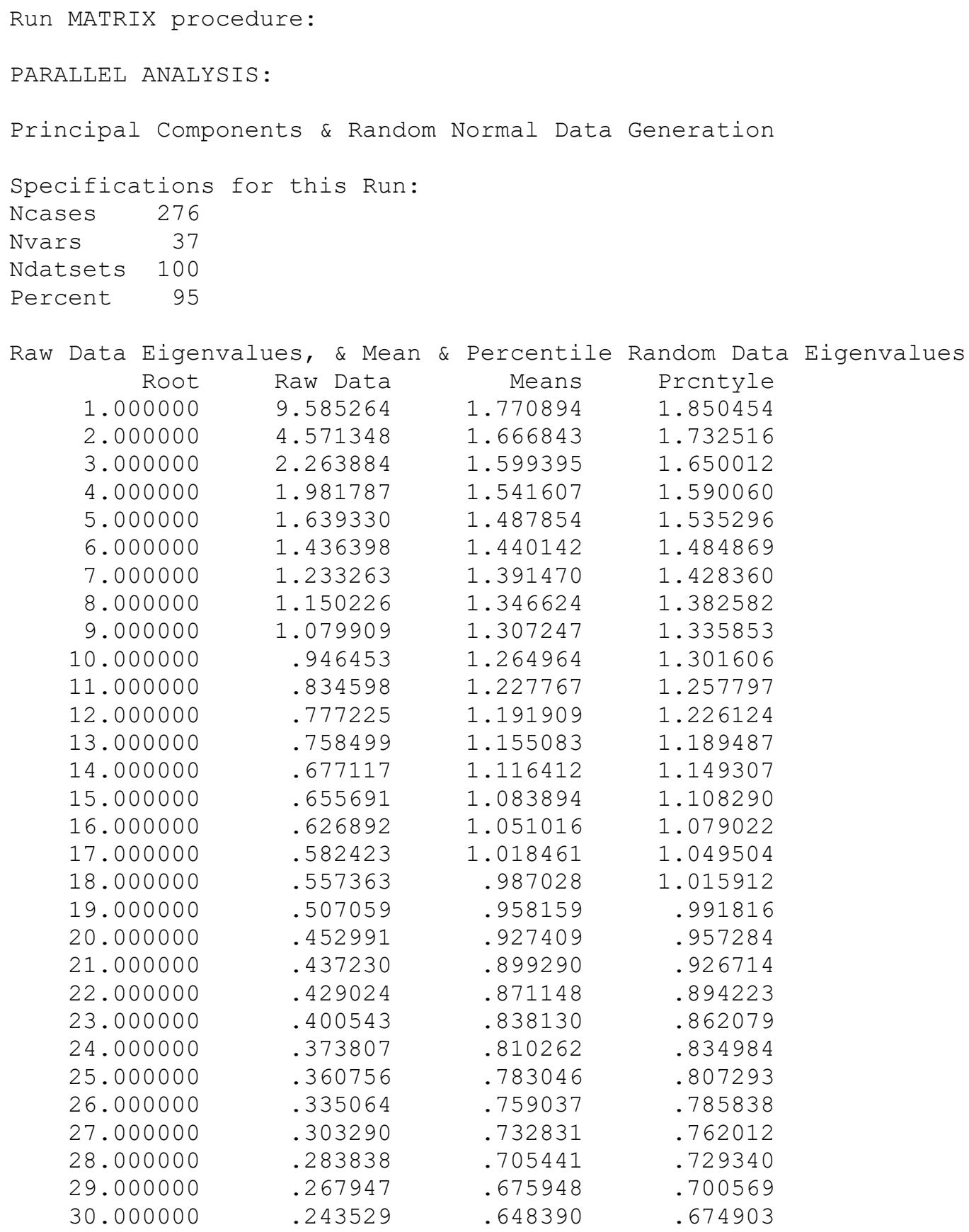




$\begin{array}{llll}31.000000 & .228108 & .621593 & .646160 \\ 32.000000 & .215337 & .594653 & .620317 \\ 33.000000 & .207880 & .568397 & .595724 \\ 34.000000 & .187108 & .540594 & .562928 \\ 35.000000 & .164562 & .509111 & .539133 \\ 36.000000 & .141842 & .473465 & .508175 \\ 37.000000 & .102416 & .434483 & .472742 \\ ----- \text { END MATRIX }----- & & \end{array}$

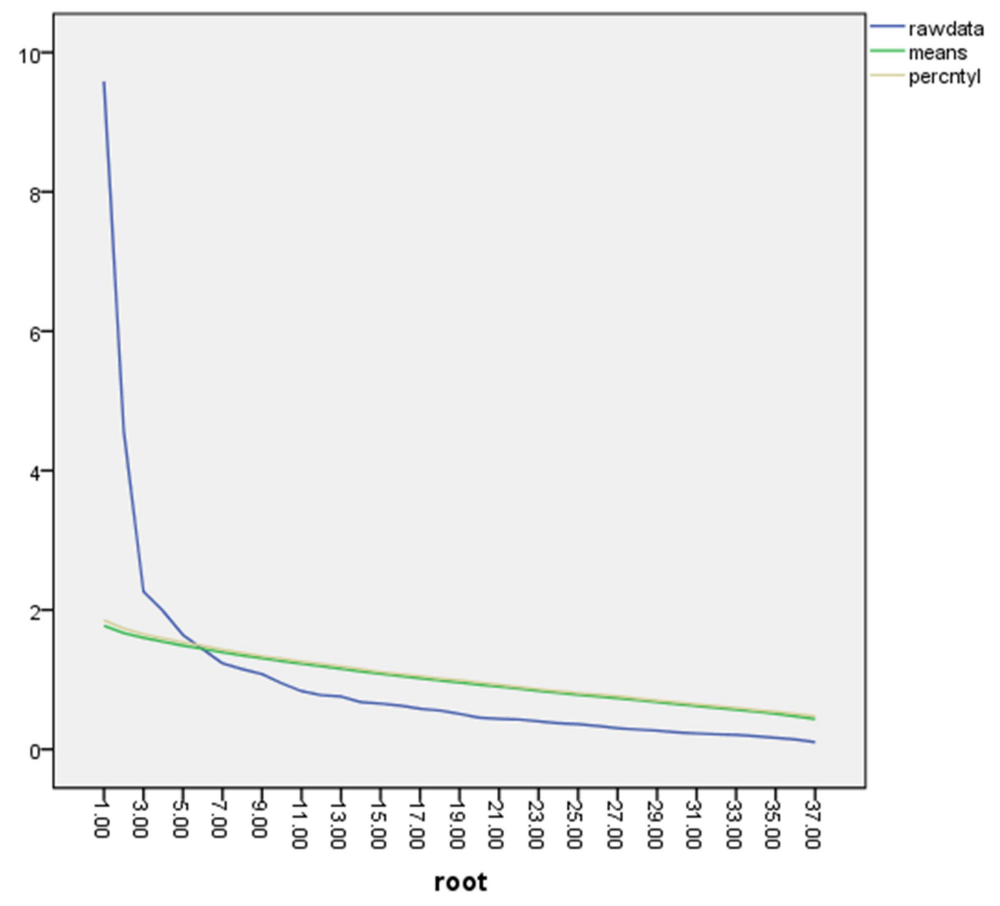




\section{APPENDIX D.}

\section{Results of The Parallel Analysis for The Second Research Question.}

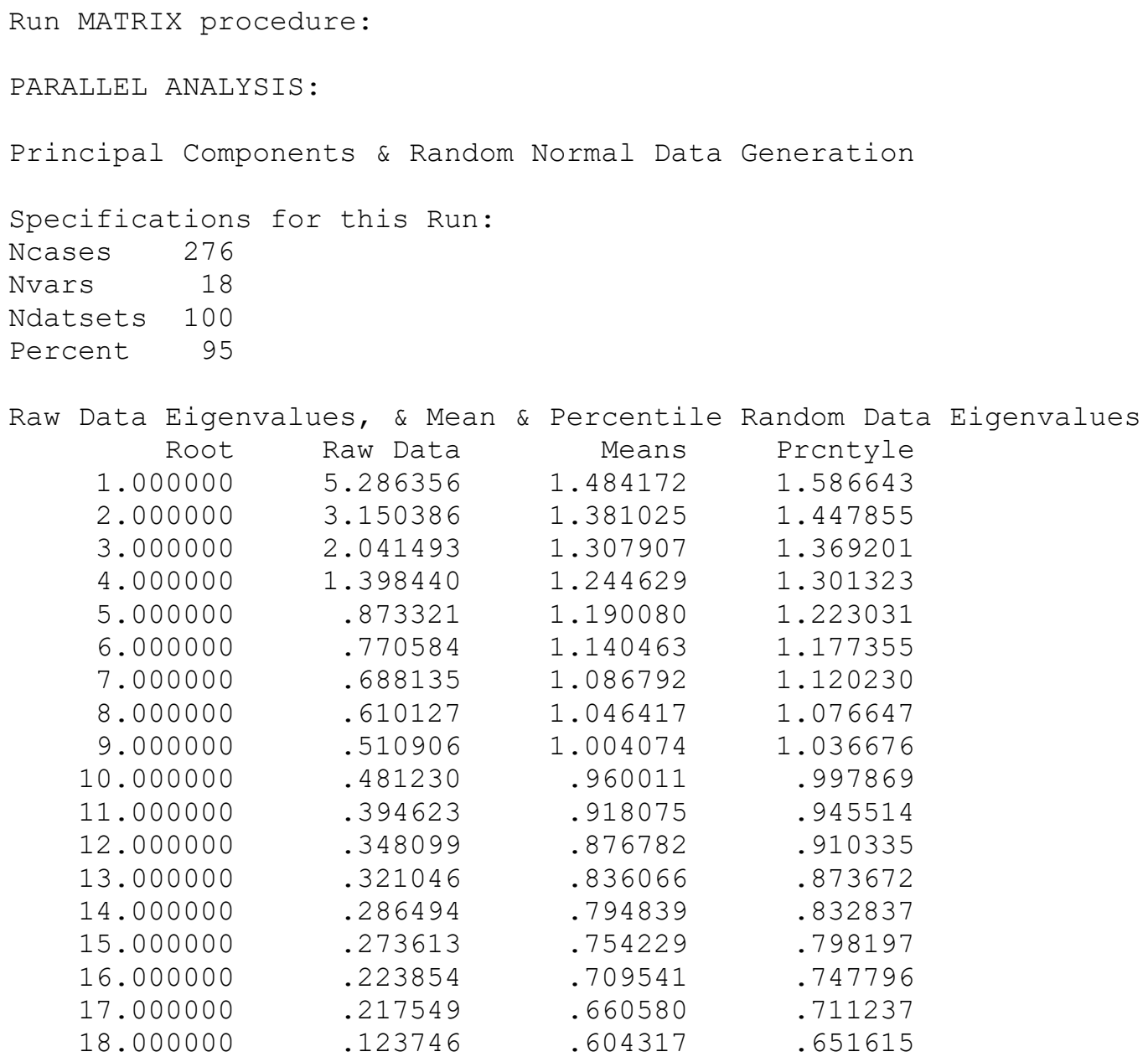




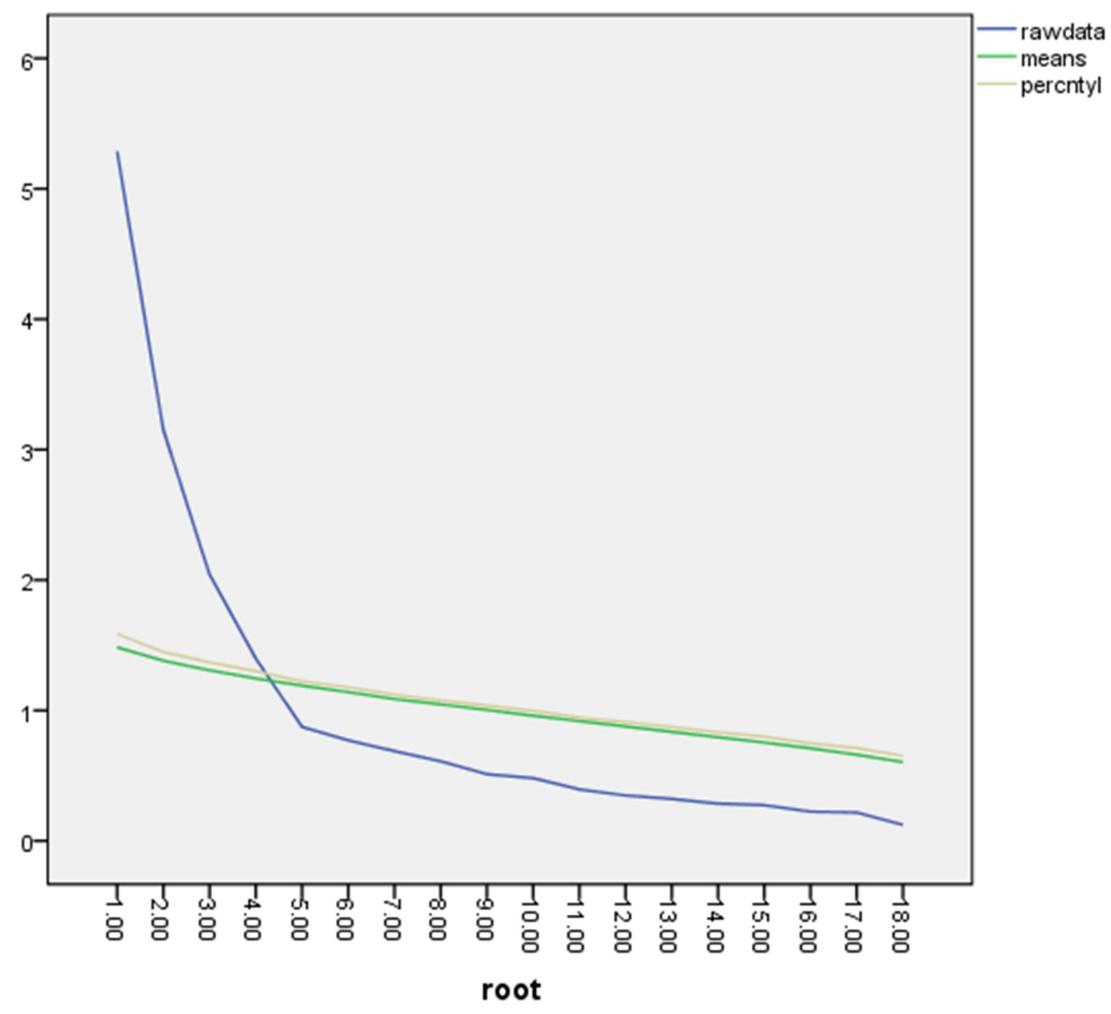




\title{
CURRICULUM VITA
}

\section{Seonghun Lee}

\author{
11802 Duane Point Cir Apt. 102 \\ Louisville, KY 40243 \\ leeseonh@hotmail.com
}

(513) 280-2916

\section{EDUCATION}

Ph.D., Educational Leadership \& Organizational Development May 2020

Specialization: Sport Administration

University of Louisville, Louisville, Kentucky

M.S., Social and Applied Economics

May 2014

Wright State University, Dayton, Ohio

\section{M.S., Sport Administration}

University of Louisville, Louisville, Kentucky

May 2010

B.S., Sport Management

December 2006

Minor: Business Administration

University of Dayton, Dayton, Ohio

\section{TEACHING EXPERIENCE}

Undergraduate Courses Taught (Instructor) at University of Louisville

SPAD 390 Sport Governance (Online; Spring 2019; Enrolled: 34): This course is designed to provide knowledge and awareness of the rules and laws governing various sport organizations and their participants.

SPAD 383 Sport Marketing (Online; Spring 2019; Enrolled: 33): The application of the principles of promotion and marketing to the sport and fitness industry including the areas of professional sports, corporate fitness, college/high school athletics, clubs, resorts, and more.

SPAD 405 Sport Facility Management (Online; Fall 2018; Enrolled: 37): This course investigates the development and support of athletic facilities in diverse settings. Subject matter focuses on specific management skills and adaptations required by the athletic environment. During the semester students examine corporate, community, not for profit, and commercial facilities for strengths and weaknesses in design and management procedures.

SPAD 382 Sport Management and Leadership (Online; Fall 2018; Enrolled: 33): This course is designed to expand the student's understanding of various management techniques and their application to sport organizations and administration. 
SPAD 383 Sport Marketing (Online; Spring 2018; Enrolled: 40)

SPAD 405 Sport Facility Management (Online; Fall 2017; Enrolled: 30)

HSS 114-01 Fitness Walking (Fall 2017; Enrolled: 15): Promotion of cardiovascular fitness through a walking program.

HSS 114-02 Fitness Walking (Fall 2017; Enrolled: 30)

\section{Guest Lectures at University of Louisville}

SPAD 489 Legal Aspects of Sport (Fall 2019): Development and Protection of Intellectual property

SPAD 525 Sport Event Management (Spring 2019): Event Evaluation

SPAD 524 Mgt. of Pro Baseball (Spring 2019): Baseball in South Korea

SPAD 404 Financial Prin. in Sport (Spring 2018): Professional Soccer Leagues Around the World

SPAD 509 International Sport (Spring 2018): Sports in Korea

SPAD 524 Mgt. of Pro Baseball (Spring 2017): Baseball in South Korea

SPAD 382 Org. Behavior in Sport (Spring 2017): Management and Leadership

SPAD 404 Financial Prin. in Sport (Spring 2017): Financial Impacts of Chinese Super League

SPAD 509 International Sport (Spring 2016): Sports in South Korea

\section{Class Shadowing at University of Louisville}

SPAD 637 Sport Analytics (Spring 2020)

SPAD 489 Legal Aspects of Sport (Fall 2019)

SPAD 525 Sport Event Management (Spring 2019)

SPAD 383 Sport Marketing (Spring 2018)

SPAD 382 Sport Management and Leadership (Fall 2018)

SPAD 382 Org. Behavior in Sport (Spring 2017)

\section{RESEARCH \& SCHOLARLY ACTIVITIES}

\section{Research Interests}

My research interests include, but are not limited to, the fields of sport participation and sport consumer behavior. Additionally, I am interested in exploring the social and psychological impacts of sports on individuals and society in general.

\section{Dissertation}

Lee, S. (2020). Promoting healthy aging: an investigation of the relationships among sport identity, sport satisfaction, and sport commitment in the well-being of older adults. Committee: Dr. Hums (Chair), Dr. Hambrick, Dr. Choi, and Dr. Greenwell

\section{Refereed Publications}

Lee, S., Spencer, T., Hums, M \& Alagaraja, M. (2020). Qualitative examination of international graduate students' experiences with campus recreation services. Recreational Sports Journal. https://doi.org/10.1177/1558866120917176 


\section{Manuscripts under Review}

Baek, H., Nicholson, J, \& Lee, S. (major revision). Sport participation and underage drinking in America: Mediation effects of self-esteem across gender.

\section{Manuscripts in Progress}

Lee, S., \& Greenwell, T. C. (in progress). The effects of enjoyment and commitment on sport consumption behaviors among adult recreational golfers.

Lee, S., \& Greenwell, T. C. (in progress). Determinants of golf commitment, participation frequency, and word-of-mouth behavior among recreational golfers.

\section{Scholarly Presentations}

Lee, S. \& Hums, M. (advisor) (2020, February). Healthier aging through organized sport participation. Presented to the Graduate Student Council Regional Research Conference, Louisville, KY.

Lee, S. \& Greenwell, T. C. (2019, November). Determinants of golf commitment, participation frequency, and word-of-mouth behavior among recreational golfers. Presented to the annual conference of Sport Marketing Association Conference, Chicago, IL.

Lee, S., Spencer, T., Hums, M., \& Alagaraja, M. (2019, May). Qualitative examination of international graduate students' experiences with campus recreation services. Presented to the annual conference of the North American Society for Sport Management, New Orleans, LA.

Lee, S. \& Greenwell, T. C. (advisor) (2019, February). The effects of enjoyment and commitment on sport consumption behaviors among adult recreational golfers. Presented to the annual conference of Applied Sport Management Association Conference, Nashville, TN.

Baek, H., Nicholson, J, \& Lee, S. (2018, June). Sport participation and underage drinking in America: Mediation effects of self-esteem across gender. Presented to the annual conference of the North American Society for Sport Management, Halifax, Nova Scotia, Canada.

Lee, S. (2018, March). A qualitative approach to understanding participation in campus recreation services among international graduate students. Presented to the annual Spring Research Conference at the University of Louisville, Louisville, KY.

Park, J., Yoo, S-W., Lee, S., \& Hums, M. (2016, June). An examination of gender differences in student-athletes' perceived career barriers and coping efficacy: A perspective from Social Cognitive Career Theory. Presented to the annual conference of the North American Society for Sport Management, Orlando, FL.

\section{Non-Refereed Publications}

Lee, S., \& Taylor, A. (2005, July 7). UD to close English Language Institute - Poor enrollment, funding woes, Sept. 11 play roles. Dayton Daily News, pp. Z7-5.

Lee, S., \& Taylor, A. (2005, July 14). UD to keep English language program - Classes to operate on smaller scale. Dayton Daily News, pp. Z7-2.

\section{Grants and Funding}

Doctoral Dissertation Completion Award (Full tuition, health insurance, and \$1,500 monthly stipend) granted for Spring 2020 by Graduate School at the University of Louisville.

The Graduate Student Council (GSC) Research Grant (\$500) awarded for Fall 2019 by Graduate School at the University of Louisville.

Conference registration fee (\$200) funded by Health and Sport Sciences department for the 2019 Sport Marketing Association (SMA) Conference. 
Travel funded by the University of Louisville in the amount of $\mathbf{\$ 3 5 0}$ to New Orleans, LA for the 2019 North American Society of Sport Management (NASSM) Conference.

Conference registration fee (\$190) funded by Health and Sport Sciences department for the 2019 North American Society of Sport Management (NASSM) Conference.

Conference stipend $(\mathbf{\$ 1 0 0})$ was received as a finalist of the graduate student research competition at the 2019 Applied Sport Management Association Conference (ASMA), Nashville, TN.

Travel funded by the University of Louisville in the amount of $\mathbf{\$ 3 5 0}$ to Halifax, Nova Scotia (CN) for the 2018 North American Society of Sport Management (NASSM) Conference.

Travel funded by the University of Louisville in the amount of $\mathbf{\$ 3 5 0}$ to Orlando, FL for the 2016 North American Society of Sport Management (NASSM) Conference.

Conference registration fee funded by Health and Sport Sciences department for the 2016 North American Society of Sport Management (NASSM) Conference.

\section{ACADEMIC WORK EXPERIENCE}

\section{Graduate Assistant}

International Student and Scholar Services (ISSS), University of Louisville: Fall 2019-Present

- Assist a director and coordinators of ISSS in a verity of administrative duties

- Conduct research on international programs and services in US higher education

- Assist the International Student Council

\section{Teaching and Research Graduate Assistantships}

Department of Health and Sport Sciences, University of Louisville: Fall 2017-Summer 2019

- Assisted professors in the department with research projects, book editions and publications

- Taught undergraduate courses related to Sport Administration and Health \& Sport Sciences

Department of Economics, Wright State University: Fall 2011-Spring 2012

- Assisted professors in the Economics department with research on social, health and economics issues in Asia

- Assisted in Economics seminars hosted by the economics department

\section{PROFESSIONAL WORK EXPERIENCE}

Business \& Marketing Analyst / Customer Service Representative, Total Display Solutions, Erlanger, KY: June 2012-October 2013

- Supervised the product return approval \& verification, and product receiving \& returning processes

- Provided customer support to address product return and invoice processes, status, and service inquiries about warranty conditions for Best Buy, Samsung, Apple, and other vendors

- Coordinated customer service activities with management, operations, warehouse, technical support, quality, and engineering departments so products exceeded customer expectations

- Trained and developed new employees within the customer service department

- Generated daily/weekly/monthly customer repair production/service reports

Athletics Facilities/Operations Department Intern, University of Louisville, KY: Fall 2009-Spring 2010

- Assisted with Facility Operations and Maintenance departments

- Assisted in games and event operations and planning for several NCAA and Big East Tournaments hosted by University of Louisville 
- Conducted pre-game set up, in-game operations, and post-game breakdown for men's and women's athletics

Event Coordinator (Short-term contract), Tee Golf Studio, Seoul, Korea: March-July 2008

- Assisted with LPGA, KLPGA and KPGA players' scheduling and management - LPGA players: Jiyai Shin and In-Kyung Kim

- Conducted strategic event planning and promotions for amateur golf tournaments

- Managed and supervised AUDI amateur and championship golf tournaments - 6 events

- Supervised 12-15 volunteer and student intern crews during the AUDI amateur golf tournaments

- Supervised the company's first website creation project

Assistant Manager, TNT Fashion, Retail Store, Cincinnati, OH: January-November 2007

- Managed store operations and staff schedules

- Controlled inventory and customer service

- Coordinated customer service activities

Major Gifts / Income Development Department Intern, American Cancer Society, Cincinnati, OH: Fall 2006

- Assisted managers with daily responsibilities

- Involved in the complete plan of Cincinnati Hope Lodge Capital Campaign

- Participated in Smoke Free Ohio Campaign

- Assisted Income Development special events

Sport Marketing and Management Department Intern, SK Telecom Sports Group, Seoul, Korea: Summer 2006

- Participated in front office duties, managing professional sports teams, athletics and events such as Basketball, Baseball, Golf, and eSports

- Researched organization situational assessment and Korean professional sports industry

- Involved in sporting team event plans and two website creation projects

Athletics Communication Department Intern, University of Dayton, Dayton, OH: Spring 2006

- Assisted the Assistant Director of Athletic Communications

- Controlled electric devices in the press box for softball and baseball games - Scoreboard \& music

- Generated approximately $\$ 120$ revenue per game from concessions in the baseball stadium

Intercollegiate D-I Baseball Team Intern, University of Dayton, Dayton, OH: Fall 2005

- Assisted 152 guests for golf outing fundraiser and 80 attendants for showcase

- Supervised 17 fall scrimmage games

- Conducted head coach office duties

- Controlled scoreboard, sound system during the games

- Recorded 21 players' quality at bat chart each game

Korean Military Service, Public Safety Division, Seoul Agricultural \& Marine Products Corporation, Seoul, Korea: 1999-2002

- Oversaw 18 major facilities and 10 major markets along with public safety, traffic, and parking (4000 vehicles per day)

\section{SERVICES \& ACTIVITIES}

\section{University \& College}

- Panelist of the cross-cultural conversation between $\mathrm{U}$ of $\mathrm{L}$ international and national students, "My process of leaning a second language as an international student" at the international education week, 
hosted and sponsored by Modern Languages and International Student and Scholar Services (ISSS): Fall 2018

- Panelist of the PLAN Professional Development Workshop, "Surviving and Thriving for International Graduate Students" for international graduate students, hosted by the School of Interdisciplinary and Graduate Studies (SIGS): Fall 2018

- Panelist of the PLAN Professional Development Workshop, "Succeeding in the U.S. University" for international graduate students, hosted by the School of Interdisciplinary and Graduate Studies (SIGS): Fall 2017

- Volunteer at the 30th Anniversary Celebration Education Award Symposium - the Grawemeyer Awards, University of Louisville, Louisville, KY: October 15, 2015

- Agent of English Language \& Multicultural Institute at the University of Dayton, OH: 2003-2005 - Assisted new international students in the program to adapt to American culture

- Provided resources to understand the educational system and adjust to life in the U.S.

\section{Department \& Program}

- Member of the International Student Council, organized by International Student and Scholar Services (ISSS), University of Louisville: Fall 2019-Present

- Volunteer, 2019 Cardinal Cornhole Classic, Organized by sport event management course project (SPAD 525), University of Louisville: Spring 2019

- Member of Sport Administration Master's Admissions Committee, University of Louisville: 2016Present

- Participant, SPAD PhD Program Virtual Open House for potential applicants: Fall 2017

- Volunteer member of Health and Sport Science department (HSS) Student Engagement and Welcome Week Event: Fall 2017

- Participated in the section of meeting time with potential candidate faculty members and current $\mathrm{PhD}$ students in the Sport Administration tenure-track faculty search: April 2016

- Participant, SPAD PhD Program Virtual Open House for potential applicants: Fall 2015

- Organized auction and awards plans University of Louisville SPAD Golf Scramble: Spring 2009 - Obtained 15 auction and awards items from local restaurants, retail, and merchandise stores

- Study Abroad in Australia - Sport Marketing Program: Summer 2006

- Conducted research plan with National Basketball League (NBL) Marketing department for the preseason and All-Star Games project

- Researched cultural difference between American and Australian basketball fans

- Provided marketing strategies and event plans

- Experienced Australian culture from traveling to two different cities (Sydney and Cairns)

- Experienced professional sports and markets in Australia (e.g., Australian rules of football, cricket, and rugby)

- Sinclair Community College Basketball Pride Preview: Fall 2004

- Project group awarded \$1,000 contract to implement Executive Briefing Plan

- Designed "Pride Preview" pep rally for Sinclair's basketball teams

- Drew over 100 people in attendance to Pride Preview Night

- Assisted in selling over 100 tickets 


\section{Community}

- Volunteer, Control Center at Southeast Sports \& Fitness Center, Southeast Christian Church: February 2020-Present

- Volunteer, 2019 Women's Golf, 16th Annual Cardinal Cup, University of Louisville Golf Club, Louisville, KY: October 2019

- Volunteer, Free Lunch for Students on Campus every Friday, Organized by Card Reach (a member of Recognized Student Organizations [RSO] of University of Louisville): Fall 2018-Present

- Treasurer of Ratio Christi (a member of RSO and Christian ministry on campus) of University of Louisville: Fall 2019-Present

- Volunteer, 2019 Tully Invitational (Kentucky 2019 Cross Country Event), hosted by Tully Elementary, Charlie Vettiner Park, Louisville, KY: August 2019

- Volunteer golf instructor, Free Golf \& Family Picnic (Summer) at Seneca Park \& Crescent Hill Golf Course, Organized by St. Matthews Baptist Church, Louisville, KY: 2017, 2018, 2019

- Volunteer, 2019 NCAA Men's Golf Regional Championship, hosted by University of Louisville Golf Club, Louisville, KY: May 2019

- Volunteer, 2019 Kentucky Derby, Transportation and mobility services, Organized by SP+Game Day Management Group \& University of Louisville Sport Administration Program: May 2019

- Volunteer, 2018 Ironman Louisville, Louisville, KY: October 2018

- Volunteer, 2017 US Cycling National Championships, Louisville, KY: July 2017

- Young Adults Group Leader, Dayton Korean Grace Church, Dayton, OH: 2014-2015

- Volunteer substitute teacher, Miami Valley Korean School, Dayton, OH: 2013-2015

- College students group leader and education committee of Dayton Korean Grace Church, Dayton, OH: 2010-2014

- GIS Specialist - Introduced and showcased 8 maps and walkability study during the Urban Nights event, Montgomery County and City of Dayton, Ohio: May 2014

- Created 8 maps featuring the historic district, St. Anne's Hill in Dayton, OH: Car parking map, speed limits map, traffic signs map, signs of St. Anne's Hill map, walking path map, and three additional maps that related with a walkability study of the historic district, St. Anne's Hill neighborhood

- Volunteer, 2008 Ryder Cup at Valhalla Golf Club, Louisville, KY: Fall 2008

- Treasurer of Korean American Scholar and Students Association, Wright State University, University of Dayton, and Sinclair Community College, Fairborn, OH: 2004-2006

\section{HONORS, AWARDS \& RECOGNITION}

Recipient of the Poster Presentation Award ( $\left(1^{\text {st }}\right.$ place presenter), the $13^{\text {th }}$ Annual Graduate Student Regional Research Conference (GSRRC), Graduate Student Council (GSC), University of Louisville: Spring 2020 
Recipient of University of Louisville International Student Tuition Support Scholarship (Awarded \$500): Spring 2020

Recipient of University of Louisville International Affairs Scholarship (Awarded \$3500): Spring 2020

Recipient of a Doctoral Dissertation Completion Award (Full tuition, health insurance, and \$1,500 monthly stipend) for Spring 2020, Graduate School, University of Louisville.

Nominated for Faculty Favorites, University of Louisville's Delphi Center for Teaching and Learning: Fall 2018- Spring 2019

"I have had Professor Lee for multiple SPAD classes, both of which were online. It takes a certain kind of professor to successfully deliver an online class, and Professor Lee does that exactly. He is always reachable, regardless of this course being online, and is always willing to answer questions and help students whenever needed. Professor Lee has made me enjoy taking online classes and has made sure the content is understandable and teachable through the online course and truly makes sure we are set up for success." - Student nominator

Recipient of the Graduate Student Council (GSC) Research Grant (\$500) awarded by Graduate School at the University of Louisville: Fall 2019

Recipient of University of Louisville International Student Tuition Support Scholarship (Awarded \$500): Fall 2019

Recipient of University of Louisville International Affairs Scholarship (Awarded \$4000): Fall 2019

Finalist of the Graduate Student Research Competition at the 2019 Applied Sport Management Association Conference (ASMA) (Awarded \$100), Nashville, TN: Spring 2019

Recipient of University Fellowship, University of Louisville (Full tuition, fees, and \$18,000 annual stipend): Fall 2015- Summer 2019

Recipient of University of Louisville International Student Scholarship (Awarded \$500): Spring 2009

\section{CERTIFICATIONS}

Certificate of Completion of MinistrySafe Sexual Abuse Awareness Training program with the examination following the training material: approved by the Texas Department of State Health Services, and complies with the Texas Youth Camp Act (Training Code \#YC 060034): September 2019

School of Interdisciplinary and Graduate Studies (SIGS): The Graduate Teaching Assistant Academy II: Advanced Concepts and Strategies in Post-Secondary Teaching Certificate, Graduate Student Dean's Reception, University of Louisville: Spring 2019

SIGS PLAN Professional Development Certificate (Frequent attendee), Graduate Student Dean's Reception, University of Louisville: Fall 2018 \& Spring 2019

Graduate Student Dean's Reception, SIGS: The Graduate Teaching Assistant Academy I: Introduction to Teaching in Higher Education Certificate, University of Louisville: Fall 2018

University of Louisville Delphi U Online Teaching Certificate: Summer 2017

Graduate Student Dean's Reception, School of Interdisciplinary and Graduate Studies (SIGS) Publishing Academy Certificate, University of Louisville: Spring 2017 
Graduate Student Dean's Reception, SIGS PLAN Professional Development Certificate (Frequent attendee), University of Louisville: Fall 2016 \& Spring 2017

Technical Certificate of the Geographic Information Systems, Sinclair Community College, Dayton, Ohio: December 2014

- Expertise in ArcGIS - Mapping, Spatial \& Location Analysis

Applied Statistics: Authorized for 0.8 Continuing Education Units (CEUs) certificate. Wright State University Statistical Consulting Center: July 2011

\section{PROFESSIONAL DEVELOPMIENT \& TRAINING}

The 2019 Mentoring Academy (7 weeks), the University of Louisville Graduate School: Summer 2019

- Contents of the sessions: Introduction \& Maintaining Effective Communication, Aligning Expectations \& Addressing Equity and Inclusion, Personalities \& Conflict Resolution, Assessing Understanding, Fostering Independence, Promoting Professional Development \& Research and Mentoring Ethics, Your Mentoring Philosophy \& Plan

Career Colloquium, the University of Louisville Graduate School: Summer 2019

- Intensive, half-day workshop covering career basics from top to bottom include job materials (resumes, CVs, and cover letters), job interviewing, transferable skills, and making a PLAN for graduate students' next steps

The Graduate Teaching Assistant Academy II: Advanced Concepts and Strategies in Post-Secondary Teaching, School of Interdisciplinary and Graduate Studies (SIGS): Spring 2019

- Contents of the sessions: Discussion for Teaching and Learning, Inclusive Teaching, Motivation in Teaching and Learning, and Developing a Course Assessment Plan

The Graduate Teaching Assistant Academy I: Introduction to Teaching in Higher Education, SIGS: Fall 2018

- Understanding of teaching in a higher education environment and 9 sessions of the collaborative program between the School of Interdisciplinary Studies and the Delphi Center for Teaching and Learning

- Contents of the 9 sessions included learning, motivation, and student development theory, learning assessment, proactive classroom management, designing assignments, activities, and effective lessons, crafting a statement of teaching philosophy, and practice teaching for peers

Celebration of Teaching and Learning Conference: Fostering rich conversations on teaching in higher education, University of Louisville, Louisville, KY: Spring 2018

Part-Time Faculty Institute: Explore active learning strategies for grading, assessment, and rubrics, Delphi Center for Teaching and Learning, University of Louisville: Fall 2017

University of Louisville Delphi U Online Teaching Training: May 2017

SIGS Publishing Academy (5 weeks): Spring 2017

- Gather practical tips and reflective strategies for enhancing your publishing skills;

- Interact with and learn from UofL faculty and staff who are committed to excellence in publishing;

- Participate in a welcoming and inclusive learning environment in which you and faculty guests share and learn from one another;

- Explore and discuss discipline-specific publishing perspectives with peers and mentors from across campus and beyond 
PLAN (Professional Development, Life Skills, Academic Skills, \& Networking) Workshops, SIGS: Fall $2015 \sim$ Present

- Workshopping the CV; Academic Mock Interview; Why you need a statement of teaching philosophy and how to develop one; Developing and refining your elevator pitch; Power literature searching; What do you mean you'd like me to present my research; Leveraging LinkedIn for career exploration and job searching; Approaches to successful grant writing; Succeeding in the U.S. University for international graduate student; The Academic Job Search; What GTAs Need to Know About Blackboard; Introduction to EndNote; Writing a Literature Review; Be Searchable; An Introduction to Data Sources for Graduate Student Researchers; Organizing and Writing a LargeScale Writing Project; Teaching philosophy statements

\section{MEMBERSHIPS}

North American Society for Sport Management: 2009-Present

The North American Society for the Sociology of Sport: 2015, 2017-Present

Sport Marketing Association: 2016-Present

Korean American Association for Sport Management: 2016-Present 